\title{
WestVirginiaUniversity
}

THE RESEARCH REPOSITORY @ WVU

Graduate Theses, Dissertations, and Problem Reports

2006

\section{Gas turbine control and load sharing of a shipboard power system}

Anisha M. C. Fernandes

West Virginia University

Follow this and additional works at: https://researchrepository.wvu.edu/etd

\section{Recommended Citation}

Fernandes, Anisha M. C., "Gas turbine control and load sharing of a shipboard power system" (2006). Graduate Theses, Dissertations, and Problem Reports. 1768.

https://researchrepository.wvu.edu/etd/1768

This Thesis is protected by copyright and/or related rights. It has been brought to you by the The Research Repository @ WVU with permission from the rights-holder(s). You are free to use this Thesis in any way that is permitted by the copyright and related rights legislation that applies to your use. For other uses you must obtain permission from the rights-holder(s) directly, unless additional rights are indicated by a Creative Commons license in the record and/ or on the work itself. This Thesis has been accepted for inclusion in WVU Graduate Theses, Dissertations, and Problem Reports collection by an authorized administrator of The Research Repository @ WVU. For more information, please contact researchrepository@mail.wvu.edu. 


\title{
GAS TURBINE CONTROL AND LOAD SHARING OF A SHIPBOARD POWER SYSTEM
}

\author{
by \\ Anisha M. C. Fernandes \\ Thesis submitted to the College of Engineering and Mineral Resources \\ at West Virginia University \\ in partial fulfillment of the requirements \\ for the degree of \\ Master of Science \\ in \\ Electrical Engineering
}

Professor Ali Feliachi, Ph.D., Chair

Professor Muhammad Choudhry, Ph.D.

Professor Powsiri Klinkhachorn, Ph.D.

Assistant Professor Kourosh Sedghisigarchi, Ph.D.

Lane Department of Computer Science and Electrical Engineering

Morgantown, West Virginia

2006

Keywords: Gas Turbine, PID Controller, Particle Swarm Optimization, Electric Shipboard Power System, Energy Management

Copyright 2006 Anisha M. C. Fernandes 


\author{
Abstract \\ GAS TURBINE CONTROL AND LOAD \\ SHARING OF A SHIPBOARD POWER \\ SYSTEM \\ by \\ Anisha M. C. Fernandes \\ Master of Science in Electrical Engineering \\ West Virginia University \\ Professor Ali Feliachi, Ph.D., Chair
}

The objective of this research is to design a controller for a gas turbine of an Electric Shipboard Power System (ESPS) and to develop a load sharing strategy for its energy management. A suitable model for the gas turbine is selected and the effects of the dynamics are investigated for the different loads of the ESPS. The gas turbine controller is a Proportional Integral Derivative (PID) controller, whose parameters are tuned using the Particle Swarm Optimization (PSO) technique. The load on the system has three components: a propulsion load, a pulsed load to simulate a high energy weapon system and a power supply load for the remaining loads such as pumps, lighting systems, etc. Load sharing is inevitable when demand exceeds the available power supply. In this case, based on the priorities of the loads and the available power, a strategy is presented to supply power to the most critical loads. To illustrate this, a load allocation algorithm is developed using stateflow diagrams. The potential of this algorithm is demonstrated by two case studies performed using the three loads, with the highest priority assigned to the propulsion load in case 1 , and power supply load in case 2 . The results of this research can be further extended to real time applications. 


\section{Dedication}

To my parents, Anil and Anita Fernandes, and my brother, Angelus Fernandes, for their unconditional love, encouragement and continuous support, enabling me to accomplish all that I have.

Also to my fiancé, Amit Hegde, for being such a wonderful influence and inspiration in my life. 


\section{Acknowledgments}

I would like to express my deep and sincere gratitude to my advisor Dr. Ali Feliachi for giving me the opportunity to work on this project under his guidance. His encouragement and advice have been instrumental throughout my research.

I am extremely grateful to Dr. Kourosh Sedghisigarchi for his continuous encouragement and supervision during the formative stages of this research and for always being available when I needed his advice the most. I also sincerely thank Dr. Karl Schoder for his advice and guidance throughout this research work.

I would like to extend my appreciation to Dr. Muhammad Choudhry and Dr. Powsiri Klinkhachorn for serving on my committee and for their valuable comments and feedback.

Also, I would like to thank Dr. John Sneckenberger for his guidance during the initial phases of this research. I am also grateful to all my friends and colleagues at the Advanced Power and Electricity Research Center (APERC) who have helped me throughout this endeavor.

My family has been the source of my strength and motivation during this research. I am forever indebted to my parents and brother for their encouragement and support every step of the way. I am also grateful to my closest friend and fiancé, Amit, who has been a

true source of inspiration and encouragement. Last but not the least, I thank the Lord Almighty for His countless blessings.

Funding for this work was provided by the US DEPSCoR and Office of Naval Research (ONR) under grant (DOD/ONR N000 14-031-0660). 


\section{Contents}

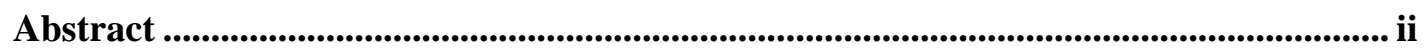

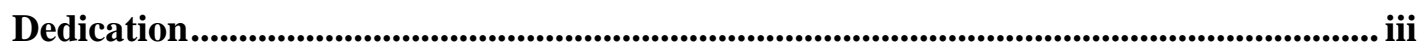

Acknowledgments ........................................................................................................................ iv

List of Figures ....................................................................................................... vii

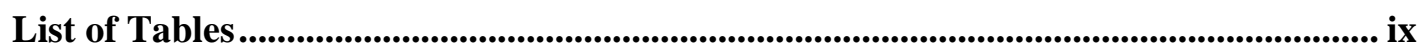

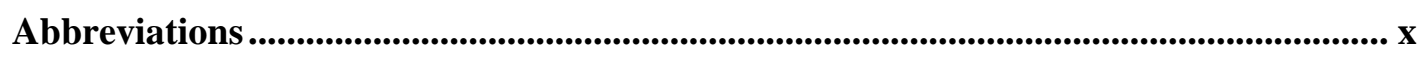

1 INTRODUCTION..................................................................................... 1

1.1 Motivation............................................................................................................................ 1

1.2 Objectives and Contributions ................................................................................. 3

1.3 Organization of Thesis.......................................................................................................... 4

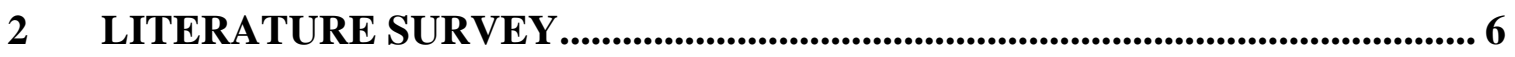

2.1 Overview of Gas Turbines..................................................................................................... 6

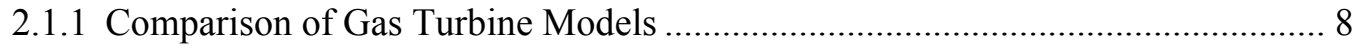

2.1.2 Selection of Model and Control Issues............................................................ 12

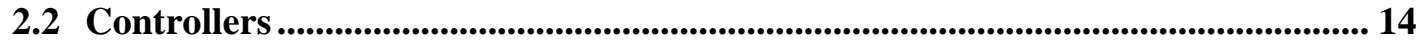

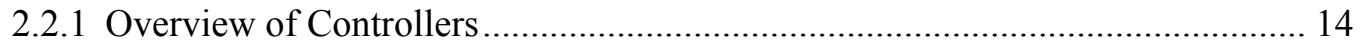

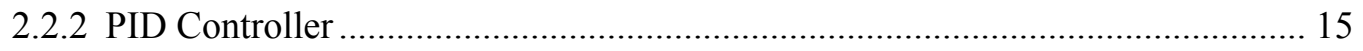

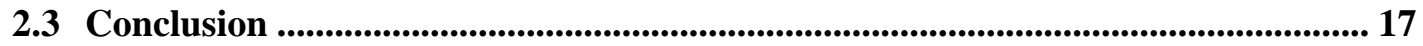

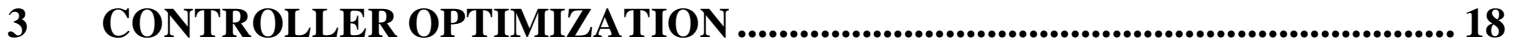

3.1 Concept of Particle Swarm Optimization (PSO)......................................................... 18

3.2 Selection of Performance Index .......................................................................................... 20

3.3 PSO Algorithm and Flowchart .................................................................................... 22

4 ELECTRIC SHIPBOARD POWER SYSTEM .............................................. 26

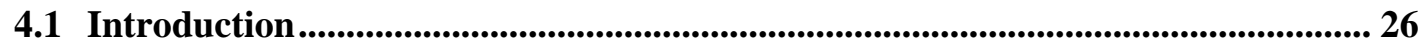

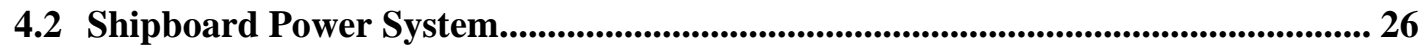

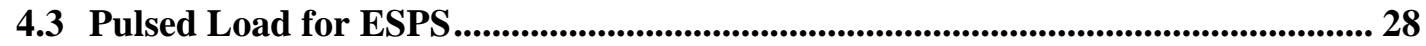

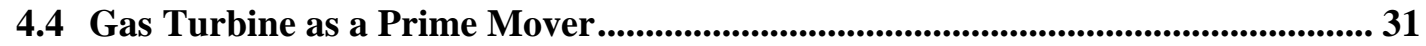

4.5 Tuning of Gas Turbine Speed, Temperature and Acceleration Controllers ......... 42

4.6 Effect of Loading on Controller Parameters ................................................................ 49

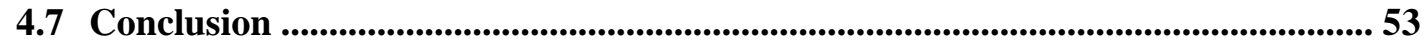

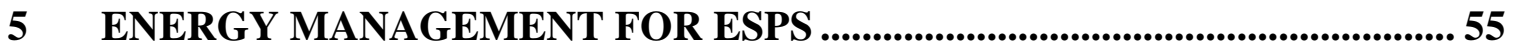

5.1 Need for Energy Management ............................................................................... 55

5.2 Energy Management System Architecture ............................................................. 57 
CONTENTS

5.3 Expansion of Implementation Layer ............................................................................... 60

5.4 Load Allocation Scheme ...................................................................................61

5.5 Case Studies for Load Allocation Scheme ........................................................... 65

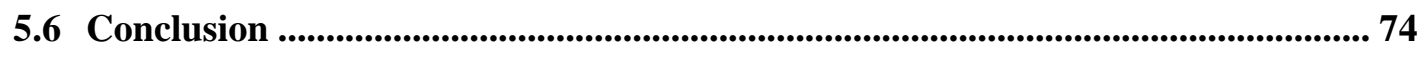

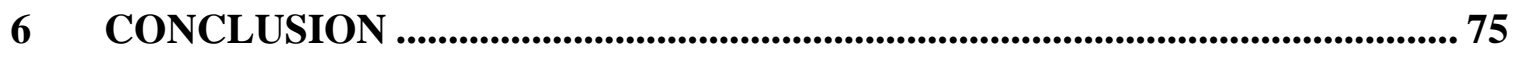

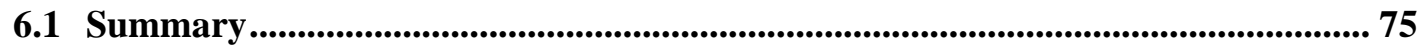

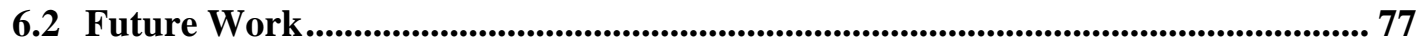

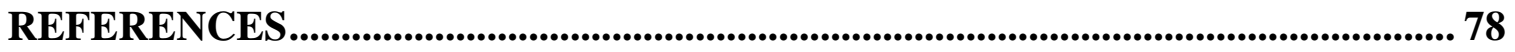

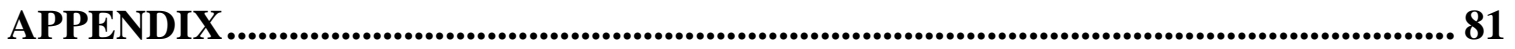

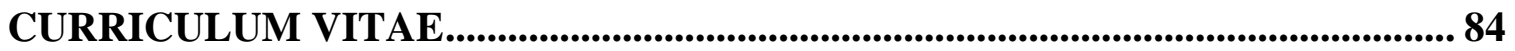




\section{List of Figures}

Figure 1.1: ESPS Simulink subsystem with prime mover as a constant speed mechanical source. .2

Figure 1.2: Response of generator with constant speed mechanical source ......................3

Figure 2.1: Single shaft gas turbine ...........................................................................

Figure 2.2: Schematic of Low Value Selector .............................................................

Figure 2.3: Gas turbine speed response comparison...............................................13

Figure 3.1: Block diagram of DC motor speed control - PID controller tuned using PSO21

Figure 3.2: Comparison of Performance Indices ........................................................21

Figure 3.3: Modification of particle position using PSO Technique .............................23

Figure 3.4: Particle Swarm Optimization Flowchart .................................................24

Figure 4.1: One Line Diagram of ONR Electric Shipboard Power System Testbed........27

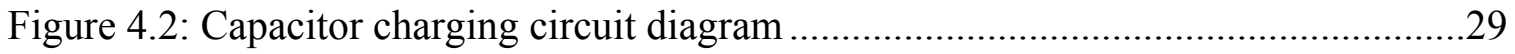

Figure 4.3: Pulsed Load controller block diagram.....................................................29

Figure 4.4: Energy storage capacitor discharge/charge cycle .....................................30

Figure 4.5: Energy storage capacitor power and current waveforms ............................31

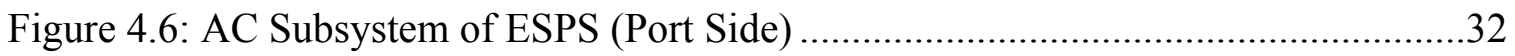

Figure 4.7: Circuit diagram of propulsion system ...................................................33

Figure 4.8: Simulink subsystem of constant slip frequency control scheme ....................33

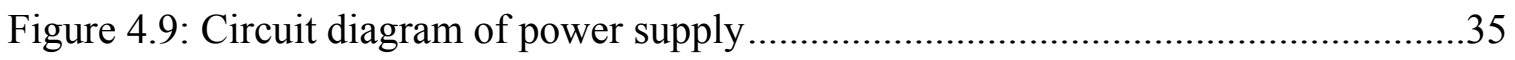

Figure 4.10: Power supply controller block diagram...............................................

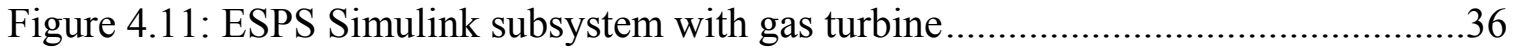

Figure 4.12: Model of gas turbine incorporated as prime mover ..................................37

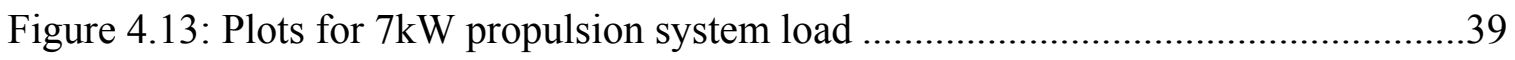

Figure 4.14: Gas turbine controller signals for $7 \mathrm{~kW}$ propulsion system load ..................39

Figure 4.15: Plots for $15 \mathrm{~kW}$ power supply load .....................................................40

Figure 4.16: Gas turbine controller signals for $15 \mathrm{~kW}$ power supply load......................40

Figure 4.17: Plots for $15.5 \mathrm{~kW}$ pulsed power load .....................................................41

Figure 4.18: Gas turbine controller signals for $15.5 \mathrm{~kW}$ pulsed power load ....................41 


\section{LIST OF FIGURES}

Figure 4.19: Energy storage capacitor waveforms ................................................42

Figure 4.20: Comparison of response for $7 \mathrm{~kW}$ propulsion load..................................43

Figure 4.21: Comparison of gas turbine controller signals for propulsion load ...............44

Figure 4.22: Comparison of response for $15 \mathrm{~kW}$ power supply load ..............................45

Figure 4.23: Comparison of gas turbine controller signals for power supply load...........46

Figure 4.24: Comparison of response for $15.5 \mathrm{~kW}$ pulsed load ..................................47

Figure 4.25: Comparison of gas turbine controller signals for power supply load...........48

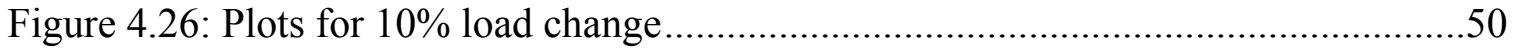

Figure 4.27: Comparison of gas turbine controller signals for $10 \%$ load change..............51

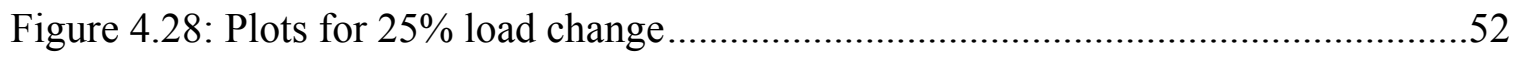

Figure 4.29: Comparison of gas turbine controller signals for $25 \%$ load change..............53

Figure 5.1: Dynamic responses of generator and gas turbine when demand exceeds

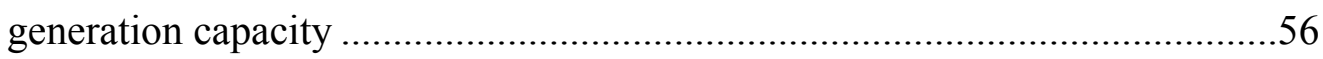

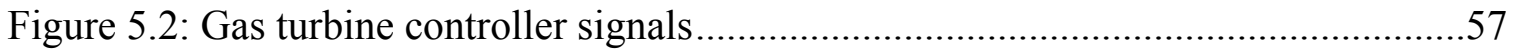

Figure 5.3: Layered architecture scheme for the ESPS energy management system ........59

Figure 5.4: Decomposition of the Implementation Layer...........................................61

Figure 5.5: Stateflow diagram for ESPS load allocation scheme .................................63

Figure 5.6: Hidden sub-state denoted by $\mathrm{o}^{-} \mathrm{o}$ in Figure 5.5 ......................................64

Figure 5.7: Reconfiguration Layer (RL), Individual and total load profiles for case (a) ..67

Figure 5.8: Generation voltage and current and load currents for case (a)......................68

Figure 5.9: Dynamic responses of generator and gas turbine for case (a) ......................69

Figure 5.10: Gas turbine controller signals for case (a) ............................................. 70

Figure 5.11: Reconfiguration Layer (RL), Individual and total load profiles for case (b) 71

Figure 5.12: Generation voltage and current and load currents for case (b)....................72

Figure 5.13: Dynamic responses of generator and gas turbine for case (b).....................73

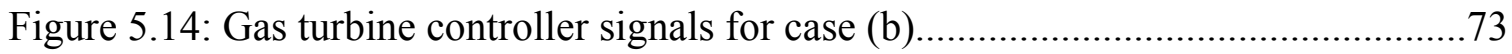




\section{List of Tables}

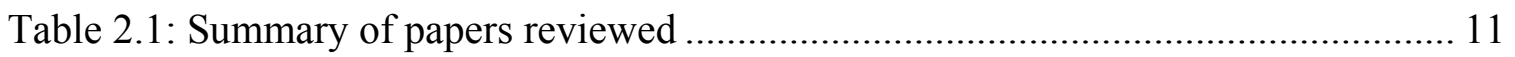

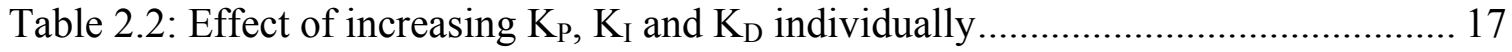

Table 3.1: Comparison of Performance Aspects ........................................................ 22

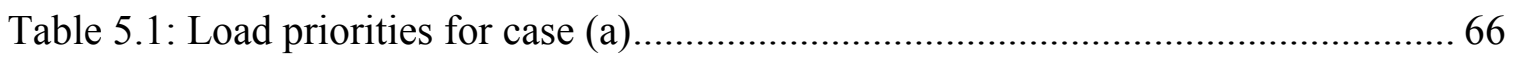

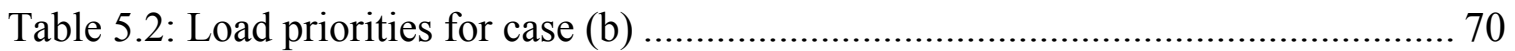

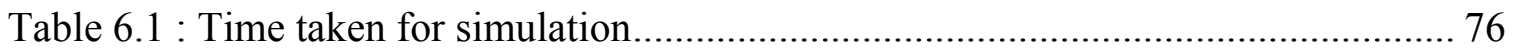

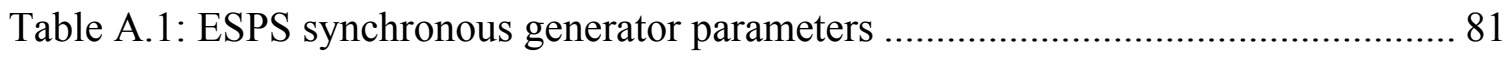

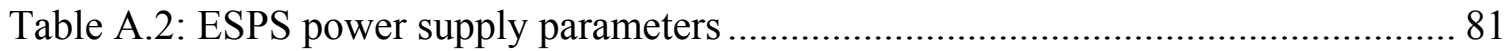

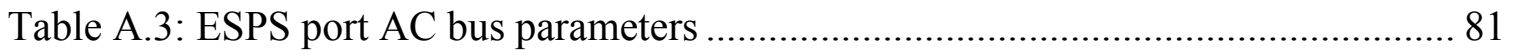

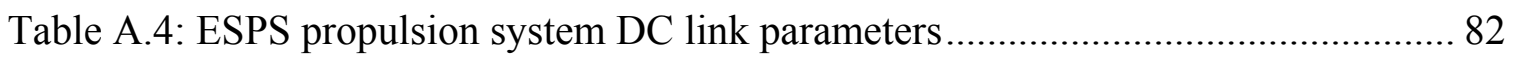

Table A.5: ESPS propulsion system induction machine parameters ............................ 82

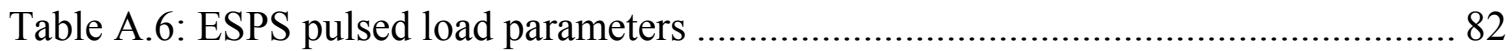

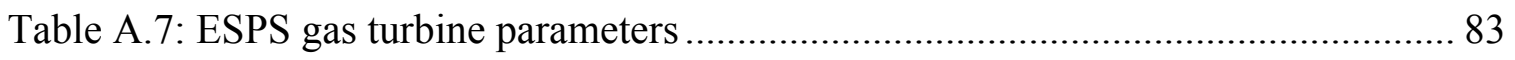




\section{Abbreviations}

ESPS

IA

IAE

ISE

ITAE

ITSE

$\mathrm{K}_{\mathrm{P}}$

$\mathrm{K}_{\mathrm{I}}$

$\mathrm{K}_{\mathrm{D}}$

ONR

PID

PSO

WSCC
Electric Shipboard Power System

Implementation Agent

Integral of Absolute Error

Integral of Squared Error

Integral of Time weighted Absolute Error

Integral of Time weighted Squared Error

Proportional gain

Integral gain

Derivative gain

Office of Naval Research

Proportional Integral Derivative

Particle Swarm Optimization

Western System Coordinating Council 


\section{CHAPTER 1: INTRODUCTION}

Advances in commercial electric ships have led to the development of a similar concept for naval warships. The need for decreasing human tasking and costs while improving survivability has led to the gradual replacement of hydro-mechanical systems with electrical systems. The all electric naval warship has significantly higher electric power demands to support the electric drive propulsion system, electrical auxiliary systems and high energy weapon systems on board. Dependable, integrated controls are necessary for these interdependent systems in order to effectively manage the limited resources available. This is vital during major disruptions due to battle and damage control operations.

Many similarities exist between a civilian power system and an electric naval shipboard power system. The power system of the electric naval warship is basically a distribution network with a main power source (gas turbine and generator) and distributed loads (propulsion system, DC zones and pulsed load). The control architecture for a shipboard power system needs to be designed in such a manner to ensure reliable operation in normal and emergency situations. Warship power systems facing extreme situations and several incidents [36] call for the development of dependable strategies for reconfiguration and energy management during emergency situations. The main issue faced by naval shipboard power systems is to decide during an emergency situation as to which critical loads need to be supplied with the limited resources available. This issue can be addressed by an energy management system which will ensure power supply to the critical loads.

\subsection{Motivation}

The motivation for this research work is derived from the representation of the prime mover as a constant speed mechanical source for the Electric Shipboard Power System (ESPS) model in Simulink. The dynamic behavior of generating equipment plays a vital role in the stability of an electric power system. The constant speed mechanical source prime mover in this ESPS model does not illustrate the speed response of the prime 


\section{CHAPTER 1: INTRODUCTION}

mover caused by disturbances such as load changes, etc. Figure 1.1 shows the subsystem of the ESPS model in Simulink comprising of the exciter, generator and prime mover represented by a constant speed mechanical source.

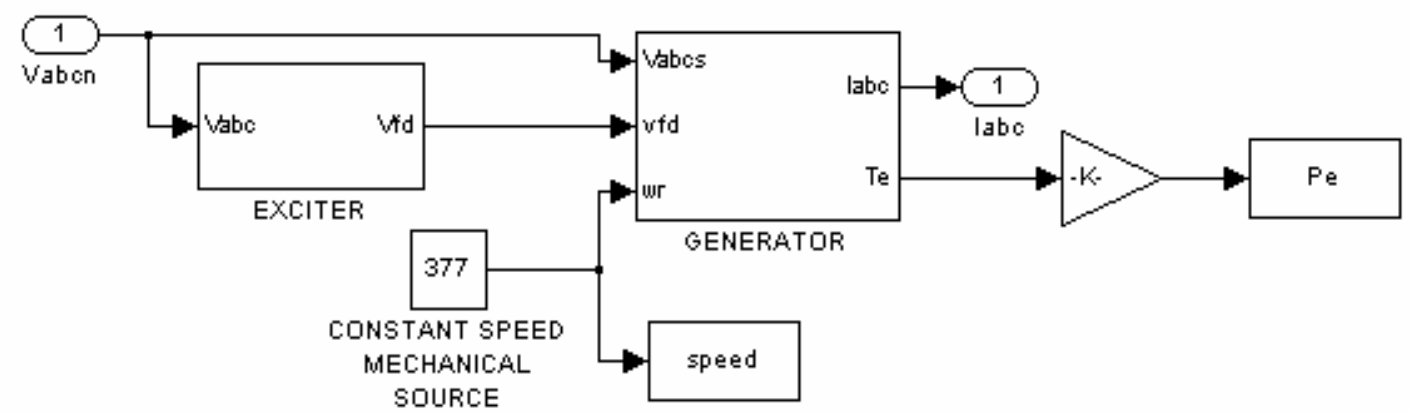

Figure 1.1: ESPS Simulink subsystem with prime mover as a constant speed mechanical source

As the prime mover is a constant speed mechanical source, effective energy management cannot be performed as all the loads are supplied irrelevant of the rating of the generator. Figure 1.2 shows a plot of the generator electrical power $(\mathrm{Pe})$ and the prime mover speed. At $5 \mathrm{~s}$ the propulsion load of $37 \mathrm{~kW}$ is turned $\mathrm{ON}$, at $25 \mathrm{~s}$ the power supply load of $15 \mathrm{~kW}$ is turned $\mathrm{ON}$, and at $45 \mathrm{~s}$ the pulsed load of $15.5 \mathrm{~kW}$ is turned $\mathrm{ON}$. The generator of the ESPS has a $59 \mathrm{~kW}$ rating, and the total power demand by these three loads exceeds $59 \mathrm{~kW}$. But, as the generator is supplied by a prime mover represented by a constant speed mechanical source, all the three loads are supplied even though the generator capacity is exceeded as shown in Figure 1.2. 

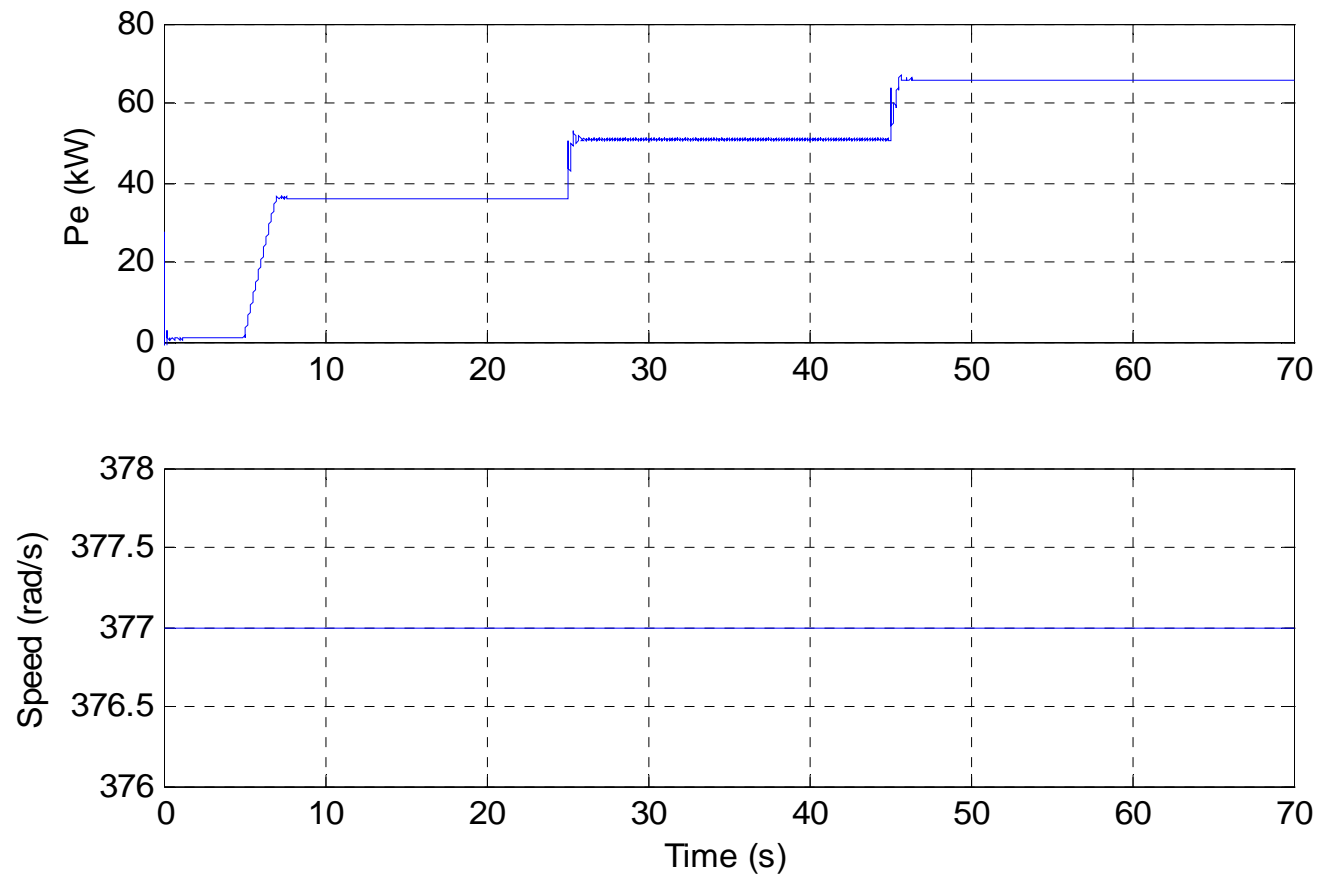

Figure 1.2: Response of generator with constant speed mechanical source

In order to design an energy management scheme for the ESPS, a dynamic prime mover model with appropriate controls is seen necessary. For this research work, a speed controller for a gas turbine model is designed which is the prime mover for the ESPS model. With the gas turbine, the dynamic behavior of the ESPS can be studied, and an energy management scheme can be developed to ensure proper balance between generation and demand of the ESPS.

\subsection{Objectives and Contributions}

The Electric Shipboard Power System (ESPS) Testbed [19] developed in Matlab/Simulink [35] is used in this research work. Details of this testbed have been described in Section 4.2 of Chapter 4.

This work incorporates a gas turbine model as prime mover, which is the main source of electric power for the ESPS. This gas turbine provides mechanical power to a generator, which supplies electric power to the loads - propulsion, DC zones and pulsed loads. The pulsed load is modeled as a capacitor charging circuit. The capacitor is charged from the 


\section{CHAPTER 1: INTRODUCTION}

ac system bus to store a peak power of 200kJ [33]. Each pulse discharges $128 \mathrm{~kJ}$ of energy from the energy storage capacitor. To maintain proper balance between generation and demand, a load allocation scheme has been developed for energy management of the ESPS. By appropriate load sharing, it is shown that all the loads can be supplied without exceeding the generation capacity. Depending on the priorities assigned to each load, the algorithm developed ensures power supply to higher priority loads first and then to the other loads, when generation is limited.

The contributions of this research work comprise of:

1. Incorporation of a simple cycle, single shaft gas turbine model as a prime mover for the electric shipboard power system: The prime mover has been represented as a constant speed mechanical source in the testbed provided. The speed controller PID parameters of the gas turbine have been tuned using Particle Swarm Optimization to enhance its performance. The speed response of this gas turbine as a prime mover has been illustrated with the 3-phase detailed loads of the ESPS.

2. Modeling and implementation of a pulsed load to supply high energy weapon systems on naval ships: This load is in addition to the propulsion load and the DC zonal loads already present in the testbed.

3. Development of an energy management scheme for the ESPS: Based on a layered architecture approach as demonstrated in [7], a generic load allocation scheme is developed to supply the loads of the ESPS based on priority in time of limited generation.

\subsection{Organization of Thesis}

An outline of the remaining chapters of this thesis is as follows:

In Chapter 2, Section 2.1 comprises of a literature survey, where selected models of single shaft, simple cycle gas turbines are compared. The control issues and strategies discussed in these papers are reviewed. Based on this, a gas turbine model is selected for 


\section{CHAPTER 1: INTRODUCTION}

incorporation in this work. Section 2.2 discusses the different types of controllers and the basic structure of a PID controller, which is used in this work.

Chapter 3 is based on the optimization technique used for tuning the gas turbine speed controller parameters. The choice of performance index used is explained here. The general concept of the particle swarm optimization technique is discussed in this chapter. A flowchart along with an explanation of the algorithm is also provided.

In Chapter 4, the incorporation of the selected gas turbine model as a prime mover for the electric shipboard power system is performed. The one line diagram of the ESPS testbed is provided with a brief description of each component. The modeling of the pulsed load has been explained along with results using a constant voltage source. Results to show the dynamics of the gas turbine as a prime mover for the 3-phase detailed AC loads are documented.

Chapter 5 discusses the need for energy management along with a suitable scheme to overcome this issue. A multiagent architecture based on a layered approach as demonstrated by [7] is incorporated to develop a generic load allocation algorithm for the implementation layer of this architecture. Using stateflow diagrams this algorithm is explained and its potential illustrated in two case studies performed with the three loads of the ESPS supplied by a $59 \mathrm{~kW}$ gas turbine and generator. 


\section{CHAPTER 2: LITERATURE SURVEY}

\subsection{Overview of Gas Turbines}

Electric energy is produced by the conversion of mechanical power to electric power using a prime mover connected to a generator. The source of this mechanical power provided by the prime mover can be obtained from hydraulic turbines, steam turbines, gas or combustion turbines, etc. This research work emphasizes on gas turbines to supply this mechanical power. Gas turbines are used in a wide variety of applications such as industrial plants for driving pumps, compressors and electric generators [2].

Gas turbines are favored as prime movers because of the following characteristics

- Low cost per unit of output

- Compact in size when compared to steam and hydraulic turbines

- Ability to be constructed and installed quickly

- Quick start up, coming up to synchronous speed and ready to accept load in a short time

- Operation on a relatively wide range of liquid or gaseous fuels

- Subjected to fewer environmental controls than other types of prime movers

Due to their low cycle efficiency, they are unsuitable for base load generating units. But since they can be started up quickly, they are used as peaking units in utility applications. Although they are incompatible with solid fuels, they can operate with a variety of liquid and gaseous fuels.

There are two types of gas turbine designs: single shaft and double (twin) shaft. A single shaft gas turbine has only one shaft connecting the compressor to the turbine. A twin or double shaft gas turbine has two shafts, one driving a high pressure turbine at a higher speed and the other driving a low pressure turbine that requires a lower speed. Single 


\section{CHAPTER 2: LITERATURE SURVEY}

shaft gas turbines have been utilized as prime movers for generators in utility and industrial power generation services for several years [31]. They are simple to operate, have a lower overall investment cost and higher reliability than twin shaft turbines. They are also considered to have superior speed performance to sudden changes in electrical power occurrences. The shaft speed deviation and frequency are lower with a faster recovery time. In a twin shaft turbine, the compressor responds before the power turbine causing a finite delay. These factors, along with the single shaft design being the most common in practice [2] have led to the choice of using a single shaft gas turbine model.

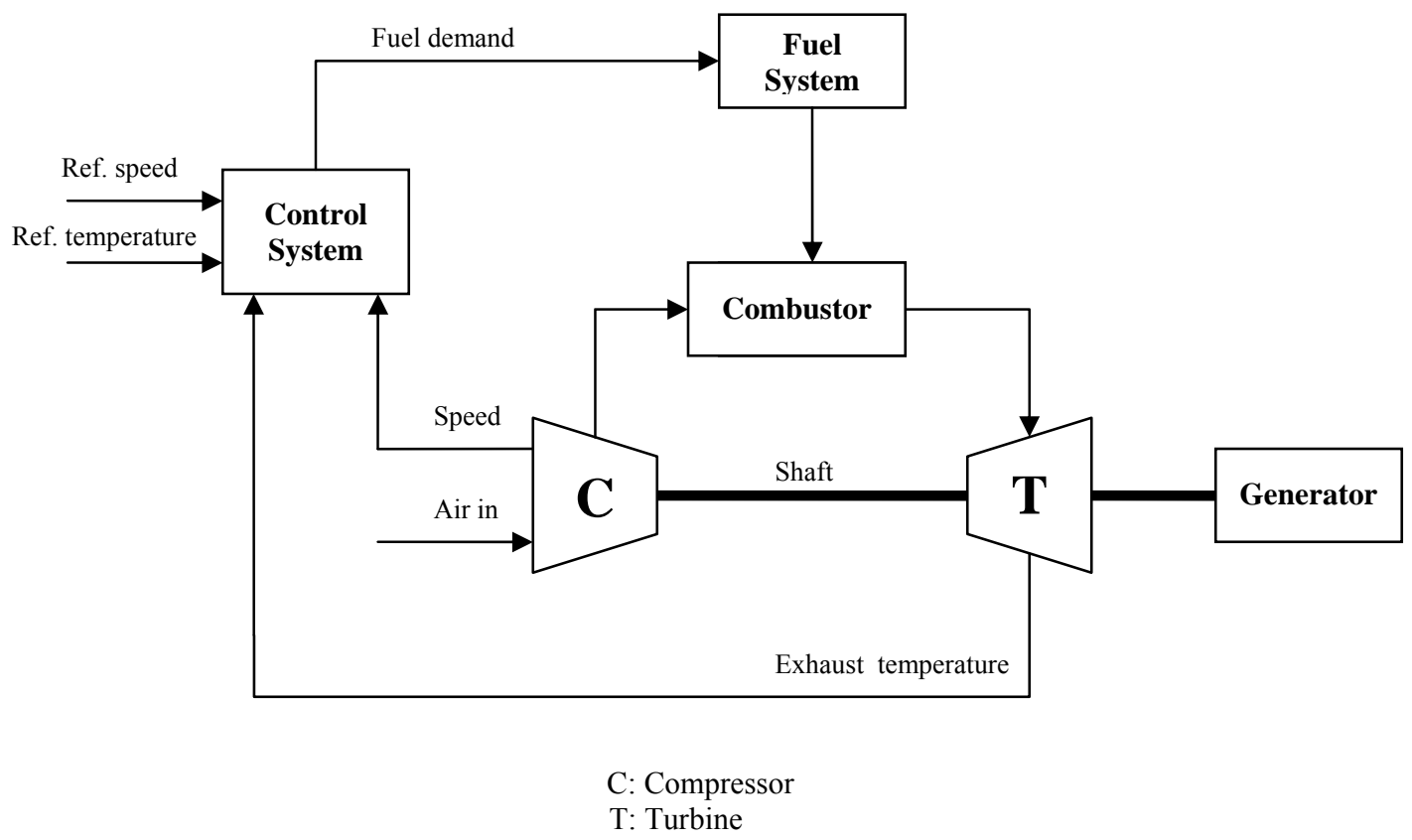

Figure 2.1: Single shaft gas turbine

The main components of a gas turbine are the compressor, the combustor and the turbine as shown in Figure 2.1. Gas turbine operation begins with air at atmospheric pressure entering the gas turbine at the compressor inlet. Fuel is then mixed with the compressed air in the combustor where combustion takes place. The hot exhaust gases from the combustor are expanded through the turbine producing mechanical power. Part of this mechanical power produced is utilized to drive the compressor and the remaining is converted to electric energy by connecting a generator to the output of the turbine. 


\subsubsection{Comparison of Gas Turbine Models}

The modeling of gas turbines and their controllers is a complex area of research. Several dynamic models of gas turbines with varying degrees of complexity are available in literature, which exemplify different makes and models of gas turbine units. A selected few of these models have been discussed in this section.

It is necessary to understand the dynamic characteristics of these units and their impact on power systems during normal and abnormal operating conditions. Thus, accurate models for gas turbines and their controllers is an essential step in simulating and evaluating the behavior of the overall performance of the system following a disturbance.

There are several gas turbine models developed till date. These models range from simple to complex design structures, single to multishaft models, etc. For this survey, simplified simple cycle, single shaft gas turbines have been considered. Most of the research work has been conducted in testing the gas turbine response with disturbances such as load rejection, load acceptance or three phase faults.

In 1983, a simplified mathematical model [30] was presented for electric power system studies. It is a simplified simple cycle, single shaft gas turbine. The control system comprises of speed control, temperature control, acceleration control and upper and lower fuel limits. The speed error is the difference between a reference speed and the actual rotor speed. During part load operation, the speed control is the primary means of gas turbine control. In order to reduce the thermal stresses encountered during startup, acceleration control is used to limit the rate of rotor acceleration before the rated speed is achieved. The three control signal outputs are fed to a low value selector as shown in Figure 2.2, which determines which signal requires the least fuel. 


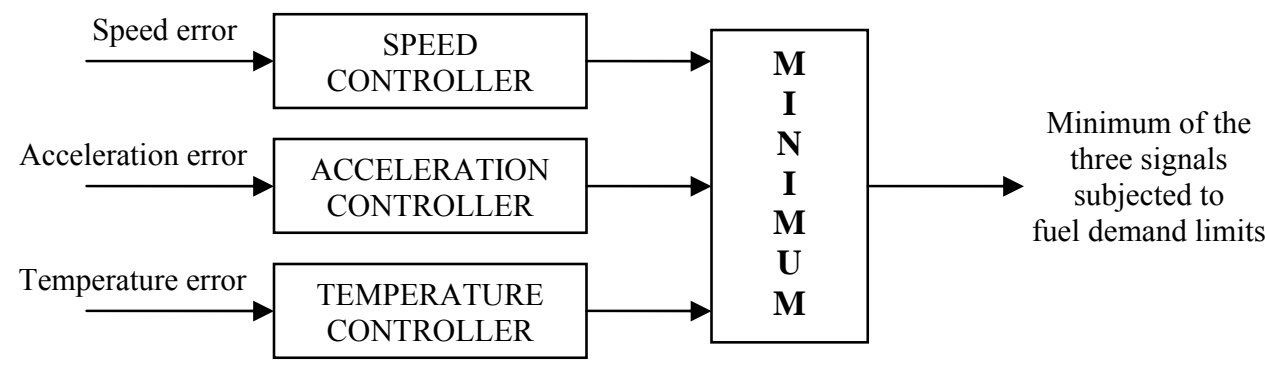

Figure 2.2: Schematic of Low Value Selector

This signal is then given priority and is subjected to upper and lower fuel demand limits. In normal operation, the upper limit is not encountered as it acts as a backup to temperature control. The lower limit is more significant as it is required to maintain adequate fuel flow to prevent flame out within the gas turbine combustor. The resulting signal is the fuel demand signal which drives the fuel valve actuator to control the output of the combustor. The hot gases from the combustion chamber are expanded in the turbine to drive the generator and compressor. The limitation of this model is that the allowable speed range is 95 to 107 percent of rated speed, limiting its application to generator drive applications.

In 1992, the model in [30] was upgraded to overcome the limitations of constant compressor inlet guide vane angle, constant ambient temperature and narrow turbine speed range [31]. Careful coordination of the prime mover, driven equipment and process controls is necessary, when using a single shaft gas turbine for variable speed mechanical drive service. This publication provides the prime mover information essential to perform dynamic system studies to ensure that this coordination is achieved. The mathematical representation of the single shaft gas turbine in this paper is similar to that presented in [30]. In addition to the control scheme in [30], this research work also considers axial flow compressor inlet guide vane control. As the inlet guide vanes are fully opened at the end of start up for simple cycle turbines, they are fixed over the normal operating range. In this case, the model becomes similar to that in [30]. 


\section{CHAPTER 2: LITERATURE SURVEY}

Two examples have been considered in [9], the first of which is a single shaft, simple cycle, heavy duty gas turbine model, based on [30]. The control scheme is the same, consisting of speed, temperature, acceleration control and upper and lower fuel limits. A multi shaft gas turbine is considered as the second example, which has a low and high pressure compressor stage. Partial load rejection tests have been performed and simulated. The measured results have been compared to the simulated results.

The gas turbine model of the combined cycle plant used in [39] is similar to the model in [30]. It consists of a simplified, single shaft model with speed and temperature controls. In addition to these controls, it also has modulating inlet guide vanes which act as an exhaust temperature controller. The speed controller is a PID controller, whose parameters are tuned by trial and error. The proposed combined cycle model is tested on a two area system. The dynamic behavior of the combined cycle plant subjected to a large disturbance was simulated by application of a three phase fault followed by permanent tripping of the circuit. A comparison of the responses of several variables simulated under the three phase fault condition with and without the PID controller has been performed in this work. It was observed that the model with the PID controller improved the dynamic performance of the system.

The combined cycle plant model in [37] was developed for use in power system simulation programs. A single shaft gas turbine with speed/load and fuel and air controls is used in this combined cycle model. Modeling of the gas turbine and its controls are based on [30]. In addition, this model also considers the effects of compressor and turbine efficiency, fuel demand on the air flow calculation and ambient temperature. It has been mentioned that this model should not be considered as a recommended model as there can be many variations in the composition of components and controls.

Following major system disturbances in July and August 1996, the Western System Coordinating Council (WSCC) performed several model validation tests on its gas turbine units [24]. The work presented focuses on the model validation of turbine governor models for gas turbine units, in compliance with the WSCC guidelines. The single shaft gas turbine model, called GAST, is a simplified version of [30]. As it can be 


\section{CHAPTER 2: LITERATURE SURVEY}

directly incorporated in commercial simulation programs, it is one of the most commonly used dynamic models. This model is simple and compliant with WSCC guidelines, which has made it the prime candidate for WSCC's model validation tests. The control scheme incorporates a speed/load regulator and temperature controller. Load rejection tests of $5 \mathrm{MW}$ and $13.7 \mathrm{MW}$ on $32 \mathrm{MW}$ and $95 \mathrm{MW}$ gas turbine units respectively were simulated using Simulink ${ }^{\circledR}$. The model does not include certain non-linearities that play a major role in over speed conditions following a sudden load rejection. For this reason, the amount of load rejected should be less than $20 \%$ of the machine rating. Furthermore, adjustments of the model parameters could not accurately reproduce the hunting phenomenon around the final settling frequency. Also, during excessive loading conditions, this model cannot give an adequate representation of the temperature control loop.

A simplified generic model of a single shaft gas turbine for application in a combined cycle power plant has been proposed by [4]. The generic gas turbine model provided in this document was studied and is appropriate for modeling the dynamic behavior of a power plant in grid studies. The control scheme in this model is similar to [30]. In addition, this model has a reset controller or outer loop MW controller which can be used to maintain the units output at a desired MW level. A dead-band is also introduced in the control system to maintain stable operation and extended life of the gas turbine. It has been stated that if the studies performed involve disturbances that would cause generation or load unbalance, then the proposed model can be used to obtain the expected response of the gas turbine [29]. This model is also suitable for transient and mid-term time domain stability analysis, small signal analysis and islanding studies or studies on small systems.

A summary of the papers reviewed is provided in Table 2.1

Table 2.1: Summary of papers reviewed

\begin{tabular}{|c|c|c|c|c|}
\hline$\#$ & Author(s) & Model Type & Controllers & Application \\
\hline 1. & $\begin{array}{l}\text { Rowen } \\
(1983)\end{array}$ & $\begin{array}{l}\text { - Simplified single shaft, } \\
\text { heavy duty gas turbine } \\
\text { - Linear model } \\
\text { - PID control } \\
\text { - 18MW-108MW }\end{array}$ & $\begin{array}{l}\text { 1. Speed } \\
\text { 2. Temperature } \\
\text { 3. Acceleration }\end{array}$ & $\begin{array}{l}\text { Dynamic power } \\
\text { system studies }\end{array}$ \\
\hline
\end{tabular}


CHAPTER 2: LITERATURE SURVEY

\begin{tabular}{|c|c|c|c|c|}
\hline 2. & $\begin{array}{l}\text { Rowen } \\
\text { (1992) }\end{array}$ & $\begin{array}{l}\text { - Simplified single shaft } \\
\text { gas turbine } \\
\text { - Linear model } \\
\text { - PID control } \\
\text { - 19MW-80MW }\end{array}$ & $\begin{array}{l}\text { 1. Speed } \\
\text { 2. Temperature } \\
\text { 3. Acceleration } \\
\text { 4. Inlet guide } \\
\text { vane }\end{array}$ & $\begin{array}{l}\text { Mechanical drive } \\
\text { service }\end{array}$ \\
\hline 3. & $\begin{array}{l}\text { Working Group } \\
\text { (1994) }\end{array}$ & $\begin{array}{l}\text { - Combined cycle, single } \\
\text { shaft gas turbine } \\
\text { - Linear model } \\
\text { - PID control } \\
\text { - } 82 \mathrm{MW}\end{array}$ & $\begin{array}{l}\text { 1. Speed/Load } \\
\text { 2. Temperature } \\
\text { 3. Fuel and Air }\end{array}$ & $\begin{array}{l}\text { Power system } \\
\text { dynamic studies }\end{array}$ \\
\hline 4. & $\begin{array}{l}\text { Zhang, So } \\
(2000)\end{array}$ & $\begin{array}{l}\text { - Combined cycle, single } \\
\text { shaft gas turbine } \\
\text { - Linear model } \\
\text { - PID control } \\
\text { - } 130 \& 700 \mathrm{MW}\end{array}$ & $\begin{array}{l}\text { 1. Speed } \\
\text { 2. Temperature } \\
\text { 3. Inlet guide } \\
\text { vane }\end{array}$ & $\begin{array}{l}\text { Power system } \\
\text { stability studies }\end{array}$ \\
\hline 5. & $\begin{array}{l}\text { Hajagos, } \\
\text { Berube (2001) }\end{array}$ & $\begin{array}{l}\text { - Simplified single shaft, } \\
\text { heavy duty gas turbine } \\
\text { - Linear model } \\
\text { - PID control } \\
\text { - 48MW }\end{array}$ & $\begin{array}{l}\text { 1. Speed } \\
\text { 2. Temperature } \\
\text { 3. Acceleration }\end{array}$ & $\begin{array}{l}\text { Power system } \\
\text { studies }\end{array}$ \\
\hline 6. & $\begin{array}{l}\text { Nagpal, et.al. } \\
\text { (2001) }\end{array}$ & $\begin{array}{l}\text { Simple cycle, single shaft } \\
\text { gas turbine } \\
\text { - Linear model } \\
\text { - PID control } \\
\text { - 32MW \& 95MW }\end{array}$ & $\begin{array}{l}\text { 1. Speed/Load } \\
\text { 2. Temperature }\end{array}$ & $\begin{array}{l}\text { Dynamic power } \\
\text { system studies }\end{array}$ \\
\hline 7. & CIGRE (2003) & $\begin{array}{l}\text { Combined cycle, single } \\
\text { shaft gas turbine } \\
\text { - Non linear model } \\
\text { - PID control } \\
\text { - MW range }\end{array}$ & $\begin{array}{l}\text { 1. Speed/Load } \\
\text { 2. Acceleration } \\
\text { 3. Temperature }\end{array}$ & $\begin{array}{l}\text { Transient } \\
\text { analysis, Small } \\
\text { signal studies, } \\
\text { Islanding studies } \\
\text { on small systems }\end{array}$ \\
\hline
\end{tabular}

\subsubsection{Selection of Model and Control Issues}

The selection of a model and the extent of detail in modeling its components depend on the purpose of study or application. A linearized representation of a model is sufficient for small signal studies. More detailed models including non-linearities such as saturation and limits are required for transient and large disturbance studies.

It is seen that the general structure of most of the existing gas turbine models are based on [30]. The simplified mathematical representation of the model in [30] is of heavy duty, single shaft type suitable for application in dynamic power system studies and dynamic analyses of connected equipment. The gas turbine model in [4] is proposed to be a simplified generic gas turbine model, reasonably accurate for speed deviations of up to 


\section{CHAPTER 2: LITERATURE SURVEY}

$+/-5 \%$ from rated speed. Figure 2.3 shows the speed response of the gas turbine model in [30] compared with the speed response of the gas turbine model put forth in [4] under similar conditions. Each model was subjected to a $40 \%$ load rejection at $10 \mathrm{~s}$, a $40 \%$ load pickup at $75 \mathrm{~s}$, a $10 \%$ load pickup at $130 \mathrm{~s}$ and a $10 \%$ load rejection at $190 \mathrm{~s}$. From the speed response obtained, it can be seen that the model in [4] performs better than the model in [30], in terms of lesser overshoot and faster settling time.

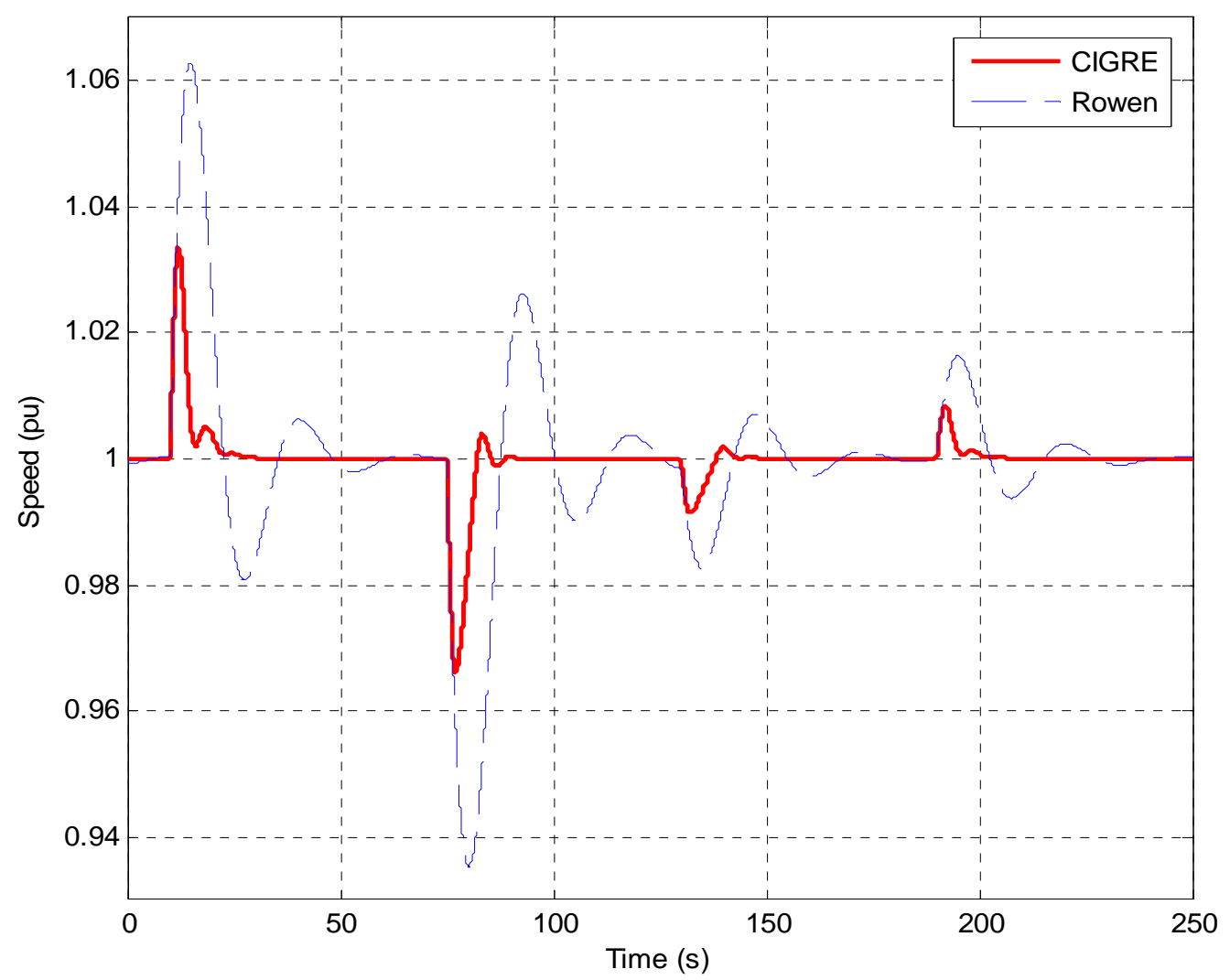

Figure 2.3: Gas turbine speed response comparison

Additionally, in [30], a linear temperature control scheme is presented comprising of two first order transfer functions, while [4] represents the temperature control scheme as a non linear lookup table, based on the variation in maximum power output as a function of frequency. The model in [4] has been put forth by a collaborative effort by manufacturers, utility engineers, consultants and research organizations around the world for the purpose of power system studies. Also, it is suitable for the study of small signal 
and transient analysis, as well as large system frequency disturbances. Based on this, the model in [4] is considered appropriate for incorporation as a prime mover in this work.

The three main control loops seen in gas turbine models are speed control, temperature control and acceleration control. Speed and temperature controls play a significant part during abnormal frequency operations. In addition to speed and temperature control, acceleration or start up control and inlet guide vane control are also present in some gas turbine models.

A loss of load results in over frequency conditions while an increase in load results in under frequency conditions. The inertia of a gas turbine is relatively lower than that of a hydraulic turbine. The round rotor type of generators is commonly used with one or two pole pairs, and they spin at higher speeds. When a sudden load rejection occurs, a machine with low inertia can result in excessive over speed conditions. This can be harmful if the speed controller fails to operate in time.

The most important control schemes in power system analysis are the governor speed/load controls and the temperature limit control loops. In some cases, particularly for islanding studies and smaller power systems, the acceleration control loop may also be of importance and may dominate momentarily following a large generation or load imbalance. From the literature review, it can be seen that the main concern is for speed control during system disturbances and temperature control during overloading conditions.

\subsection{Controllers}

\subsubsection{Overview of Controllers}

The concept of control and controllers dates back to a long, long time. In 2000 B.C., the Babylonians and Greeks constructed level control systems for automatic watering systems, water clocks and oil lamps. During the fifteenth and sixteenth century, temperature, pressure and position control systems were developed for incubators, boilers and windmills respectively. In 1788, a speed control system for a steam engine was 


\section{CHAPTER 2: LITERATURE SURVEY}

developed by James Watt. The speed was held at or near the desired set point by feeding back the measured rotational speed to the opening of the steam valve via a centrifugal controller. It is believed that the commencement of theoretical methods for analysis and design of control systems was in 1868, when James C. Maxwell performed a mathematical analysis of a speed control system [10].

Control theory has developed immensely since the 1930's. Initially controllers developed had only proportional action. Integral and derivative action was implemented at a later time. The lack of suitable methods for tuning of Proportional Integral Derivative (PID) controller parameters was solved by Ziegler and Nichols [41] around the 1940's. Their method is still one among the best methods till date. The advancement in control theory and development of various types of controllers has been attributed to the problems at hand that needed to be solved. Frequency response methods were developed for analysis and design of feedback amplifiers and feedback control systems. Some problems were solved using optimal controllers which are based on state space methods. Adaptive controllers were designed for auto pilot systems which required adaptation to the varying dynamics of the airplane during flight. In the late 1980's and 90's fuzzy controllers were developed based on the concept of fuzzy logic. Model based predictive controllers developed in the mid 1980's are another widely researched method of control.

\subsubsection{PID Controller}

Proportional-integral-derivative (PID) controller is the best known and most widely used control strategy in industry today [18]. Its three-term functionality provides treatment of both transient and steady-state responses, along with efficient and generic solutions to real world control problems. Estimation shows that over $90 \%$ of control loops employ PID control, often with the derivative gain set to zero. The wide application of PID control has focused its improvement mainly in the areas of tuning rules, adaptation techniques and identification schemes.

A few reasons for its universal acceptability are:

- Simplicity in structure 
- Easy to implement

- Robust performance in a wide range of operating conditions

- Principle of operation easy to understand than most other advanced controllers

The transfer function of a PID controller is expressed as:

$$
\begin{aligned}
& \frac{U(s)}{E(s)}=K_{P}\left(1+\frac{1}{T_{I} s}+T_{D} s\right) \\
& U(s)=K_{P} E(s)+K_{I} \frac{1}{s} E(s)+K_{D} s E(s)
\end{aligned}
$$

Where,

$\mathrm{U}(\mathrm{s})$ : control signal

$\mathrm{E}(\mathrm{s})$ : error signal

$\mathrm{K}_{\mathrm{P}}$ : proportional gain

$\mathrm{T}_{\mathrm{I}}$ : integral time constant
$\mathrm{K}_{\mathrm{I}}$ : integral gain, $\mathrm{K}_{\mathrm{P}} / \mathrm{T}_{\mathrm{I}}$

$\mathrm{T}_{\mathrm{D}}$ : derivative time constant

$\mathrm{K}_{\mathrm{D}}$ : derivative gain, $\mathrm{K}_{\mathrm{P}} \mathrm{T}_{\mathrm{D}}$

The functions of the three terms of a PID controller are as follows:

1. The proportional term produces a control action proportional to the error signal. It responds instantly to the current error signal, but often desired set point accuracy cannot be achieved without a large gain value.

2. The integral term reduces the steady state error, often to zero, by tracking a constant set point. It also provides complete rejection of constant disturbances. Although it filters higher frequency sensor noise, its response to the current error is slow.

3. The derivative term improves transient response by basing a portion of the control on a prediction of future error, but it amplifies higher frequency sensor noise. 
Table 2.1 shows the effect of increasing $\mathrm{K}_{\mathrm{P}}, \mathrm{K}_{\mathrm{I}}$ and $\mathrm{K}_{\mathrm{D}}$ individually on the closed loop response of a stable system in terms of rise time, overshoot, settling time, steady state error and stability. In order to obtain optimal performance, these three parameters should be tuned simultaneously.

Table 2.2: Effect of increasing $\mathrm{K}_{\mathrm{P}}, \mathrm{K}_{\mathrm{I}}$ and $\mathrm{K}_{\mathrm{D}}$ individually

\begin{tabular}{|l|l|l|l|}
\hline & $\mathbf{K}_{\mathbf{P}}$ & $\mathbf{K}_{\mathbf{I}}$ & $\mathbf{K}_{\mathbf{D}}$ \\
\hline Rise Time & Decrease & Small Decrease & Small Decrease \\
\hline Overshoot & Increase & Increase & Decrease \\
\hline Settling Time & Small Increase & Increase & Decrease \\
\hline Steady State Error & Decrease & Large Decrease & Small Change \\
\hline Stability & Degrade & Degrade & Improve \\
\hline
\end{tabular}

\subsection{Conclusion}

This chapter presented a brief overview of single and twin shaft gas turbines along with a summary of the research work performed with respect to simple cycle, single shaft gas turbines. Also, it provided an insight on the similarities and differences between the models reviewed, based on which a model has been selected for implementation as prime mover for the ESPS. The main control issues addressed in the publications reviewed concerning gas turbines has been discussed. Also, an introduction to PID controllers, the type of controller used in this research work has been presented. 


\section{CHAPTER 3: CONTROLLER OPTIMIZATION}

Although PID controllers are the most predominant controllers currently in use, poor tuning often limits their effectiveness and performance capabilities. Manual or trial and error tuning of PID controllers is a time consuming task, as this requires the optimization of its three parameters simultaneously. Several systematic tuning methods have been developed to address this issue [8]. Among these is the iterative search procedure where the controller parameters are tuned successively or simultaneously until certain conditions are satisfied, such as minimization of a performance index. Particle Swarm Optimization (PSO) is one such iterative search procedure which optimizes PID parameters based on the minimization of a suitable performance index. It provides an optimized solution within shorter calculation time, easy implementation with few parameters to adjust and has stable convergence characteristics. Hence PSO is considered an excellent optimization technique for optimizing the parameters of a PID controller [6].

\subsection{Concept of Particle Swarm Optimization (PSO)}

Optimization problems have grown in size and complexity and often cannot be solved using classical optimization techniques. This led to the development of a novel class of search algorithms, called heuristic algorithms. The general concept of these methods is based on the evolutionary patterns and activities observed in living organisms. Several such methods (e.g. evolutionary programming, genetic algorithms and particle swarm optimization, etc.) have been developed to solve optimization problems that were very difficult or impossible to solve. These algorithms search for the solution to an optimization problem using a population of individuals based on cooperation and competition among the population members.

Particle Swarm Optimization (PSO) was motivated by the social behavior of birds' flocking, and is considered to be an evolutionary computation technique. As an optimization tool, it provides a population based search procedure where individuals called particles change their position with time. The particles move around in a multidimensional search space, adjusting their own position and velocity. The particle 


\section{CHAPTER 3: CONTROLLER OPTIMIZATION}

position is adjusted according to its own experience as well as the experience of its neighbor, thus making use of the best position encountered by it and its neighbor. Unlike other heuristic methods, this technique balances exploration and exploitation by combining local search methods with global search methods. PSO is also more effective and economical for solving optimization problems when compared with other optimization algorithms such as genetic algorithms [40].

Particle Swarm Optimization (PSO) is a recently developed algorithm by James Kennedy, a social psychologist, and Russell Eberhart, an electrical engineer, in 1995 [16]. It relates to a family of algorithms that are used to find optimal or near optimal solutions to numerical and qualitative problems. It has proven to be very effective and quick in solving diverse optimization problems and can be easily implemented in most programming languages.

The idea originated from earlier experiments with algorithms that modeled the flocking behavior observed in many species of birds. Several such algorithms were available at the time, but Kennedy and Eberhart's interest lay in the models developed by Frank Heppner, a biologist [11]. In his study, Heppner considered the flocking behavior of birds when attracted to a roosting area. His simulations showed that the birds would start by flying around with no particular destination, forming flocks until one of the birds flew over the roosting area. Each bird controlled its own position and velocity such that a bird drawing away from the flock in order to land at the roost would result in the neighboring birds moving towards the roost. Once these birds discovered the roost, they would land there and draw other birds toward it until the entire flock had landed.

Finding a solution in a field of possible solutions in a solution space is similar to finding a roost. The manner in which a bird who has found the roost guides its neighbors to move toward it increases the odds that other birds will also find the roost. Hence as each bird learns from the success of its neighbors, similarly each particle in a solution space learns from its neighboring particles. Heppner's methodology was improved and applied by Eberhart and Kennedy to solve the optimization problem [11]. It takes into consideration 


\section{CHAPTER 3: CONTROLLER OPTIMIZATION}

the particles' explorations looking for a good solution (local solution) and takes advantage of the success of other particles' exploitations (global solution).

\subsection{Selection of Performance Index}

The selection of an appropriate performance index for minimization in the PSO algorithm is an important issue. This dictates the performance of the optimized PID controller obtained after tuning. Thus it is essential to choose a performance index that accentuates the desired performance aspects such as settling time, overshoot and rise time [17]. The typical performance indices to evaluate the closed loop system response are as follows:

1. Integral of absolute error (IAE): $J=\int|\Delta e| d t$

2. Integral of squared error (ISE): $J=\int(\Delta e)^{2} d t$

3. Integral of time weighted absolute error (ITAE): $J=\int t|\Delta e| d t$

4. Integral of time weighted squared error (ITSE): $J=\int t(\Delta e)^{2} d t$

Each performance index has its own advantages and disadvantages and will result in different system performance. The ISE is a typical performance criterion used in a number of control applications. It tends to penalize all errors with respect to the given weighting factors. The ITAE is also widely used in control applications and includes the time, $t$, in order to penalize the settling time of the controlled system. The minimization of ISE and IAE can result in a response with small overshoot but longer settling time and is seen as a disadvantage. Hence selection of a performance index should be based on the desired performance aspects for the overall system.

In this work, the desired performance aspects are to minimize the error and reduce the overshoot of the response. In order to determine which of the four performance indices mentioned above is to be selected, a comparison is made based on a simple DC motor speed control example. A PID controller is tuned using PSO, each time using one of the four performance indices. The PID controller parameters obtained in each case is used to determine the closed loop speed response to a step change in the reference speed. Figure 


\section{CHAPTER 3: CONTROLLER OPTIMIZATION}

3.1 shows the DC motor block diagram created in Simulink and Figure 3.2 shows comparison of the four responses.

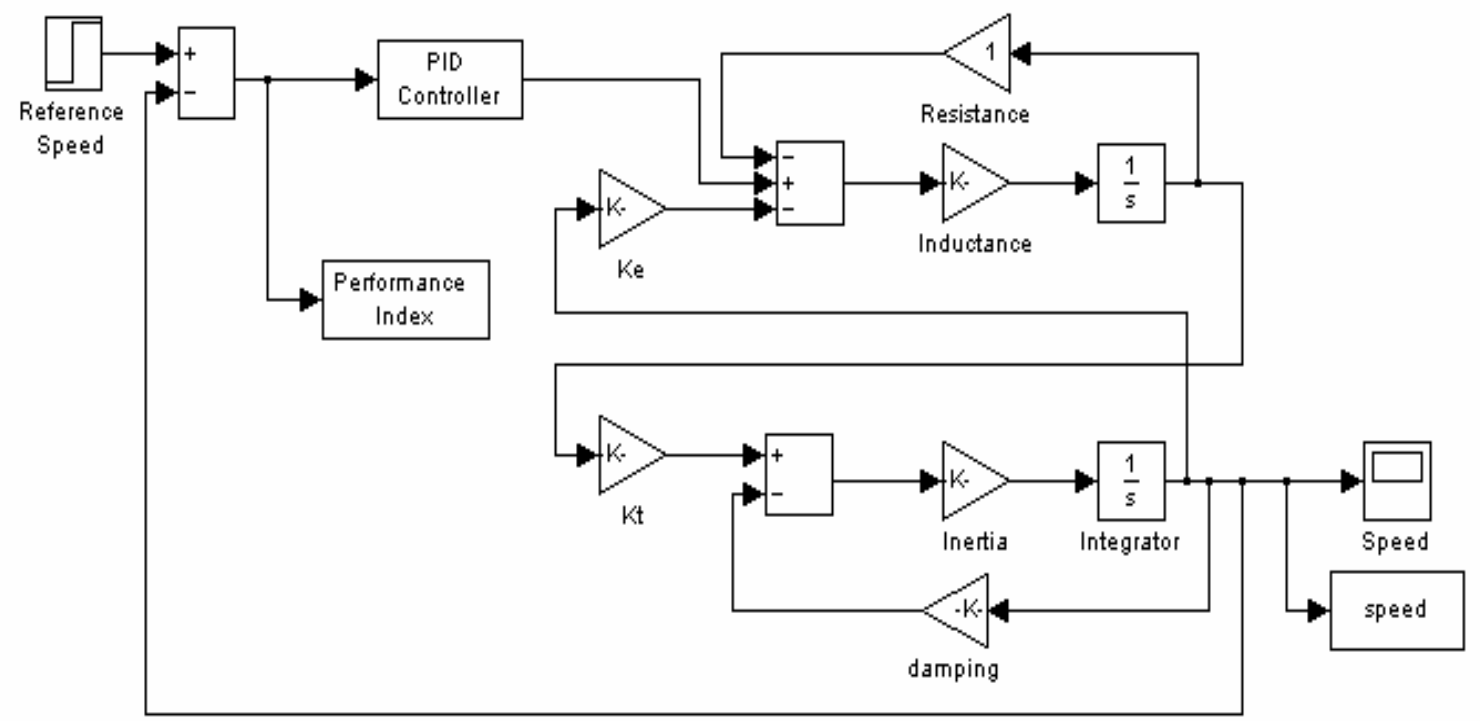

Figure 3.1: Block diagram of DC motor speed control - PID controller tuned using PSO

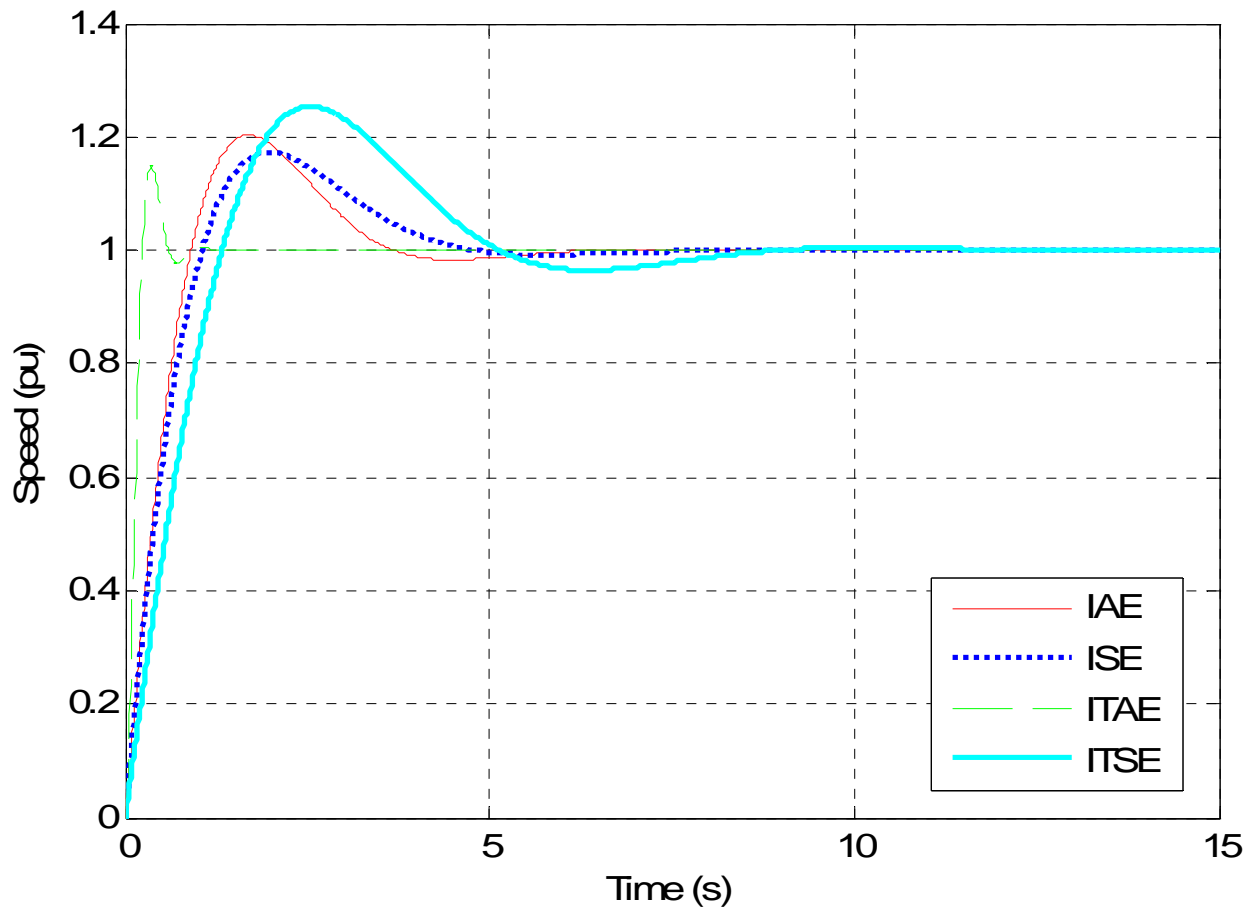

Figure 3.2: Comparison of Performance Indices 
From Figure 3.2 it can be seen that the response obtained with the PID parameters tuned using the ITAE performance index is the best compared to the other three. This is also in accordance with the results obtained in [17]. Table 3.1 below gives a comparison of each performance index to the other three on the basis of overshoot, settling time, rise time and steady state error. This led to the selection of ITAE as the performance index for tuning the PID parameters of the gas turbine using PSO.

Table 3.1: Comparison of Performance Aspects

\begin{tabular}{|c|c|c|c|c|}
\hline & IAE & ISE & ITAE & ITSE \\
\hline Overshoot & $\begin{array}{c}<\text { ITSE } \\
>\text { ISE, ITAE }\end{array}$ & $\begin{array}{c}<\text { IAE, ITSE } \\
>\text { ITAE }\end{array}$ & $\begin{array}{c}<\mathrm{IAE}, \mathrm{ISE}, \\
\text { ITSE }\end{array}$ & $\begin{array}{c}>\text { IAE, ISE, } \\
\text { ITAE }\end{array}$ \\
\hline $\begin{array}{l}\text { Settling } \\
\text { time }\end{array}$ & $\begin{array}{c}c \text { ITSE } \\
>\text { ITAE, ISE }\end{array}$ & $\begin{array}{c}<\text { ISE, ITSE } \\
>\text { ITAE }\end{array}$ & $\begin{array}{c}\text { Fastest settling } \\
\text { time }\end{array}$ & $\begin{array}{c}\text { Slowest settling } \\
\text { time }\end{array}$ \\
\hline Rise time & $\begin{array}{l}\text { Faster than ISE } \\
\& \text { ITSE, Slower } \\
\text { than ITAE }\end{array}$ & $\begin{array}{c}\text { Faster than } \\
\text { ITSE, Slower } \\
\text { than ITAE \& } \\
\text { IAE }\end{array}$ & Fastest rise time & Slowest rise time \\
\hline $\begin{array}{c}\text { Steady } \\
\text { state error }\end{array}$ & $\begin{array}{c}<\text { ISE, ITSE } \\
>\text { ITAE }\end{array}$ & $\begin{array}{c}>\text { IAE, ITAE } \\
<\text { ITSE }\end{array}$ & $\begin{array}{c}<\text { IAE, ISE, } \\
\text { ITAE }\end{array}$ & $\begin{array}{c}>\text { IAE, ISE, } \\
\text { ITAE }\end{array}$ \\
\hline
\end{tabular}

\subsection{PSO Algorithm and Flowchart}

Particle Swarm Optimization consists of a population of particles in multidimensional space, each having a position and velocity. These particles fly through the problem space and keep track of the best solutions they have achieved so far. The particles in the population compare themselves to others who have achieved a particular objective successfully and adjust their own position and velocity. The best position it has ever visited is called $\mathrm{p}_{\text {best }}$ and the best value obtained so far by any particle in the population is called $g_{\text {best. }}$ The main idea behind Particle Swarm Optimization is changing the position of each particle towards its $p_{\text {best }}$ and $g_{\text {best }}$ positions at each time step. Figure 3.3 shows the modification of a particle position using this concept. 


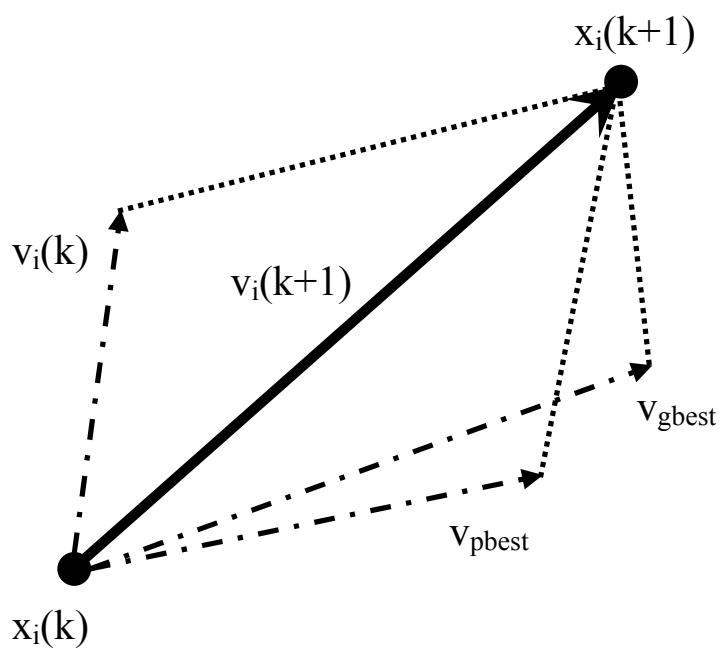

$$
\begin{array}{ll}
\mathrm{x}_{\mathrm{i}}(\mathrm{k}) \quad \text { : current particle position } \\
\mathrm{x}_{\mathrm{i}}(\mathrm{k}+1): \text { modified particle position } \\
\mathrm{V}_{\mathrm{i}}(\mathrm{k}) \quad: \text { current particle velocity } \\
\mathrm{V}_{\mathrm{i}}(\mathrm{k}+1): \text { modified particle velocity } \\
\mathrm{V}_{\mathrm{pbest}} \quad \text { : velocity based on pbest } \\
\mathrm{V}_{\text {gbest }} \quad: \text { velocity based on gbest }
\end{array}
$$

Figure 3.3: Modification of particle position using PSO Technique

Thus each particle attempts to change its current position and velocity based on the distance between its current position and $p_{\text {best, }}$, as well as the distance between its current position and $\mathrm{g}_{\text {best. }}$.

Figure 3.4 shows the PSO algorithm flowchart. The population size, n, maximum number of iterations, iter $_{\max }$, and the number of unchanged solutions, $\mathrm{M}$, are set by the user. Each particle has a position $x_{i}$ and velocity $v_{i}, i=1,2 \ldots . n$. The initial positions and velocities of each particle are generated randomly within the specified bounds. 


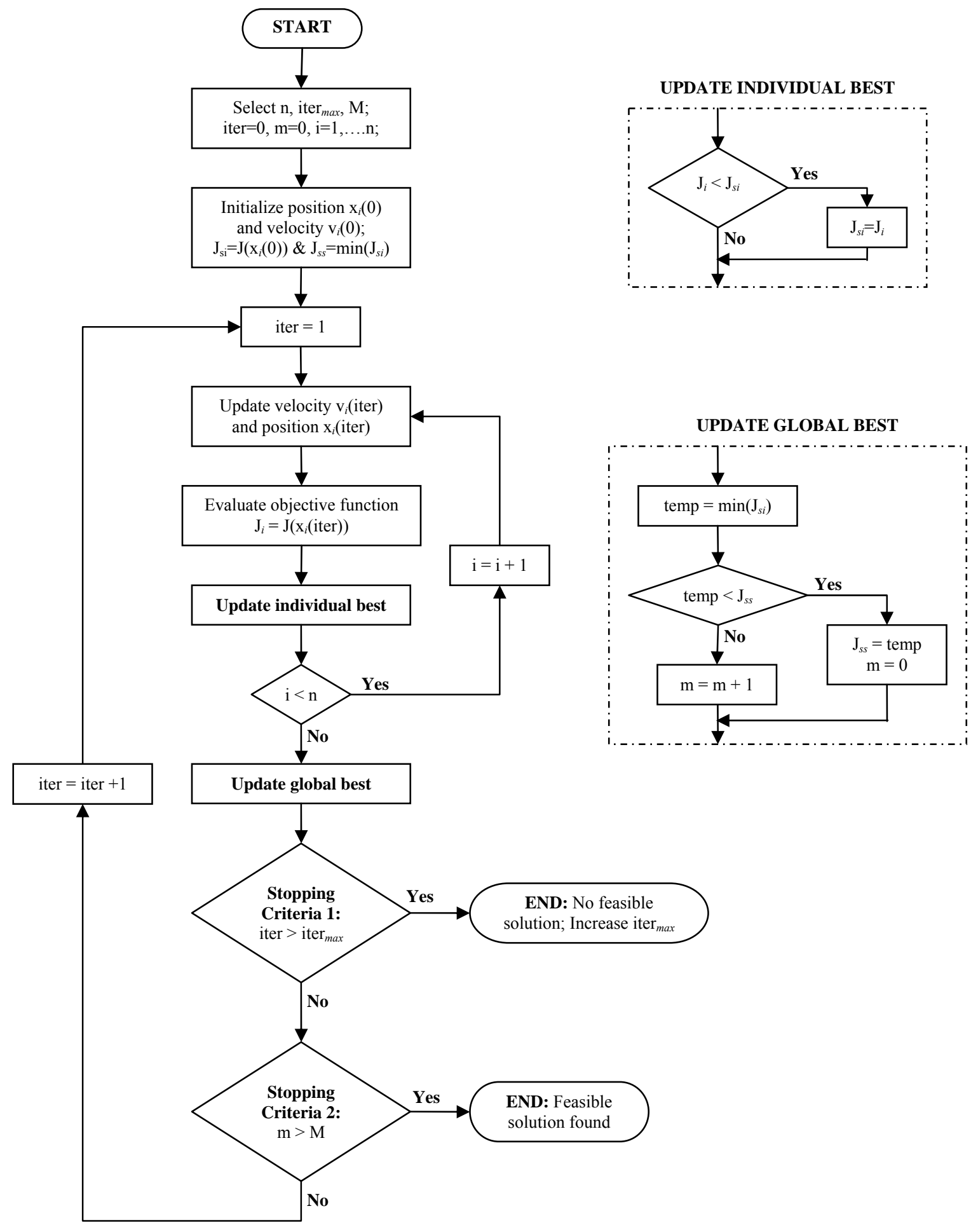

Figure 3.4: Particle Swarm Optimization Flowchart

The initial searching point is set to $\mathrm{p}_{\text {best }}$ for each particle. The best evaluated value of $\mathrm{p}_{\text {best }}$ is set to $g_{\text {best }}$. The objective function value is evaluated for each particle. If the evaluated 


\section{CHAPTER 3: CONTROLLER OPTIMIZATION}

value is less than the current $p_{\text {best }}$ of the particle, it replaces the current value. This updates the $\mathrm{p}_{\text {best }}$ for that particle. If the best value of $\mathrm{p}_{\text {best }}$ is less than the current $\mathrm{g}_{\text {best }}$, it replaces the current $g_{b e s t}$ value. In this way g gest is updated.

This search algorithm will terminate if one of the following stopping criteria is satisfied:

1. The number of iterations exceeds the pre-set maximum number of iterations (iter>iter $r_{\max }$ ). In this case, there is no feasible solution or the pre-set maximum number of iterations is not large enough.

2. The number of iterations since the last change of the best solution is greater than the pre-specified number $(\mathrm{m}>\mathrm{M})$. In this case, a feasible solution is found.

If the stopping criteria are not satisfied, the iteration number increases by 1 and the searching point of each particle is changed following the procedure described above.

The speed controller of the gas turbine has been tuned using the PSO technique described above. The speed controller PID parameters $\left(K_{p g}, K_{i g}\right.$ and $\left.K_{d g}\right)$ for the gas turbine have been optimized using the ITAE performance index for a $0.2 \mathrm{pu}$ load pickup. The tuned PID speed controller parameters are: $\mathrm{K}_{\mathrm{pg}}=21.9370, \mathrm{~K}_{\mathrm{ig}}=18.6264, \mathrm{~K}_{\mathrm{dg}}=39.2917$. 


\section{CHAPTER 4: ELECTRIC SHIPBOARD POWER SYSTEM}

\subsection{Introduction}

The most challenging support system on board a Navy warship is the electric power grid. Electric power is required to operate almost everything on board, from the sophisticated weaponry systems and computer networks to fire pumps. The main aim of an all electric shipboard power system is to provide continuous power and regulation in spite of power demand variations and component failures, in addition to decreasing human tasking.

As in a civilian power system, stability issues may arise in a naval ship power system caused by large disturbances associated with damage or attack during battle. A ship that faces a blackout during battle is unable to fight, and this could lead to the possibility of complete destruction. To some extent, the survivability of an electric naval ship depends on the stable operation of the electric power system during and after such an occurrence. The survivability can be improved to some extent by appropriate control of the electric shipboard power system.

An Electric Shipboard Power System (ESPS) testbed developed in Matlab/Simulink was provided by the Office of Naval Research (ONR) [19]. The detailed model of this testbed comprises of the power electronic switching transients and is said to be numerically intense. This tends to slow the simulation time. In this chapter, a gas turbine model will be implemented as a prime mover for the ESPS. This feature has been neglected in the testbed provided, by representing the prime mover as a constant speed mechanical source. The detailed model represents the full dynamics of the system and this makes the power system being studied even more realistic. A brief description of the detailed electric shipboard power system testbed is provided in the next section.

\subsection{Shipboard Power System}

Figure 4.1 shows a one line diagram of the ONR Electric Shipboard Power System testbed. The system has two AC subsystems, two power supplies and a DC Zonal Electric Distribution system. Six Ship Service Converter Modules, one Ship Service Inverter 
Module, one Local Bank, a Motor Controller and a Constant Power Load make up the DC Zonal Electric Distribution system.

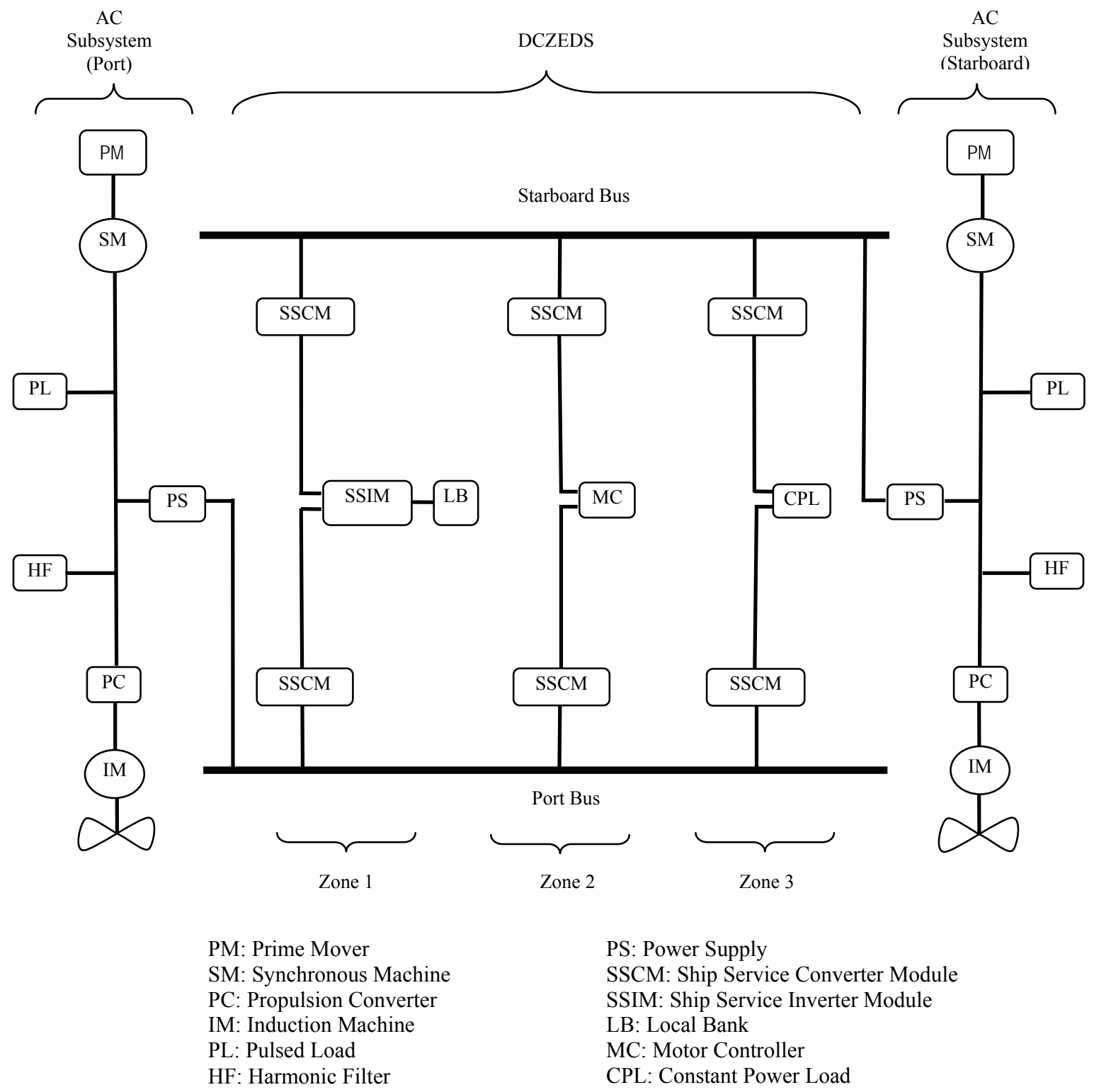

Figure 4.1: One Line Diagram of ONR Electric Shipboard Power System Testbed

Each AC subsystem comprises of a synchronous generator, an ac bus and a propulsion system. Each generator of $59 \mathrm{~kW}$ is driven by a prime mover (presently a constant speed mechanical source) and an exciter, which is the source of AC power. The generator is represented by the qd model [20]. Each three phase ac bus includes a harmonic filter to 
trap the harmonics injected by the propulsion rectifier. Each propulsion system comprises of a three phase bridge rectifier, a dc filter and an inverter connected to an induction machine of $37 \mathrm{~kW}$, which represents the primary load on the AC power system.

The two power supplies of $15 \mathrm{~kW}$ each provide the port and starboard bus voltages for the DC Zonal Electric Distribution system by AC/DC rectification. This is the secondary load on the AC power system. The loads on board are grouped into zones to improve survivability, and each zone is supplied from both of the DC buses by additional DC/DC converters. As part of this research work, a pulsed load of $15.5 \mathrm{~kW}$ has been modeled and implemented for the ESPS Testbed. Details of this model are provided in Section 4.3 of this chapter.

Regulation of the in-zone bus voltages (500 to $420 \mathrm{~V} \mathrm{DC}$ ) are obtained by each of the six Ship Service Converter Modules through a combination of the feedback and feed forward control paths within each zone. The Ship Service Inverter Module converts the zone bus voltage (420V DC to $230 \mathrm{~V}$ AC) providing clean three phase ac power to a Local Bank, which supplies a variety of loads $(15 \mathrm{~kW})$. The Motor Controller comprises of a $15 \mathrm{~kW}$ AC motor drive system. The Constant Power Load is made up of a buck converter supplying a constant $5 \mathrm{~kW}$ of power for power electronic based loads.

\subsection{Pulsed Load for ESPS}

A pulsed power load is modeled as a capacitor charging circuit to supply a high energy weapon system for the ESPS. The energy storage capacitor is charged from the AC system bus of the ESPS. From [33], the energy storage capacitor stores a maximum of $200 \mathrm{~kJ}$ of energy and each pulsed load discharges $128 \mathrm{~kJ}$ of energy in 0.15 seconds. The capacitor charging circuit is shown in Figure 4.2. It consists of an uncontrolled diode rectifier which accepts a three phase input voltage from the AC system bus. The filtered rectifier output is fed to a buck converter which regulates the output voltage to $450 \mathrm{~V} \mathrm{dc}$. 


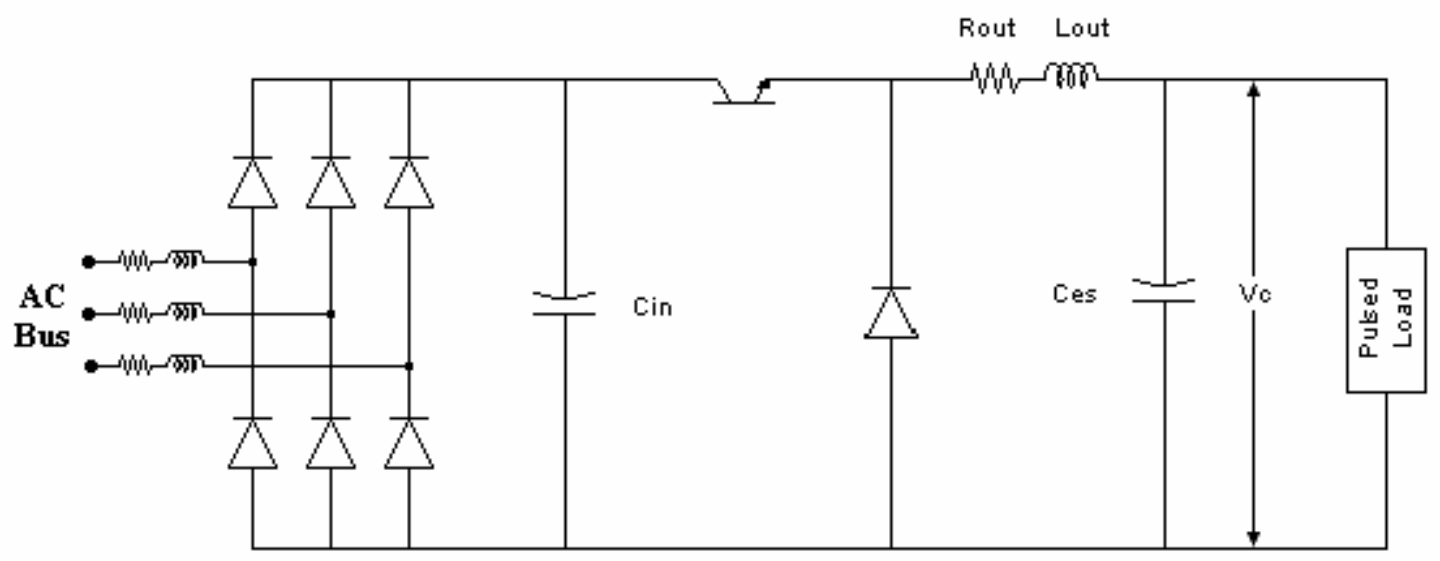

Figure 4.2: Capacitor charging circuit diagram

The block diagram of the pulsed load controller is shown in Figure 4.3. The parameter values used in the model are summarized in Table A.6. This control scheme is used to charge the energy storage capacitor as rapidly as possible, subject to the capacitor current $\left(\mathrm{I}_{\mathrm{cmax}}\right)$ and power $\left(\mathrm{P}_{\mathrm{cmax}}\right)$ limits.

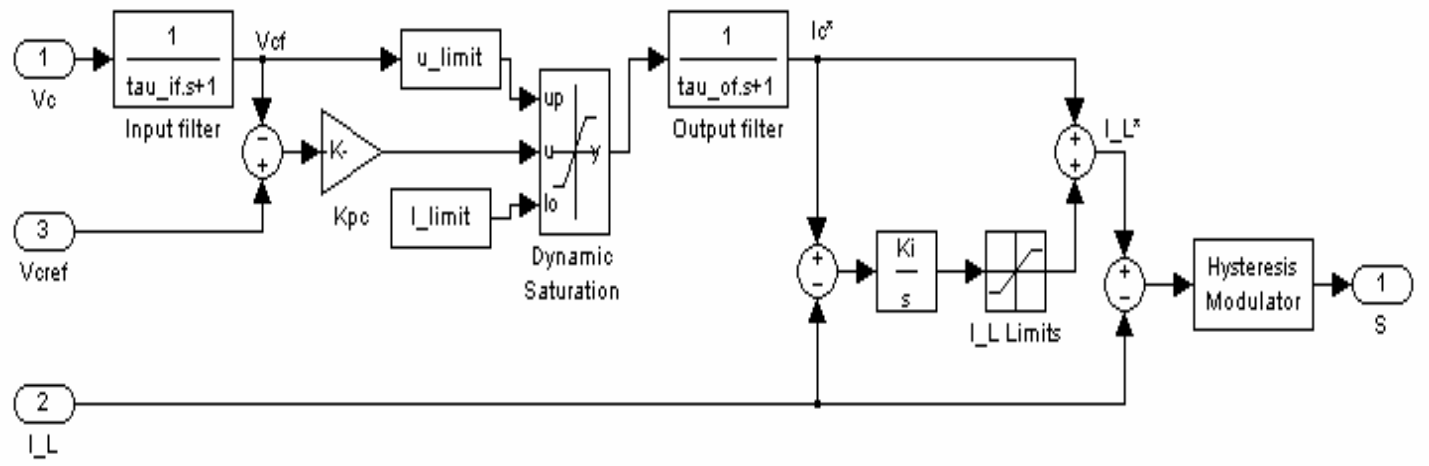

Figure 4.3: Pulsed Load controller block diagram

The measured capacitor voltage $V_{c}$ is filtered by an input low pass filter and then compared with the reference capacitor voltage $\mathrm{V}_{\text {cref. }}$. The resulting error is multiplied by a proportional gain $\mathrm{K}_{\mathrm{pc}}$ and subjected to a dynamic limit, $\mathrm{I}_{\text {climit. }}$. This limit is calculated to ensure that the energy storage capacitor power and current limits will not be violated. The capacitor current is then filtered by an output low pass filter. On summing the capacitor current command with the limited integral of the error between the capacitor current 


\section{CHAPTER 4: ELECTRIC SHIPBOARD POWER SYSTEM}

command $\mathrm{I}_{\mathrm{c}}$ and measured inductor current $\mathrm{I}_{\mathrm{L}}$, the inductor current command $\mathrm{I}_{\mathrm{L}}{ }^{*}$ is obtained. This command and the measured inductor current determine the switching state of the switch $\mathrm{S}$, using a hysteresis modulator.

A single discharge and charge cycle of the energy storage capacitor supplied by a constant voltage source is shown in Figure 4.4. Initially the capacitor is fully charged. On application of the pulse at $2 \mathrm{~s}$, the capacitor discharges across the pulsed load to produce $128 \mathrm{~kJ}$ in $0.15 \mathrm{~s}$. The capacitor then starts charging back to its reference voltage of $450 \mathrm{~V}$. The controller limits the capacitor power and current to $15.5 \mathrm{~kW}$ and $40.5 \mathrm{Amps}$ respectively as shown in Figure 4.5
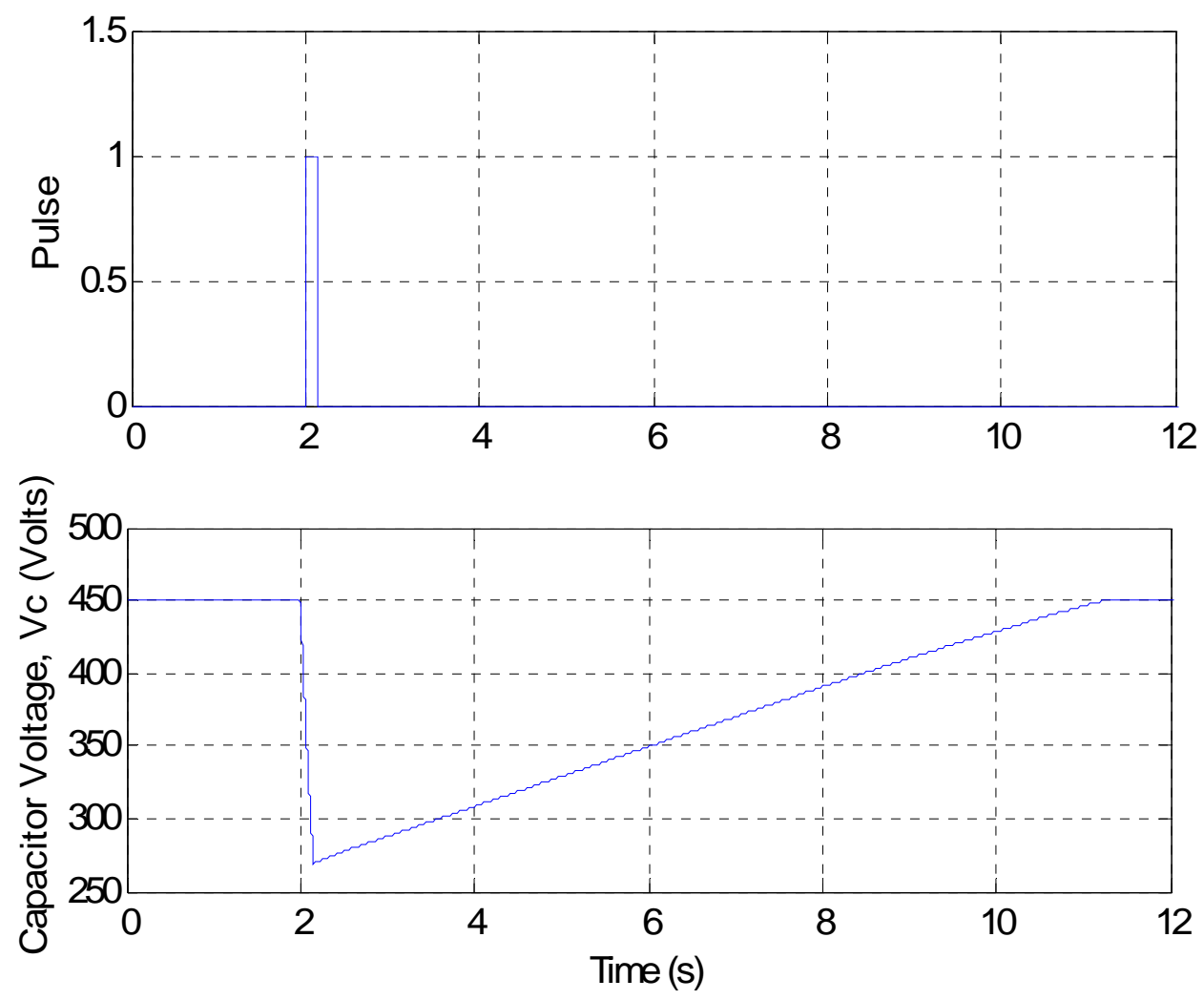

Figure 4.4: Energy storage capacitor discharge/charge cycle 

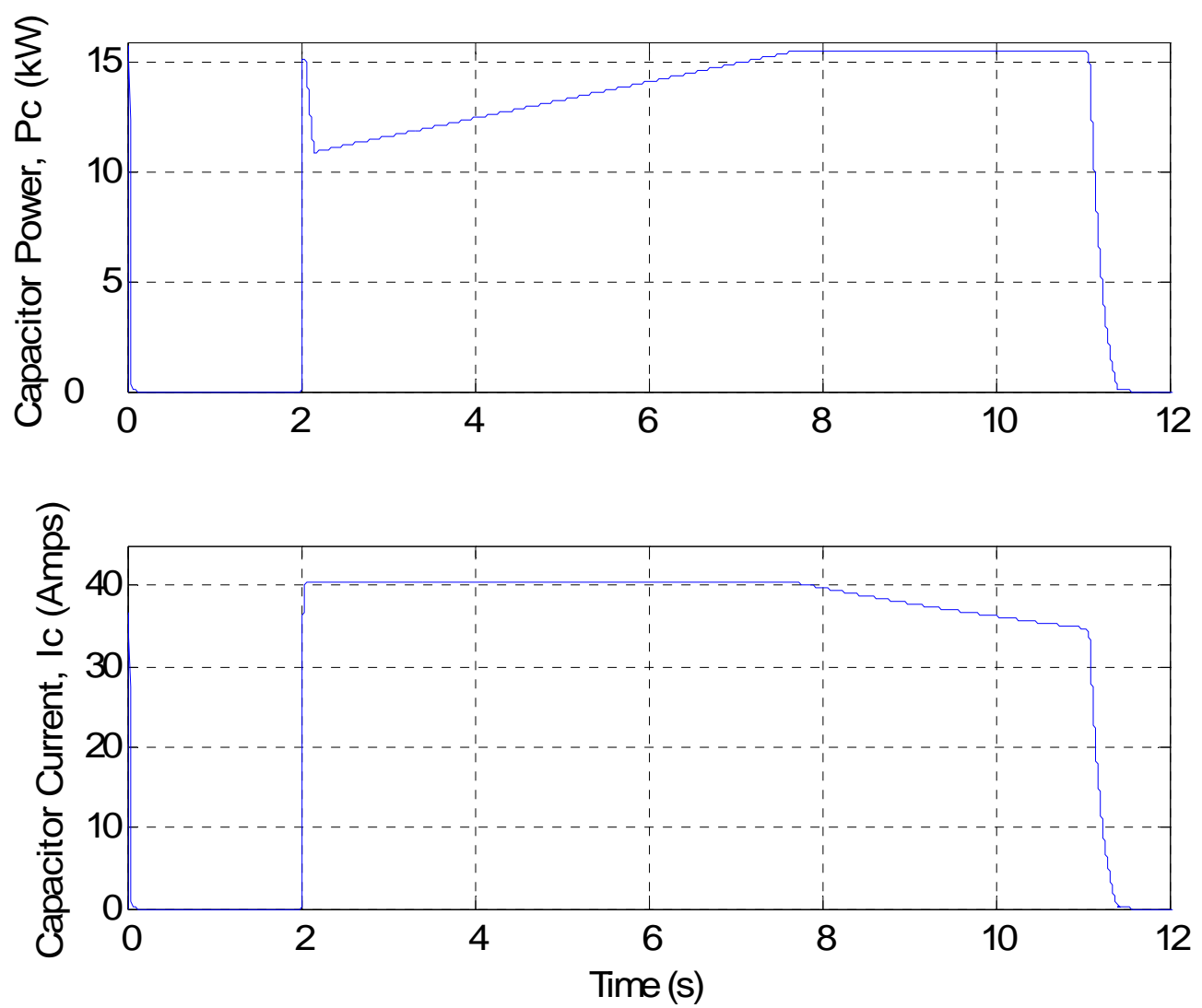

Figure 4.5: Energy storage capacitor power and current waveforms

\subsection{Gas Turbine as a Prime Mover}

In this section, the gas turbine model [4] selected in Chapter 2 is implemented as a prime mover for the ESPS. The three main loads on the system are the propulsion system, the power supply and the pulsed load. Figure 4.6 represents the AC port side subsystem schematic of the ESPS. A generation capacity of $59 \mathrm{~kW}$ is supplied to the AC bus by the synchronous generator, which is driven by the gas turbine. The propulsion system which comprises of the propulsion converter and induction machine consumes $37 \mathrm{~kW}$ of this power when operating at full load. The power supply consumes $15 \mathrm{~kW}$ of the generation which is converted to DC and supplied to the loads in the DC distribution system of the ESPS. The pulsed load consumes $15.5 \mathrm{~kW}$ from the generator to charge the capacitor after the load across the capacitor discharges it. The detailed model of the pulsed load has been described in the previous section while the propulsion system and power supply loads have been explained below. 


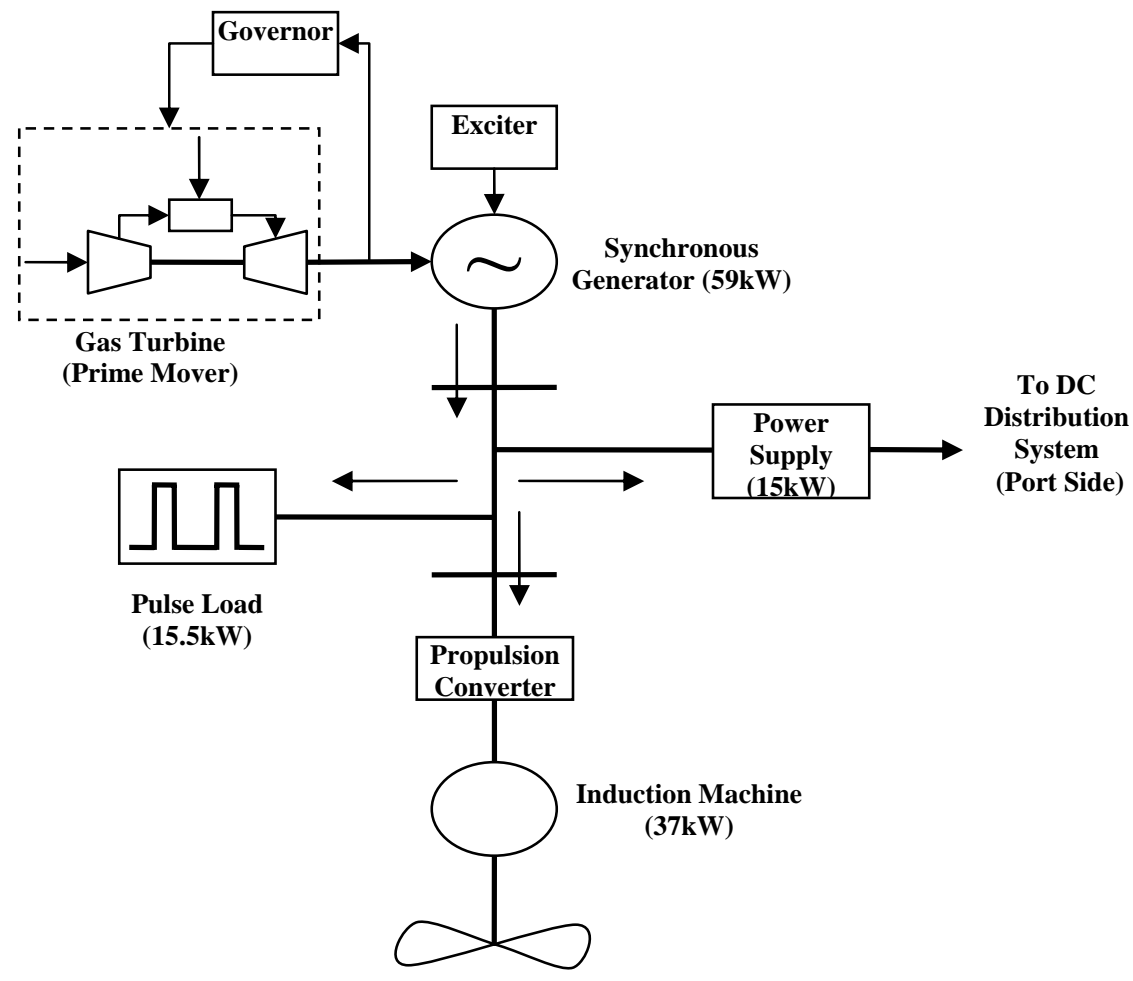

Figure 4.6: AC Subsystem of ESPS (Port Side)

\section{Propulsion System}

The propulsion system load comprises of a propulsion converter and a $37 \mathrm{~kW}$ induction machine. The propulsion converter is made up of a three phase bridge rectifier, a dc filter and an inverter. Figure 4.7 shows the circuit diagram of the propulsion system. The parameter values are summarized in Table A.4 and A.5 in the Appendix. 


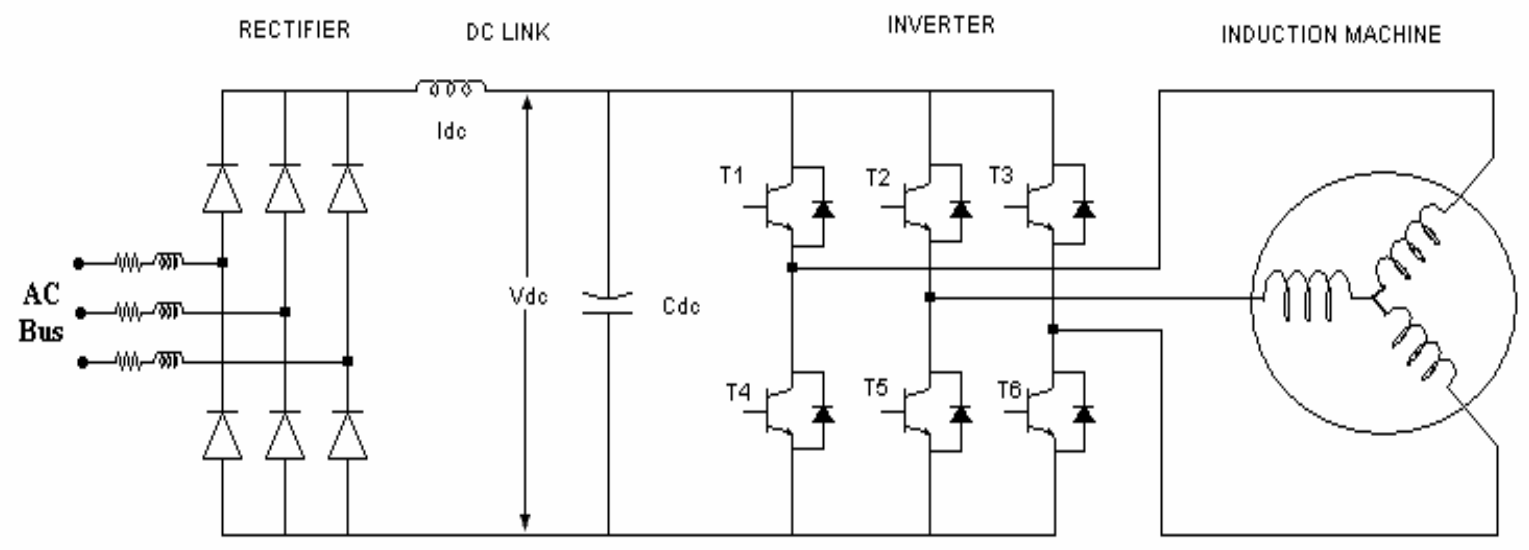

Figure 4.7: Circuit diagram of propulsion system

The induction machine drive control scheme is based on the constant slip frequency control as described in Chapter 14 of [20]. Figure 4.8 shows the Simulink subsystem of the induction machine drive control scheme.

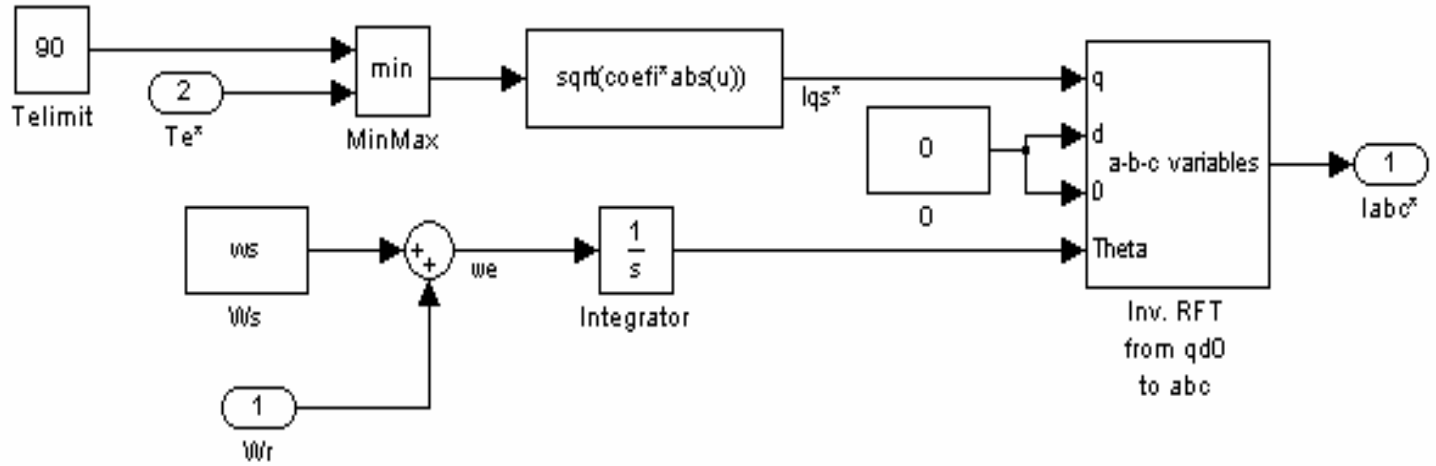

Figure 4.8: Simulink subsystem of constant slip frequency control scheme

The fixed slip frequency is defined as in equation 4.1:

$$
\omega_{s}=\omega_{e}-\omega_{r}
$$

By appropriate choice of the slip frequency $\omega_{\mathrm{s}}$, optimal torque for a given value of stator current as well as the maximum efficiency can be achieved. The electromagnetic torque is expressed in terms of slip frequency as defined in equation 4.2: 


$$
T_{e}=\frac{3\left(\frac{P}{2}\right) \omega_{s} L_{M}^{2} I_{s}^{2} r_{r}^{\prime}}{\left(r_{r}^{\prime}\right)^{2}+\left(\omega_{s} L_{r r}^{\prime}\right)^{2}}
$$

From equation 4.2 it can be seen that in order to obtain a desired torque $\mathrm{T}_{\mathrm{e}}{ }^{*}$ utilizing the slip frequency $\omega_{\mathrm{s}}$, the rms value of the fundamental component of the stator current should be set according to equation 4.3:

$$
I_{s}=\sqrt{\frac{2\left|T_{e}^{*}\right|\left(r_{r, e s t}^{\prime 2}+\left(\omega_{s} L_{r r, e s t}^{\prime}\right)^{2}\right)}{3 P\left|\omega_{s}\right| L_{M, e s t}^{2} r_{r, e s t}^{\prime}}}
$$

In equation 4.3, the parameter subscripts in equation 4.2 have been augmented with 'est' in order to indicate that this relationship will be used in a control system in which the parameter values reflect estimates of the actual values. These values are provided in Table A.5 of the Appendix. $\mathrm{T}_{\mathrm{e}}{ }^{*}$ in Figure 4.8 is input by the user in $\mathrm{Nm}$ and compared with a maximum $\mathrm{T}_{\mathrm{e}}$ of $90 \mathrm{Nm}$. The minimum of the two is used to compute the stator current $\mathrm{I}_{\mathrm{qs}}{ }^{*}$ as given in equation 4.3. Inverse reference frame transformation is used to convert the current back to the abc reference frame.

\section{Power Supply}

The power supply accepts a three phase input voltage that may vary between $480 \mathrm{~V}-$ $560 \mathrm{~V}$ line-line rms, and is designed to regulate the output to $500 \mathrm{~V}$ de for loads up to $15 \mathrm{~kW}$. The circuit diagram of the power supply model is shown in Figure 4.9. The three phase ac source is connected to an uncontrolled diode rectifier. The output of the rectifier provides the input to a buck converter that regulates the output voltage. 


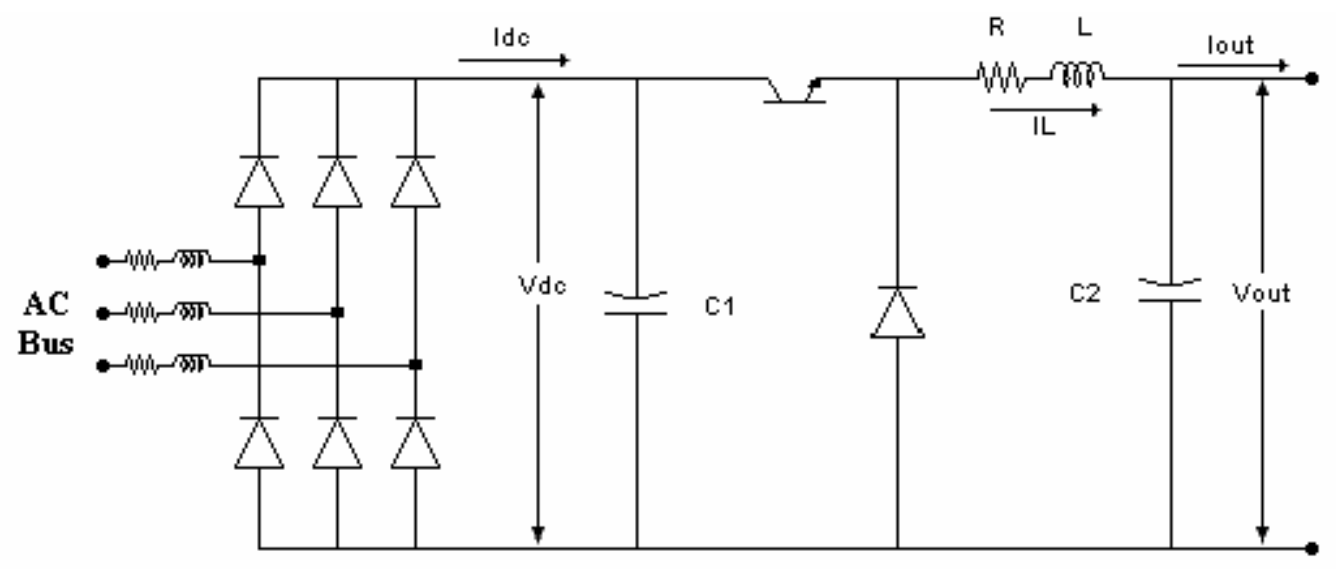

Figure 4.9: Circuit diagram of power supply

The control scheme for the power supply is shown in Figure 4.10. The parameters used in this model are summarized in Table A.2 in the Appendix.

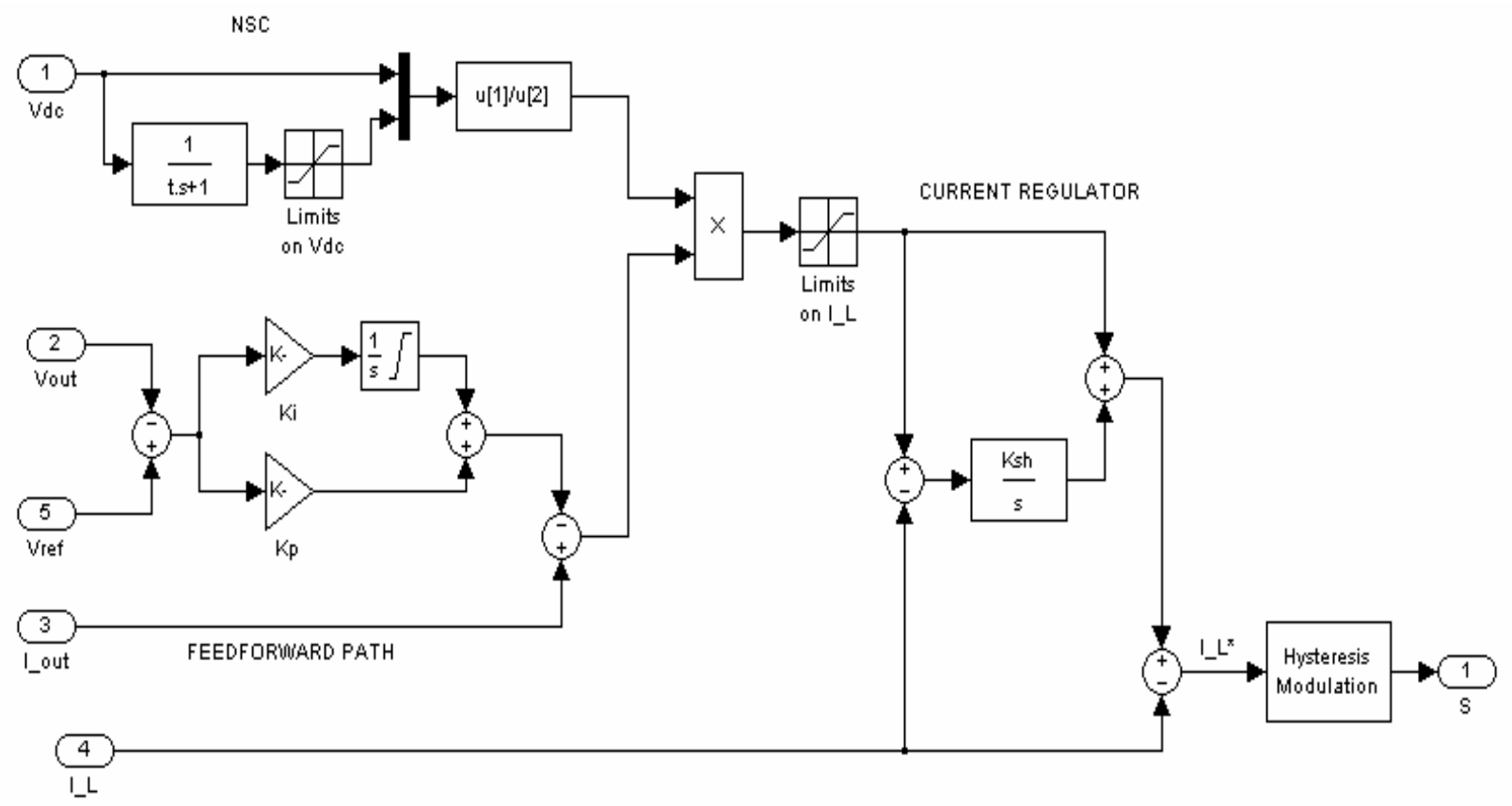

Figure 4.10: Power supply controller block diagram

The measured output voltage $V_{\text {out }}$ is compared with the reference voltage $V_{\text {ref }}$ and the error is an input to a proportional-integral (PI) controller. The feedforward path provides a fast response to changes in load. The difference between the output of the PI controller and the measured output current is multiplied by the output of the nonlinear stabilizing 
control (NSC). The result is bounded by the limits on $\mathrm{I}_{\mathrm{L}}$ and passed to the current regulator. The output of the current regulator is used for hysteresis modulation.

\section{Gas Turbine}

Figure 4.11 shows the subsystem of the ESPS model in Simulink comprising of the exciter, generator and gas turbine. The block diagram of the gas turbine model incorporated as prime mover for the ESPS is shown in Figure 4.12. The parameter values for the model are listed in the Appendix in Table A.7. The PID parameters of the gas turbine speed controller have been tuned using Particle Swarm Optimization Technique set forth in Chapter 3. The controller parameters are tuned using the ITAE performance index which minimizes the speed error and reduces the overshoot of the speed response. These tuned optimized values for $\mathrm{K}_{\mathrm{pg}}, \mathrm{K}_{\mathrm{ig}}$ and $\mathrm{K}_{\mathrm{dg}}$ of the PID speed controller have been used in this model.

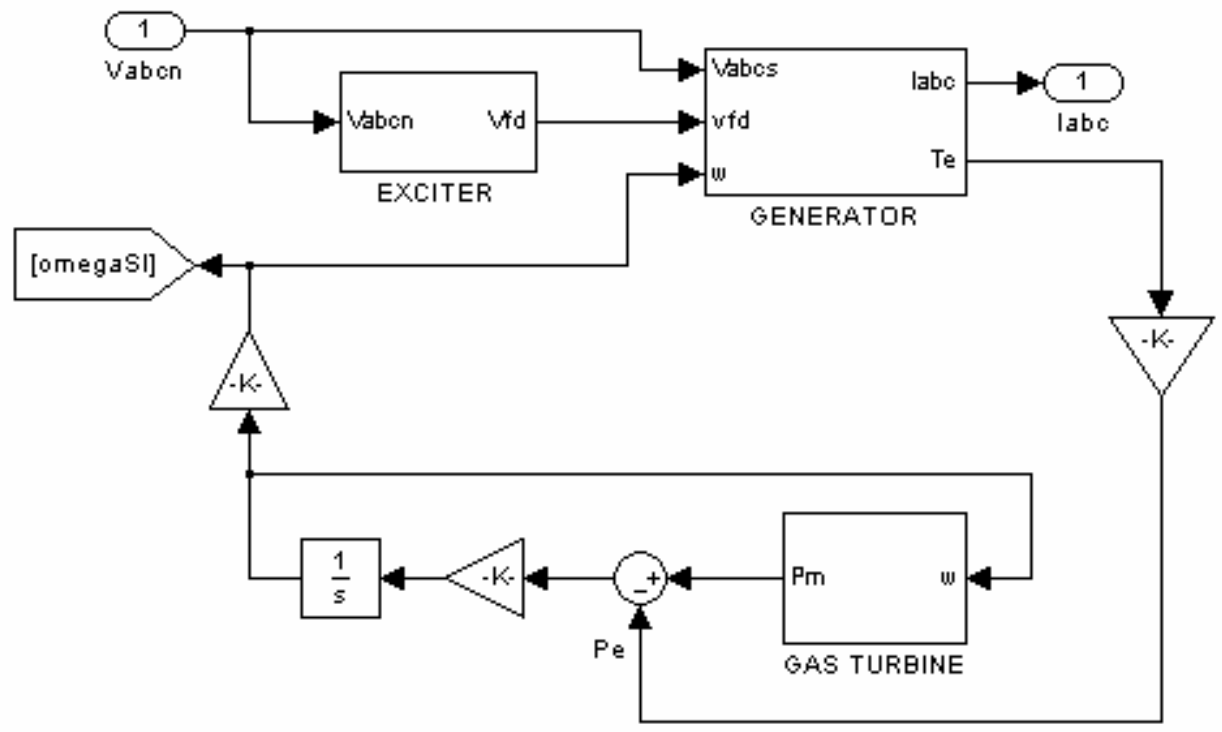

Figure 4.11: ESPS Simulink subsystem with gas turbine 


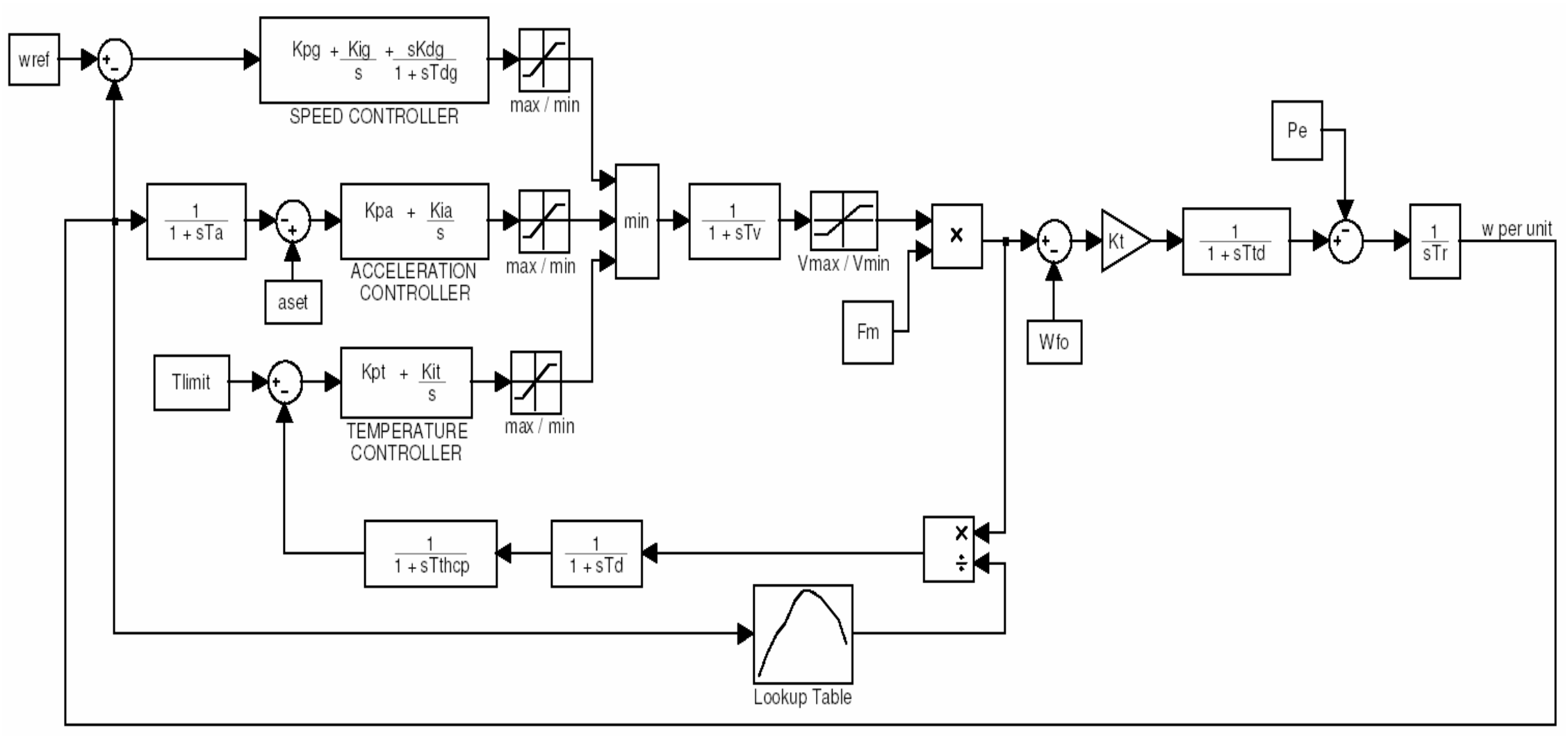

Figure 4.12: Model of gas turbine incorporated as prime mover 
Three cases have been considered herein to show the dynamics of the gas turbine as a prime mover on the application of a load. The gas turbine is a slow dynamic device, while the loads comprise of power electronic components which have faster dynamics. These three cases study the interaction between these systems on the ESPS. The loads used in each case here are the 3-phase detailed load models which are numerically intense, resulting in slow simulation time. In the first case, the propulsion system load is set to $7 \mathrm{~kW}$ and Figure 4.13 shows the results of this simulation. The propulsion load is stepped up from 0 to $7 \mathrm{~kW}$ at $0.6 \mathrm{~s}$. The gas turbine controller signals for this case are shown are in Figure 4.14. In the second case, the power supply is stepped up from 0 to $15 \mathrm{~kW}$ at $0.6 \mathrm{~s}$ as shown in Figure 4.15. The gas turbine controller signals for this case are shown in Figure 4.16. In the third case, the pulsed load is applied at $0.6 \mathrm{~s}$ and the capacitor is discharged in $0.15 \mathrm{~s}$ and then begins charging from the $\mathrm{AC}$ bus which is supplied by the gas turbine and generator. The results of this simulation can be seen in Figure 4.17 with the gas turbine controller signals in Figure 4.18. From the controller signal plots in all the three cases, the gas turbine is operating within limits and speed control is the active control loop. The temperature control signal remains constant during the simulation as exhaust temperature limits are not reached. The acceleration controller signal value is always higher than the speed controller signal value, and gets activated only during load pickup or load rejection processes. 
CHAPTER 4: ELECTRIC SHIPBOARD POWER SYSTEM
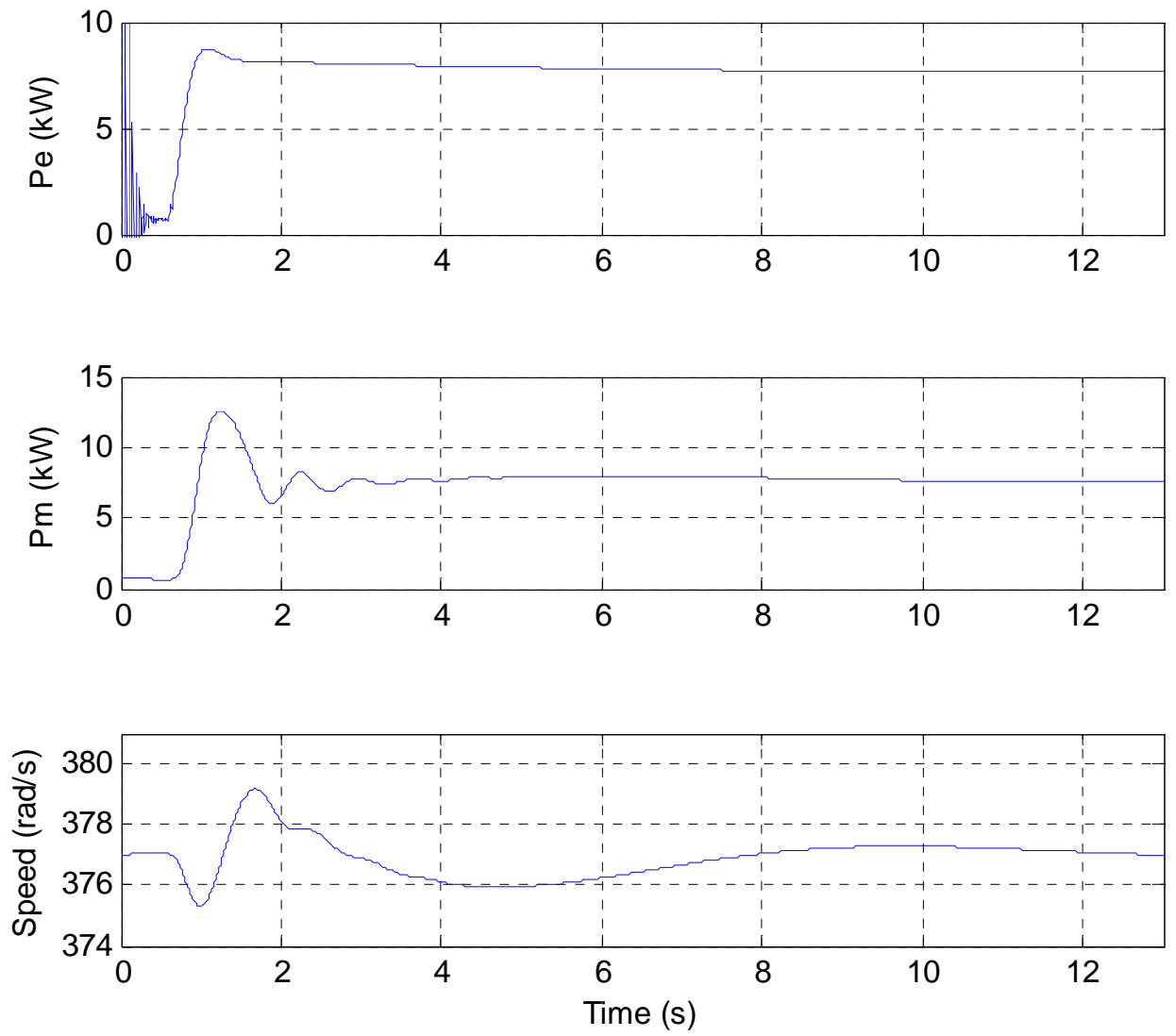

Figure 4.13: Plots for 7kW propulsion system load

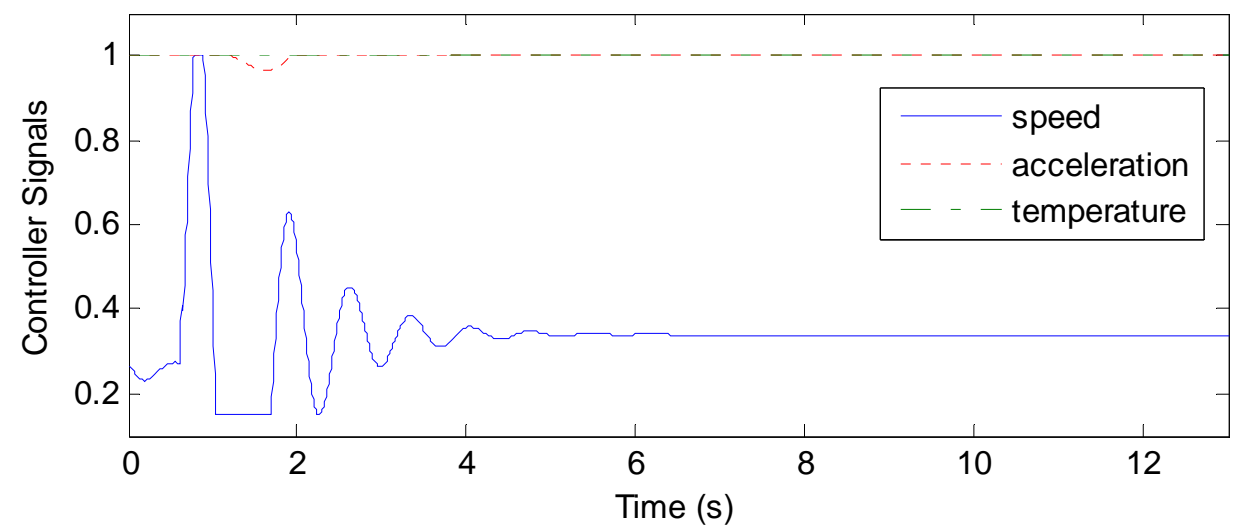

Figure 4.14: Gas turbine controller signals for $7 \mathrm{~kW}$ propulsion system load 

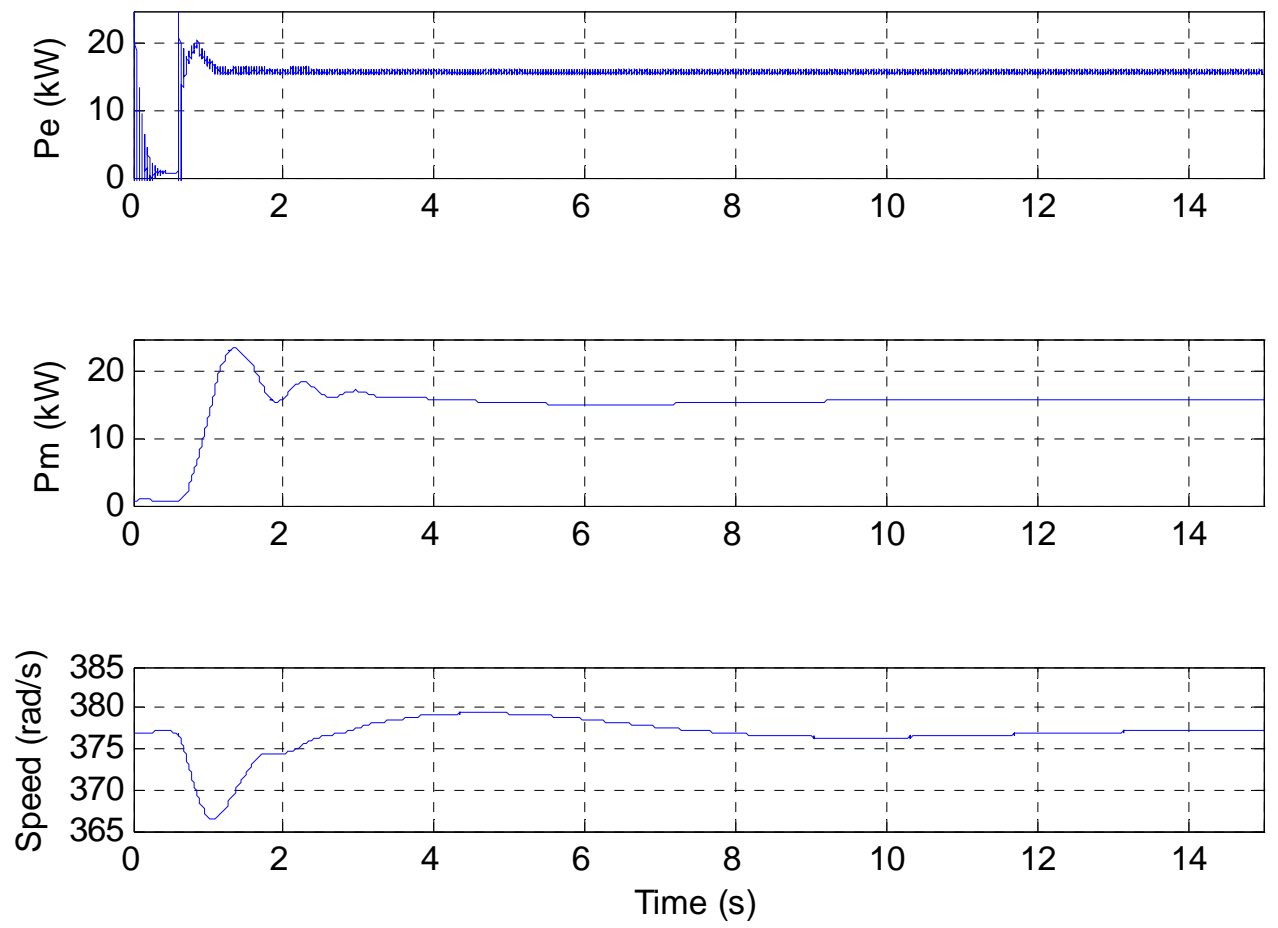

Figure 4.15: Plots for $15 \mathrm{~kW}$ power supply load

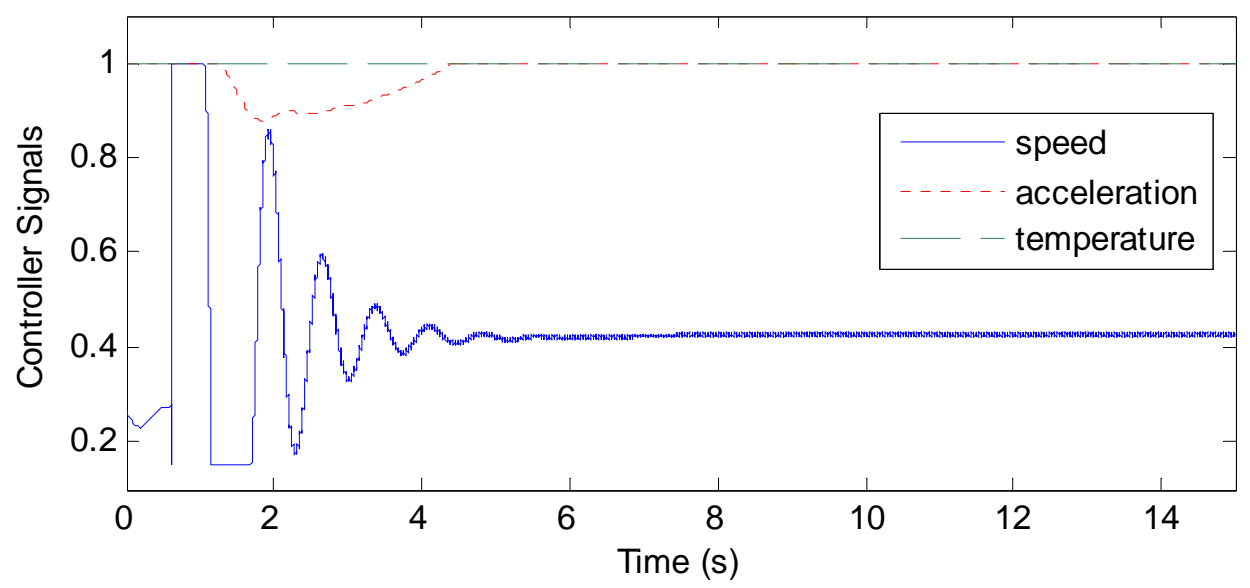

Figure 4.16: Gas turbine controller signals for $15 \mathrm{~kW}$ power supply load 

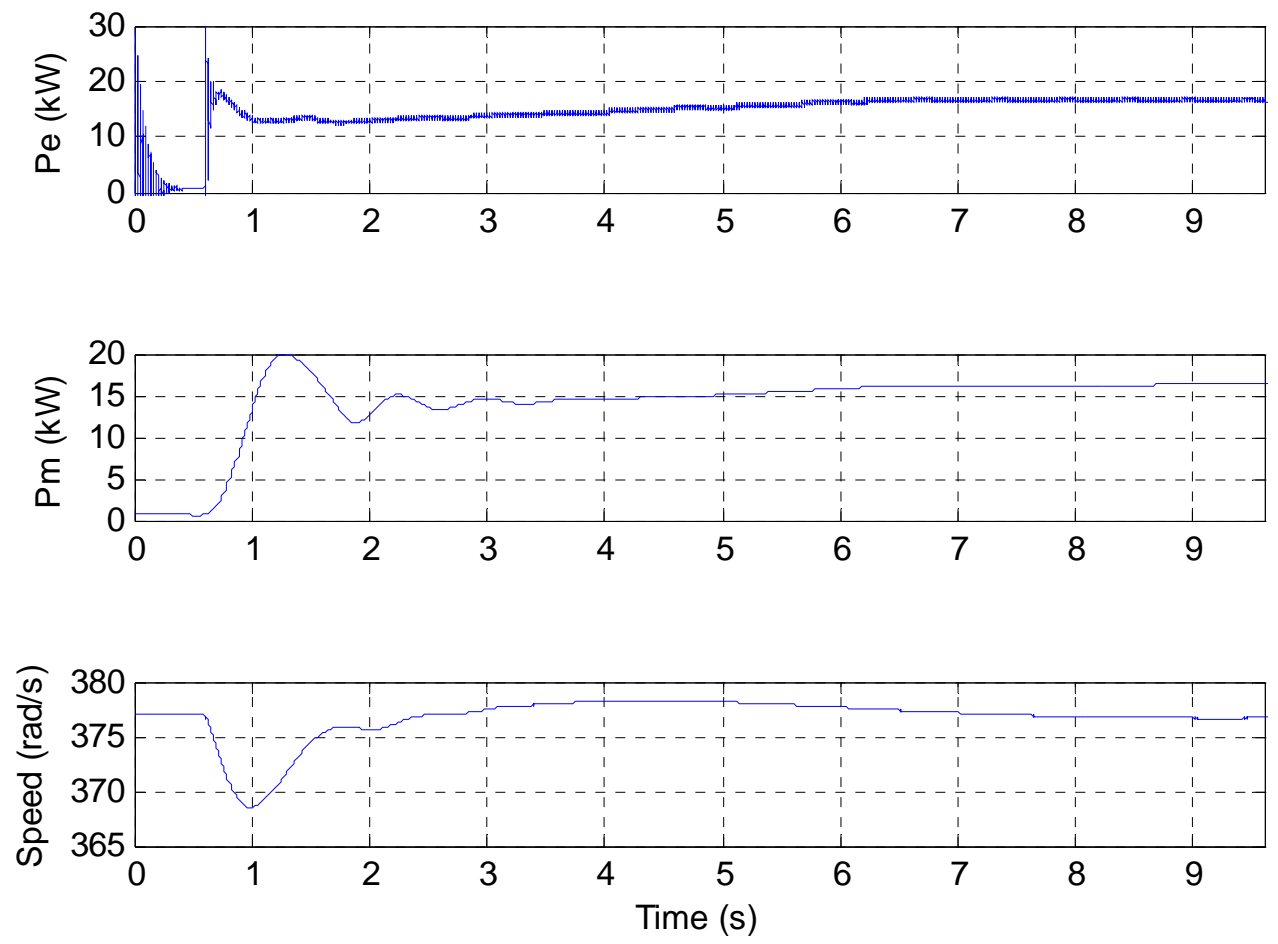

Figure 4.17: Plots for $15.5 \mathrm{~kW}$ pulsed power load

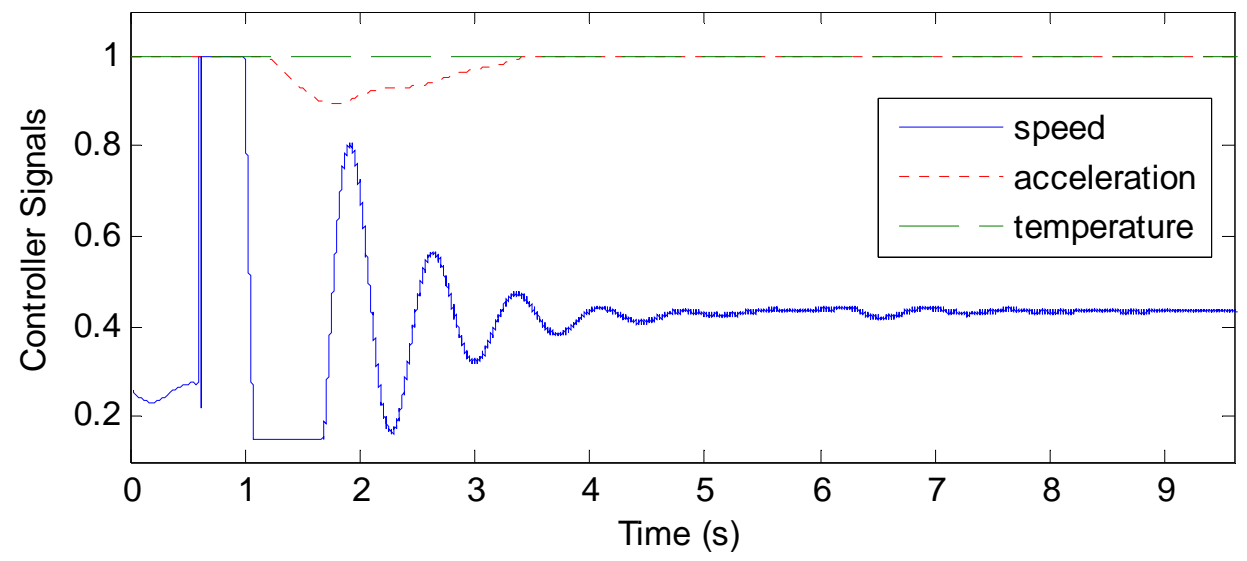

Figure 4.18: Gas turbine controller signals for $15.5 \mathrm{~kW}$ pulsed power load

Figure 4.19 shows the pulse applied at $0.6 \mathrm{~s}$, and the discharging and charging of the energy storage capacitor in terms of the capacitor voltage $\left(\mathrm{V}_{c}\right)$ and power $\left(\mathrm{P}_{\mathrm{c}}\right)$. These are found to be similar to the results in Figure 4.4 where the capacitor was charged from a constant voltage source. 

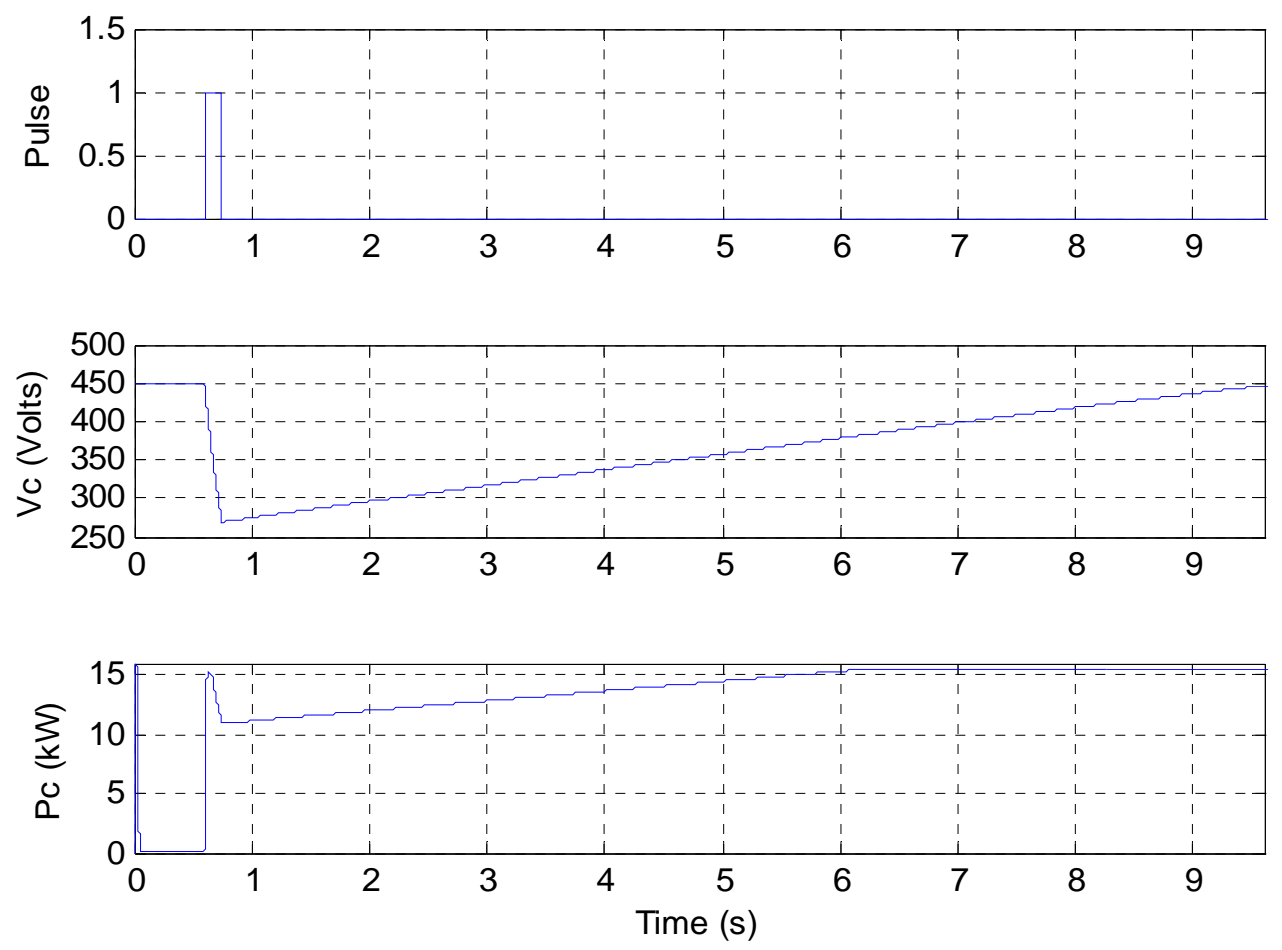

Figure 4.19: Energy storage capacitor waveforms

\subsection{Tuning of Gas Turbine Speed, Temperature and Acceleration Controllers}

In this section, all the three controllers of the gas turbine have been tuned simultaneously using the PSO technique. The speed controller PID parameters $\left(\mathrm{K}_{\mathrm{pg}}, \mathrm{K}_{\mathrm{ig}}\right.$ and $\left.\mathrm{K}_{\mathrm{dg}}\right)$, the acceleration controller PID parameters $\left(\mathrm{K}_{\mathrm{pa}}, \mathrm{K}_{\mathrm{ia}}\right.$ and $\left.\mathrm{K}_{\mathrm{da}}\right)$ and the temperature controller parameters $\left(\mathrm{K}_{\mathrm{pt}}, \mathrm{K}_{\mathrm{it}}\right.$ and $\left.\mathrm{K}_{\mathrm{dt}}\right)$ for the gas turbine have been optimized using the ITAE performance index. The three cases as simulated in Section 4.4 have been considered here with the optimized parameters for the three controllers. The first case shows the response of the gas turbine to a step from 0 to $7 \mathrm{~kW}$ at $0.6 \mathrm{~s}$ for the propulsion system load. The results of this simulation have been compared with the results obtained with only speed controller tuning, and can be seen in Figure 4.20. The corresponding comparison of gas turbine controller signals is shown in Figure 4.21. The power supply load is stepped up from 0 to $15 \mathrm{~kW}$ at $0.6 \mathrm{~s}$ in the second case and compared with the results obtained with only speed controller tuning, as shown in Figure 4.22. The gas 


\section{CHAPTER 4: ELECTRIC SHIPBOARD POWER SYSTEM}

turbine controller signals comparison for this case is shown in Figure 4.23. In the third case, the pulsed load is applied at $0.6 \mathrm{~s}$ and the capacitor is discharged in $0.15 \mathrm{~s}$ and then begins recharging from the AC bus which is supplied by the gas turbine and generator. The results obtained are compared with the results with only speed controller tuned and is shown in Figure 4.24 with the gas turbine controller signals comparison for this case shown in Figure 4.25.
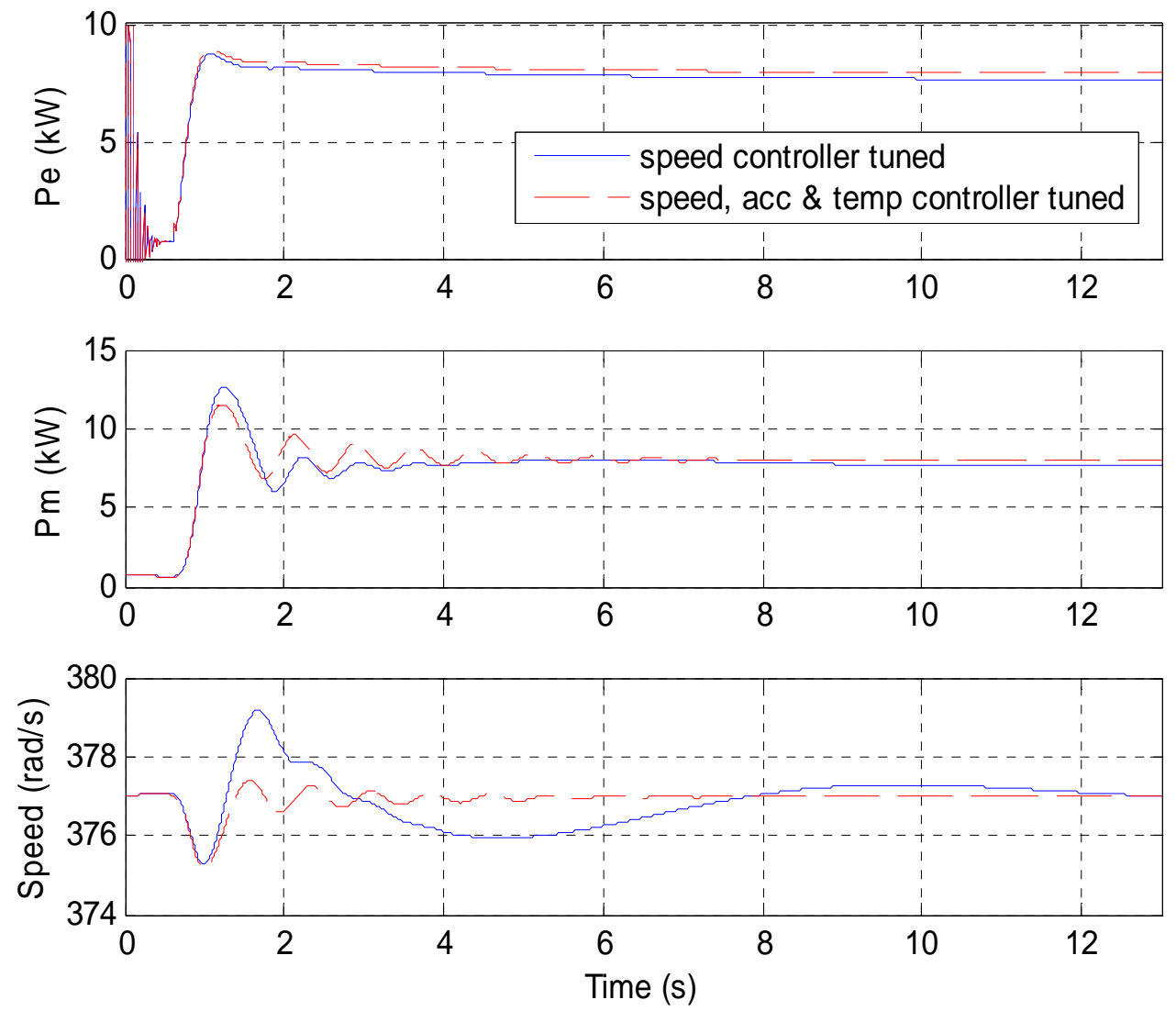

Figure 4.20: Comparison of response for $7 \mathrm{~kW}$ propulsion load 


\section{CHAPTER 4: ELECTRIC SHIPBOARD POWER SYSTEM}
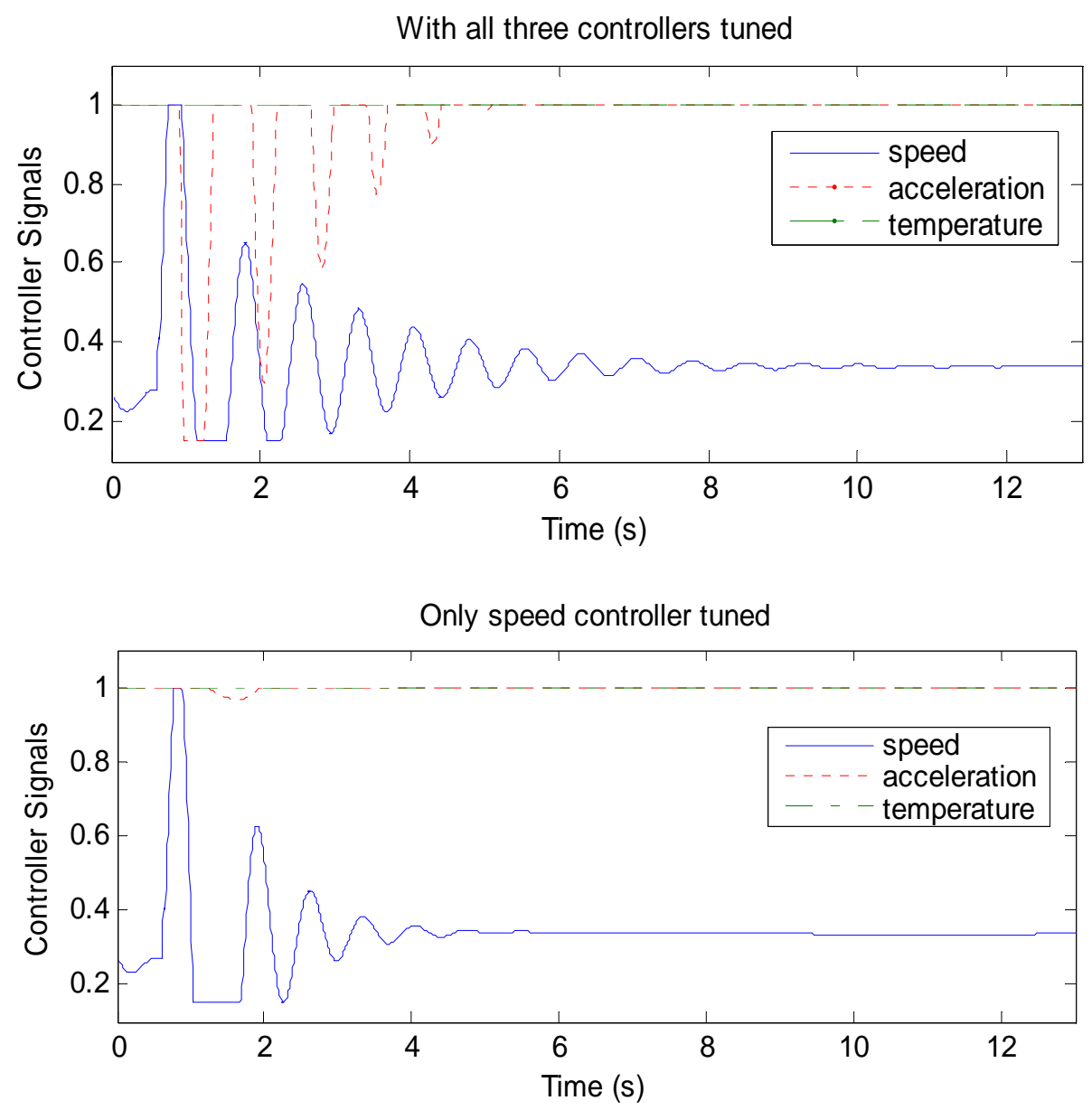

Figure 4.21: Comparison of gas turbine controller signals for propulsion load 


\section{CHAPTER 4: ELECTRIC SHIPBOARD POWER SYSTEM}
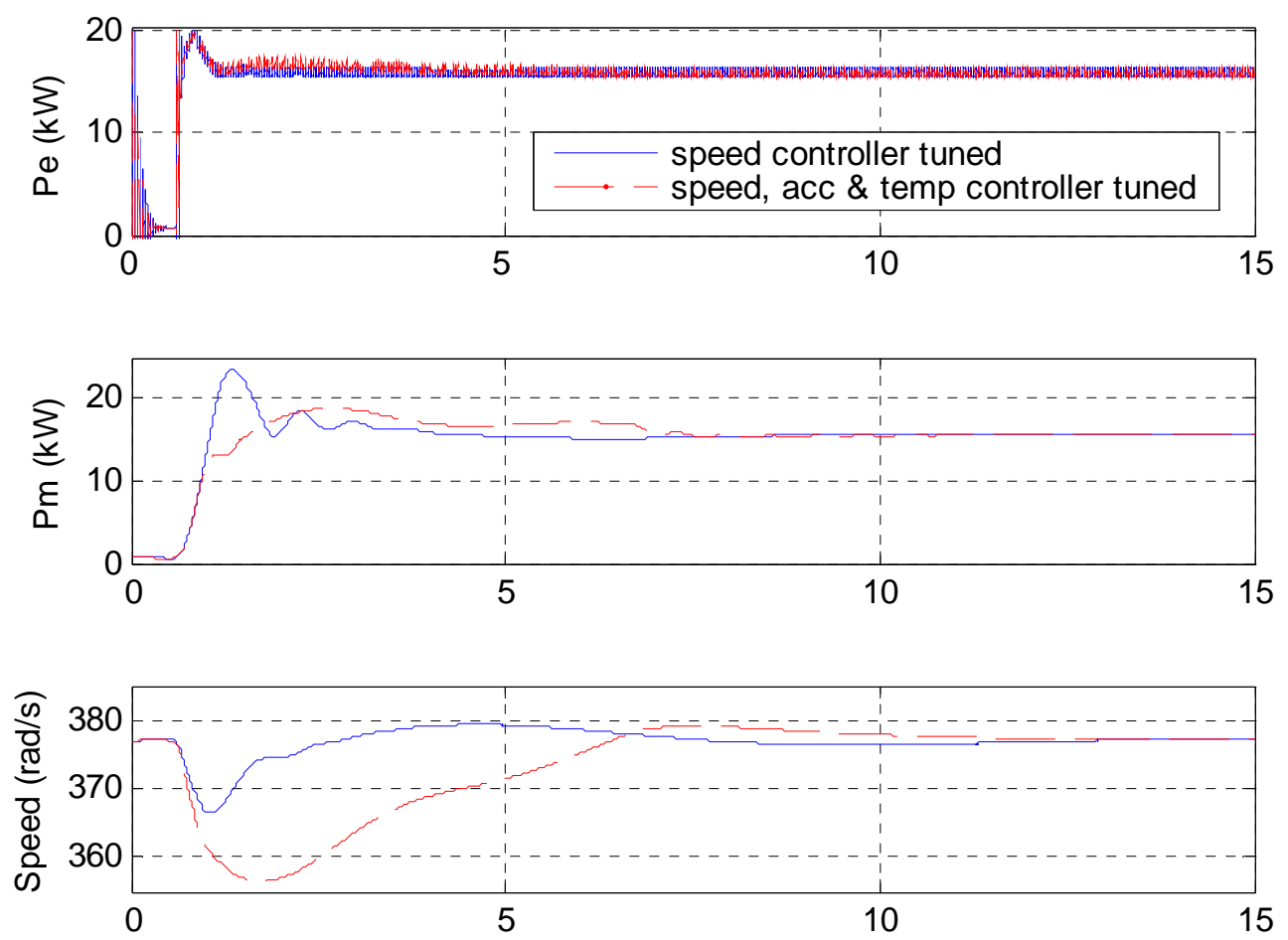

Figure 4.22: Comparison of response for $15 \mathrm{~kW}$ power supply load 


\section{CHAPTER 4: ELECTRIC SHIPBOARD POWER SYSTEM}
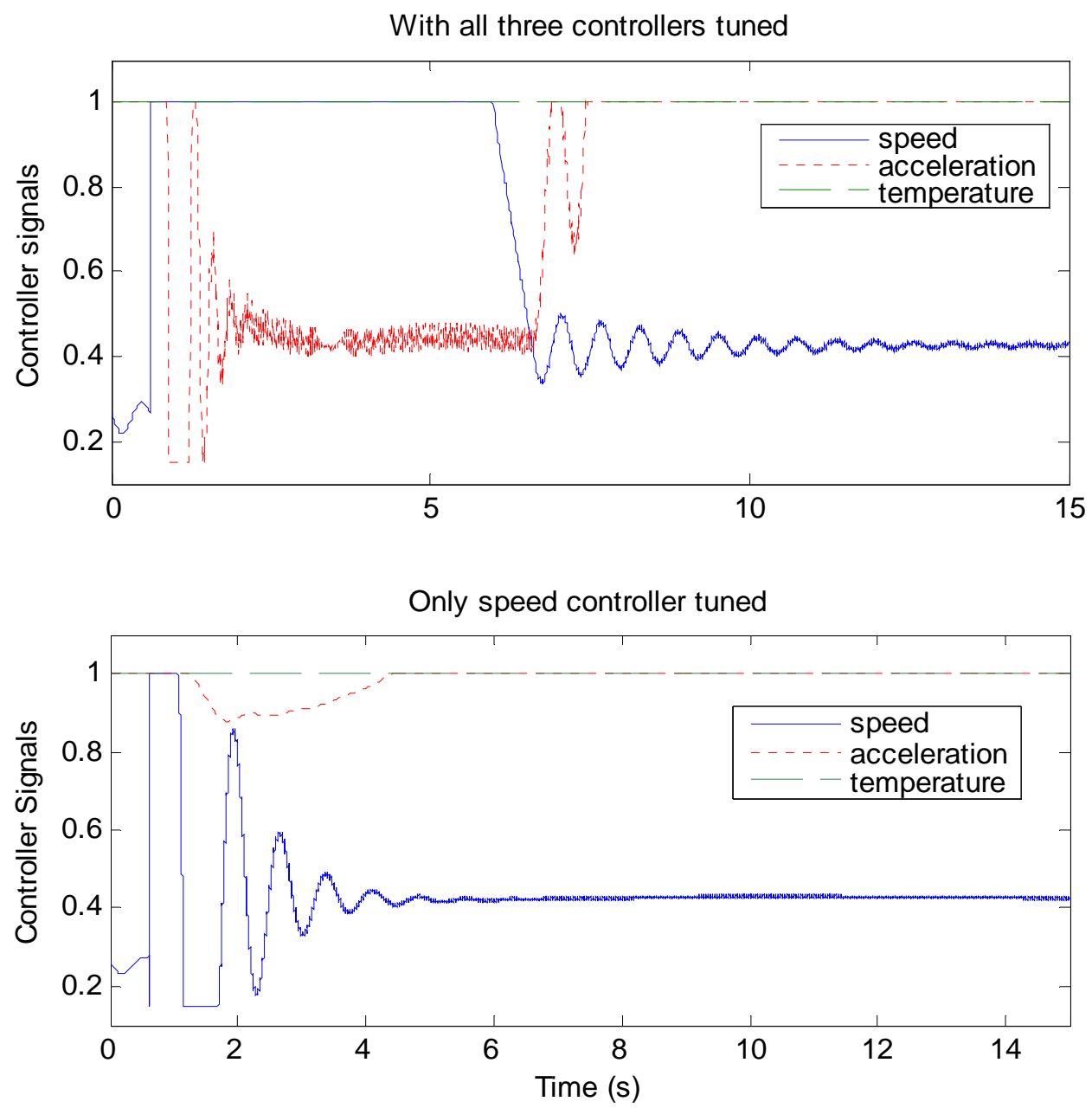

Figure 4.23: Comparison of gas turbine controller signals for power supply load 


\section{CHAPTER 4: ELECTRIC SHIPBOARD POWER SYSTEM}
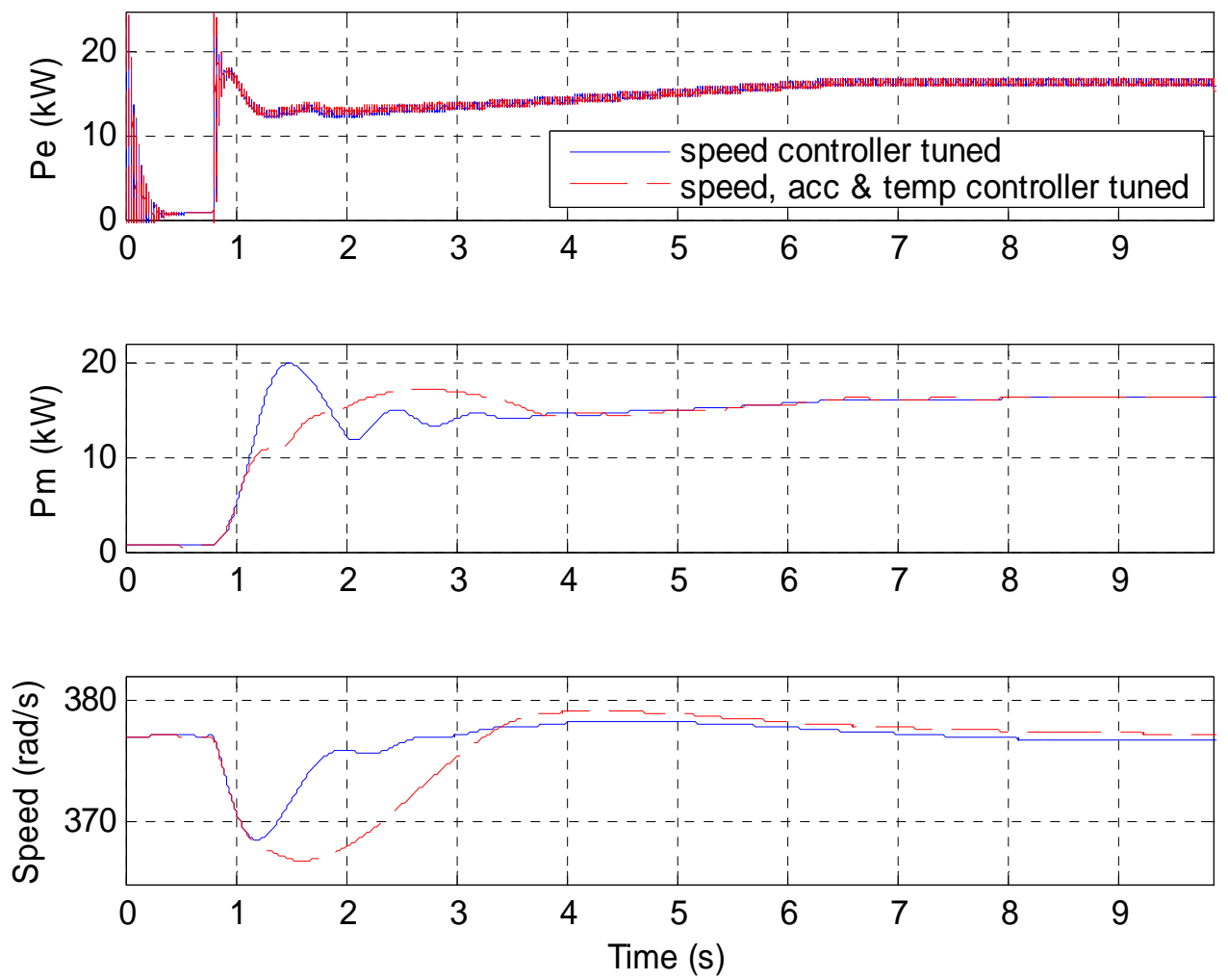

Figure 4.24: Comparison of response for $15.5 \mathrm{~kW}$ pulsed load 
CHAPTER 4: ELECTRIC SHIPBOARD POWER SYSTEM
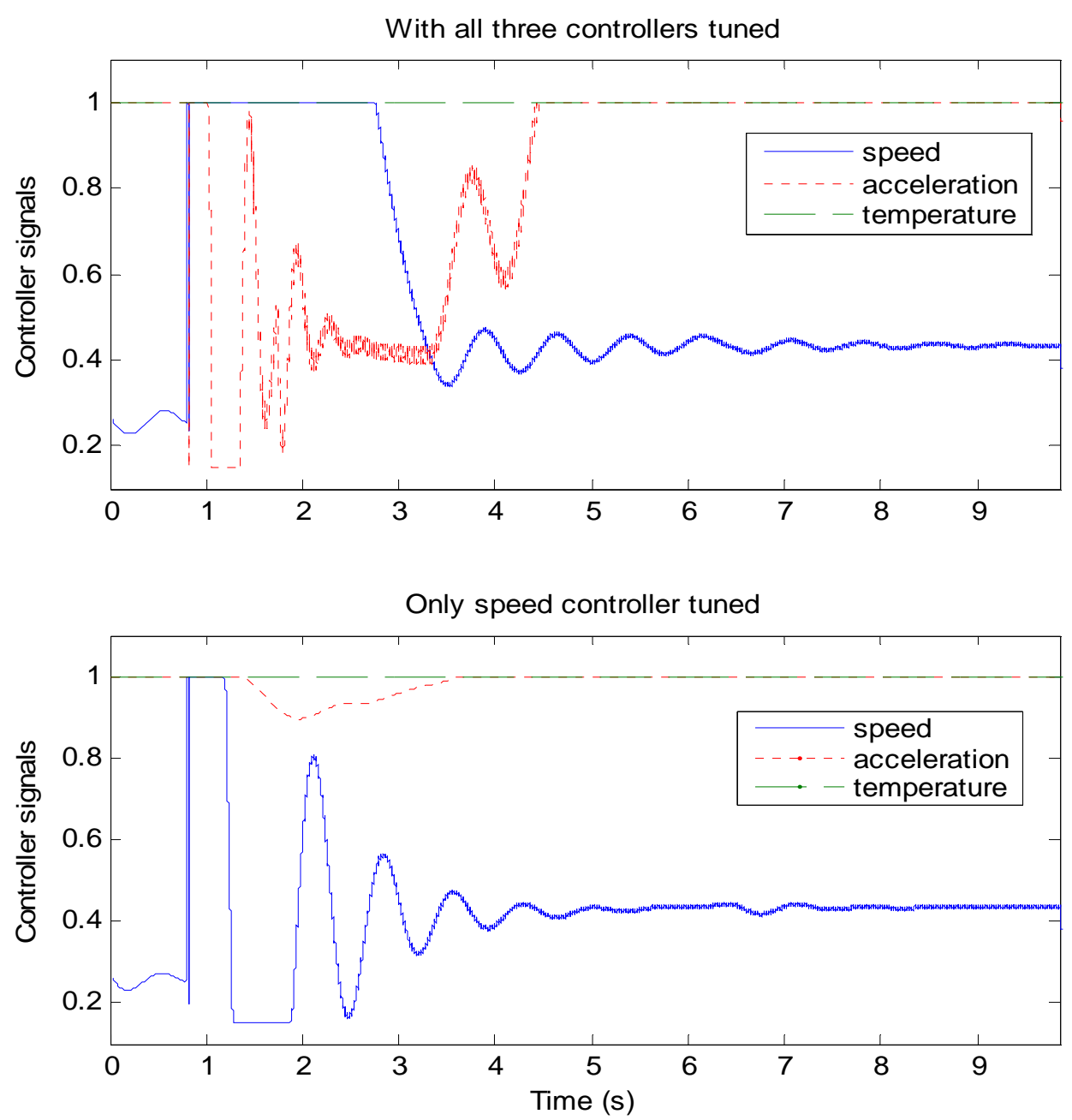

Figure 4.25: Comparison of gas turbine controller signals for power supply load

In all the three cases, the gas turbine is operating within the limits and speed control is the active control loop. The acceleration control loop takes control during load rejection or load pickup. From the comparison of the controller signals in each case, it can be seen that during the first $0.6 \mathrm{~s}$, the speed control commands the response of the gas turbine. On application of the load at $0.6 \mathrm{~s}$, for the case with all three controller gains tuned, the turbine accelerates and the acceleration loop takes control of the response until the speed control loop gets activated again to bring the speed back to its rated value. The acceleration control loop does not get activated in the case where only the speed controller is tuned. The temperature control does not get activated in both cases as exhaust temperature limits are not reached. For the propulsion system load, the response of the gas turbine are generator are seen to be better with the three controllers tuned when 
compared to the response obtained with only the speed controller tuned. For larger load changes as in the case of the power supply load and pulsed load, the fixed tuned controller gains do not produce the best results and so it may be necessary vary the controller gains according to each loading scenario. The effect of varying the controller gains based on loading scenarios has been discussed in the following section.

\subsection{Effect of Loading on Controller Parameters}

In the above section, fixed PID controller parameters obtained using PSO have been used for different loading scenarios. In this section, the PID controller parameters are tuned using PSO for each loading scenario and the results compared with those obtained in Section 4.5. In order to observe the effect of loading on the tuned controller parameters, the gains of the PID controllers have been redesigned using PSO for two different loading scenarios. The power supply load has been considered here to compare the response obtained with fixed controller gains and controller gains tuned for the two loading scenarios.

In the first case the controller parameters are tuned for a $10 \%$ load pickup. The power supply load is stepped up at $0.6 \mathrm{~s}$ from 0 to $6 \mathrm{~kW}$. Figure 4.26 shows the response obtained using the controller gains tuned for a $10 \%$ load change compared with the fixed controller gains used in Section 4.5. The plots in Figure 4.27 show the comparison of the gas turbine controller signals for this case. 
CHAPTER 4: ELECTRIC SHIPBOARD POWER SYSTEM
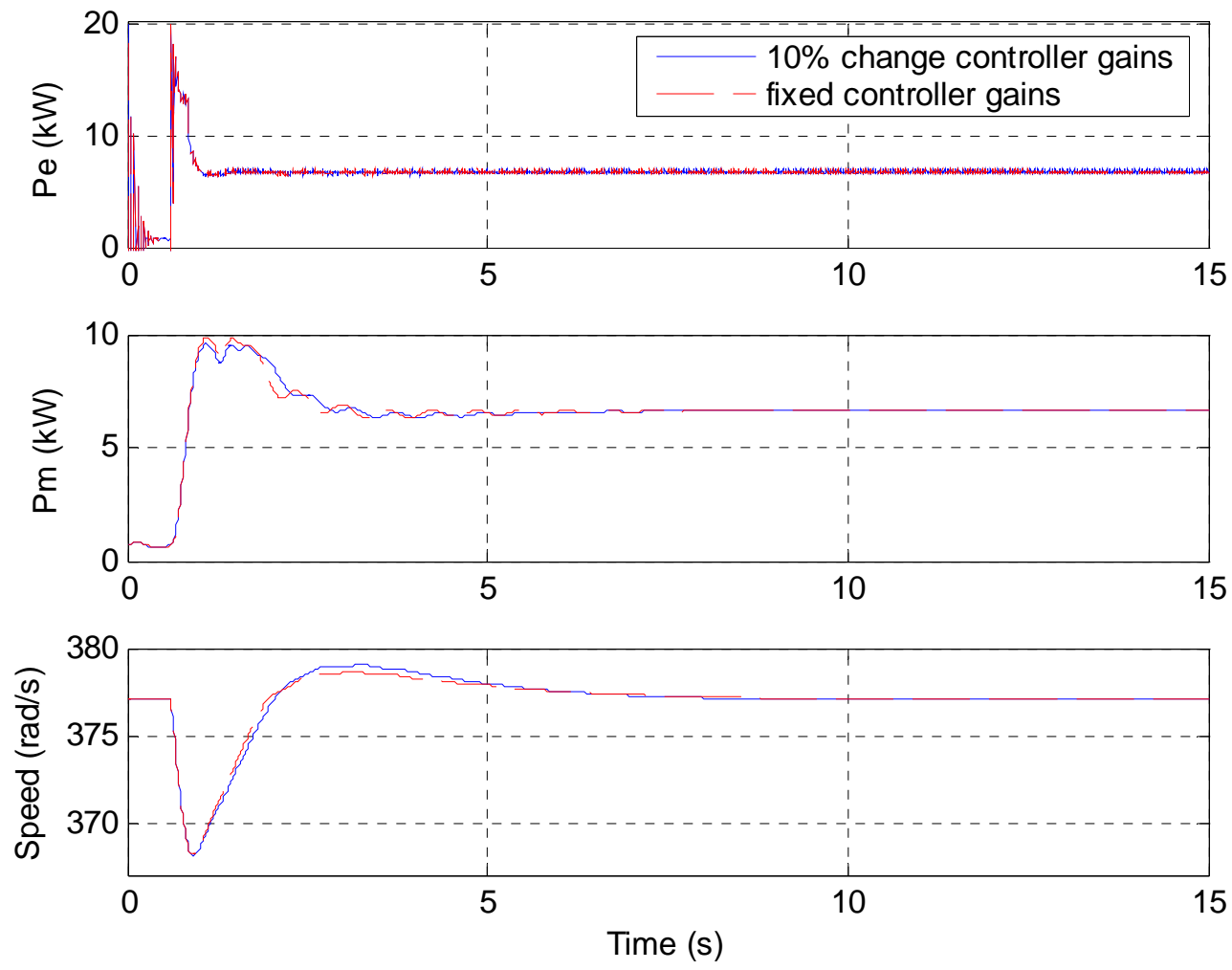

Figure 4.26: Plots for 10\% load change

From Figure 4.26 it is seen that the response obtained in both cases is almost the same. The comparison of the controller signals in Figure 4.27, it is seen that the acceleration loop gets activated once the load is applied in both cases until the speed control loop takes over at approximately the same time in both cases. Thus for small changes in load, varying of controller gains with loading is not seen necessary. 
CHAPTER 4: ELECTRIC SHIPBOARD POWER SYSTEM
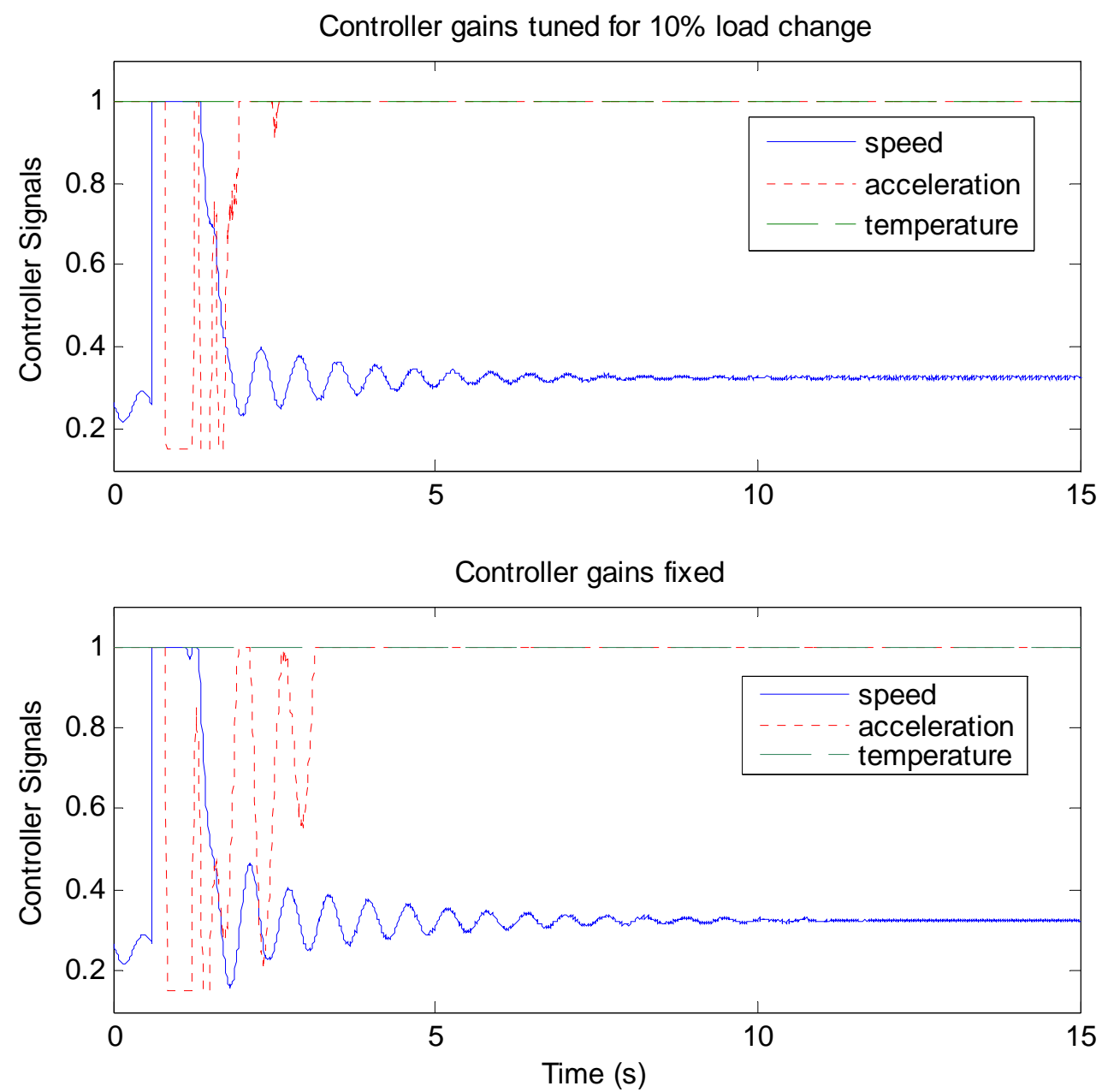

Figure 4.27: Comparison of gas turbine controller signals for $10 \%$ load change

In the next case, the controller parameters are tuned for a $25 \%$ load pickup. The power supply load is stepped up at $0.6 \mathrm{~s}$ from 0 to $15 \mathrm{~kW}$. Figure 4.28 shows the response obtained using the controller gains tuned for a $25 \%$ load change compared with the fixed controller gains used in Section 4.5. The plots in Figure 4.29 show the comparison of the gas turbine controller signals for this case. 

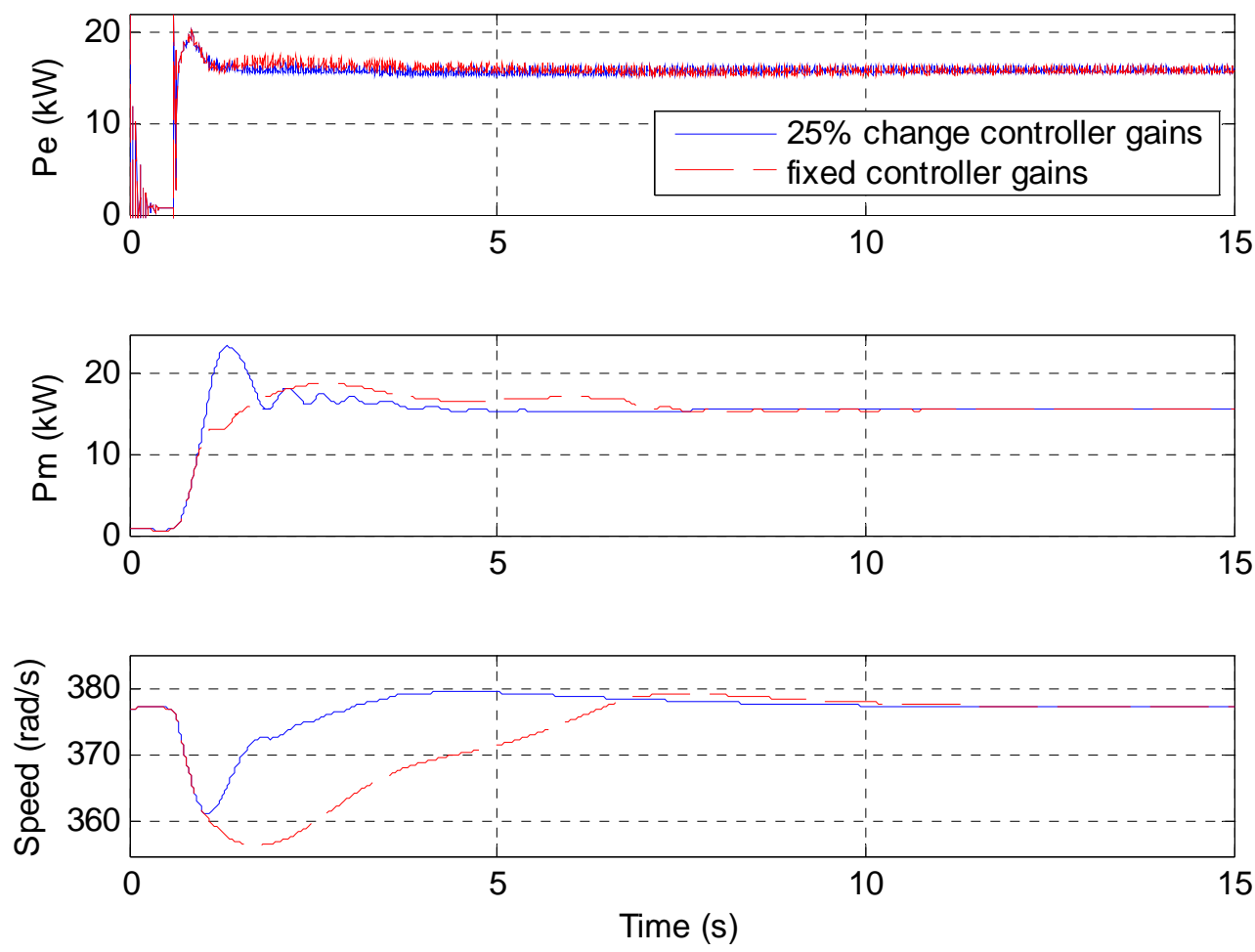

Figure 4.28: Plots for 25\% load change

It can be observed from the plots in Figure 4.28 that the response obtained in the case where the controller gains are tuned for a $25 \%$ load change is much better than that obtained using the fixed controller gains. From the comparison of the controller signals in Figure 4.29, it is seen that the acceleration loop gets activated once the load is applied in both cases. The speed control loop takes over from the acceleration control loop much earlier in the case where the controller gains are tuned for the $25 \%$ load change when compared with the case where the controller gains are fixed. Hence it is seen that for larger changes in load, using fixed controller gains may not be suitable and the use of controller gains varying according to changes in loading conditions is seen fit. This can be achieved in the form of a look up table containing the controller parameter gains tuned for different loading conditions. During simulation, these controller gains can be accessed for each specific loading condition. 
CHAPTER 4: ELECTRIC SHIPBOARD POWER SYSTEM
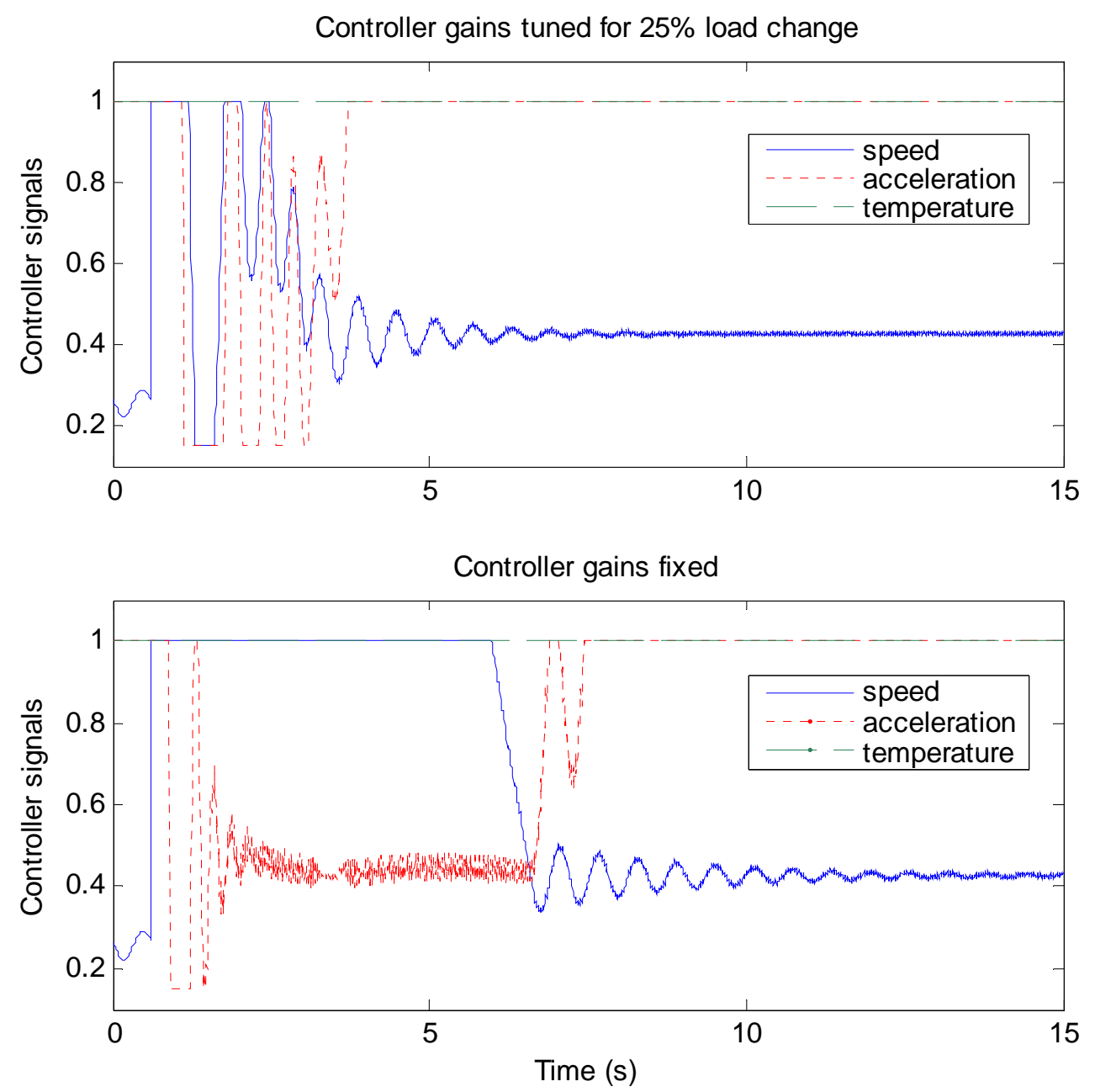

Figure 4.29: Comparison of gas turbine controller signals for $25 \%$ load change

\subsection{Conclusion}

This chapter has shown the successful incorporation of the selected gas turbine model as a prime mover for the ESPS. A pulsed load has been modeled and implemented for the ESPS based on a capacitor charging circuit. The results of the pulsed load supplied by a constant voltage source have been compared to the pulsed load supplied by the ESPS AC bus. These are seen to be consistent with each other. The gas turbine with the optimized PID controller is implemented to supply each of the three ESPS loads. The gas turbine controller signals have also been documented, showing that speed control is the active controller signal during normal operation in each case. From the results it is evident that the gas turbine follows each load and provides the generator with power required for each 


\section{CHAPTER 4: ELECTRIC SHIPBOARD POWER SYSTEM}

load. Also, the effect of fixed and varying controller gains on small and large loading conditions has been documented. 


\section{CHAPTER 5: ENERGY MANAGEMENT FOR ESPS}

\subsection{Need for Energy Management}

Reliable power generation alone is not sufficient for the smooth operation of an electric shipboard power system (ESPS). The generated power must also be distributed among the various loads, ensuring that the generator is not overloaded at any time. A shipboard power system is an autonomous system, with its own power generating facility on board. As it has fixed or limited generating units, load shedding is inevitable when the demand would exceed the generation capacity.

In the ESPS, most of the power generated is consumed by the propulsion load. The other two loads supplied by the generator are the power supply which feeds the dc zones of the ship and the pulsed load to supply high energy weapon systems. When connected together, the detailed model of the ESPS exhibits switching transients and excessive harmonics which make it unsuitable for this study. To facilitate the design and implementation of energy management, loads modeled by resistive and inductive components have been considered: $37 \mathrm{~kW}$ load for the propulsion system, $15 \mathrm{~kW}$ load for the power supply and a $15.5 \mathrm{~kW}$ load for the pulsed load system. This setup is suitable for the energy management studies conducted here as it eliminates high-frequency switching events and decreases the required simulation time. Figure 5.1 shows a case where the power demand exceeds the power generation. 


\section{CHAPTER 5: ENERGY MANAGEMENT FOR ESPS}
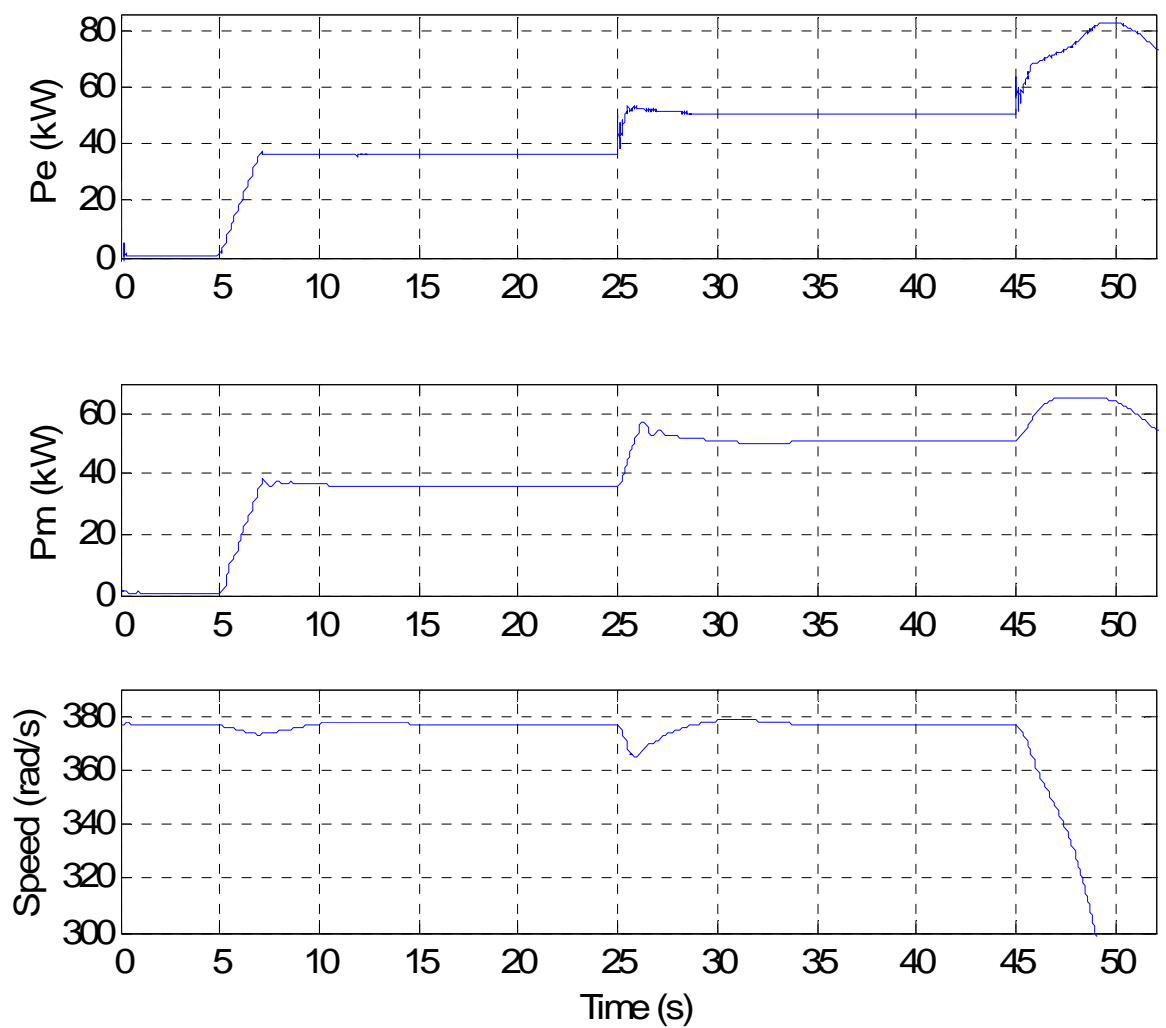

Figure 5.1: Dynamic responses of generator and gas turbine when demand exceeds generation capacity

In this scenario, the propulsion load is ramped up from 0 to $37 \mathrm{~kW}$ between 5 and $7 \mathrm{~s}$, the power supply is switched on at $25 \mathrm{~s}$ and the pulsed load is applied at $45 \mathrm{~s}$. It can be seen that on application of the pulsed load, the generation capacity $(59 \mathrm{~kW})$ of the gas turbine and generator is exceeded, and the speed controller signal reaches its limit. The system loses the capability of operating at the nominal speed of $377 \mathrm{rad} / \mathrm{s}$ and the gas turbine speed starts to decrease. Also, temperature control begins to take action at $48 \mathrm{~s}$. The turbine output increases until it is limited by the temperature control loop. Figure 5.2 shows a plot of the corresponding gas turbine controller signals. After a few seconds, depending on the time constant associated with the thermocouples measuring the exhaust temperature, the temperature control loop takes control in order to maintain the exhaust temperature limit. 


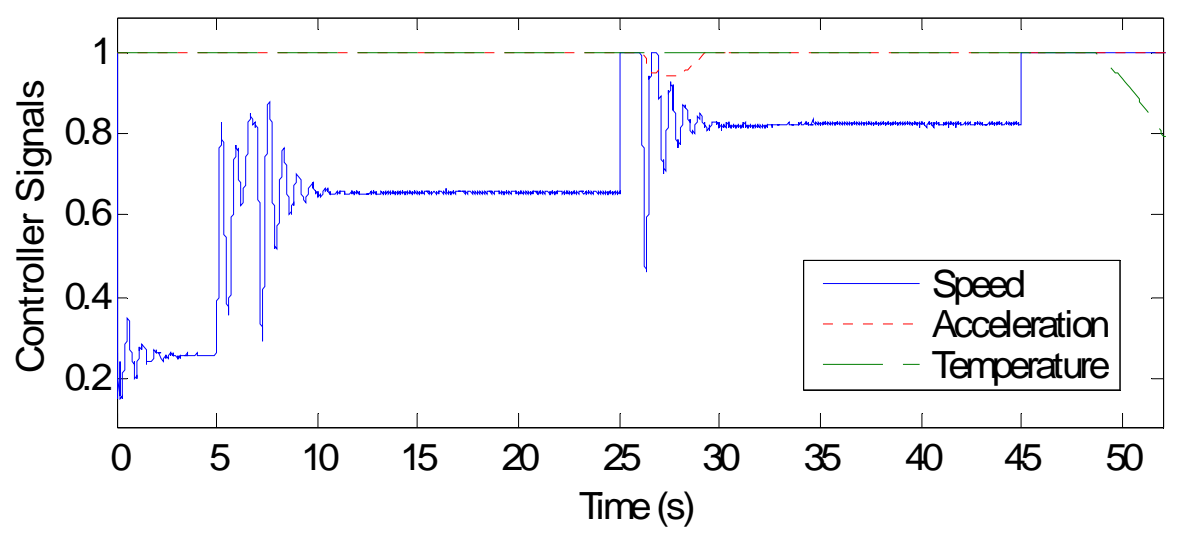

Figure 5.2: Gas turbine controller signals

To avoid the occurrence of such a situation, flexible sharing of power among the propulsion, power supply and pulsed loads are a critical requirement as generation capacity is limited. The focus of this chapter is on load shedding for the reliable operation of the ESPS. An energy management system architecture [7] based on a layered approach is explained in the next section. Section 5.3 explains the decomposition of the implementation layer of the multilayered architecture scheme. In Section 5.4, a load allocation scheme algorithm is developed for the decision implementation agent in the implementation layer. The algorithm is represented by means of a stateflow diagram. Each load of the ESPS is assigned a priority and two case studies are performed in Section 5.5 to show the potential of this algorithm.

\subsection{Energy Management System Architecture}

A multiagent architecture scheme based on a layered approach can be implemented to solve the energy management problem for the ESPS as demonstrated in [7]. The design in [7] is based on a graph theoretic approach and an agent based maximum flow algorithm for the energy management system has been developed. The agents' task is to ensure that the various load demands are supplied, taking into consideration the system constraints and load priorities. Depending on system conditions, each load is assigned a priority value. Each agent performs individually, observing its environment and taking corrective measures to achieve its goals, i.e., routing of power according to load 


\section{CHAPTER 5: ENERGY MANAGEMENT FOR ESPS}

priorities, requesting power for a load, etc. A blackboard system acts as an interaction protocol for the various layers.

A layered architecture is seen fit for two reasons. First, the functional separation makes it organized and easy to modify. Second, this separation also supports independence between layers allowing replacement, addition or removal of a layer without affecting the other layers. The blackboard system is a shared memory structure, facilitating interlayer communication. It is a convenient way for the various layers to post their solutions and status and fetch the required results.

The ESPS energy management system is based on grouping the different parts into a layered architecture. Based on their functionality, the layers form a logical architecture. Figure 5.3 shows the layered architecture scheme for the ESPS energy management system. 


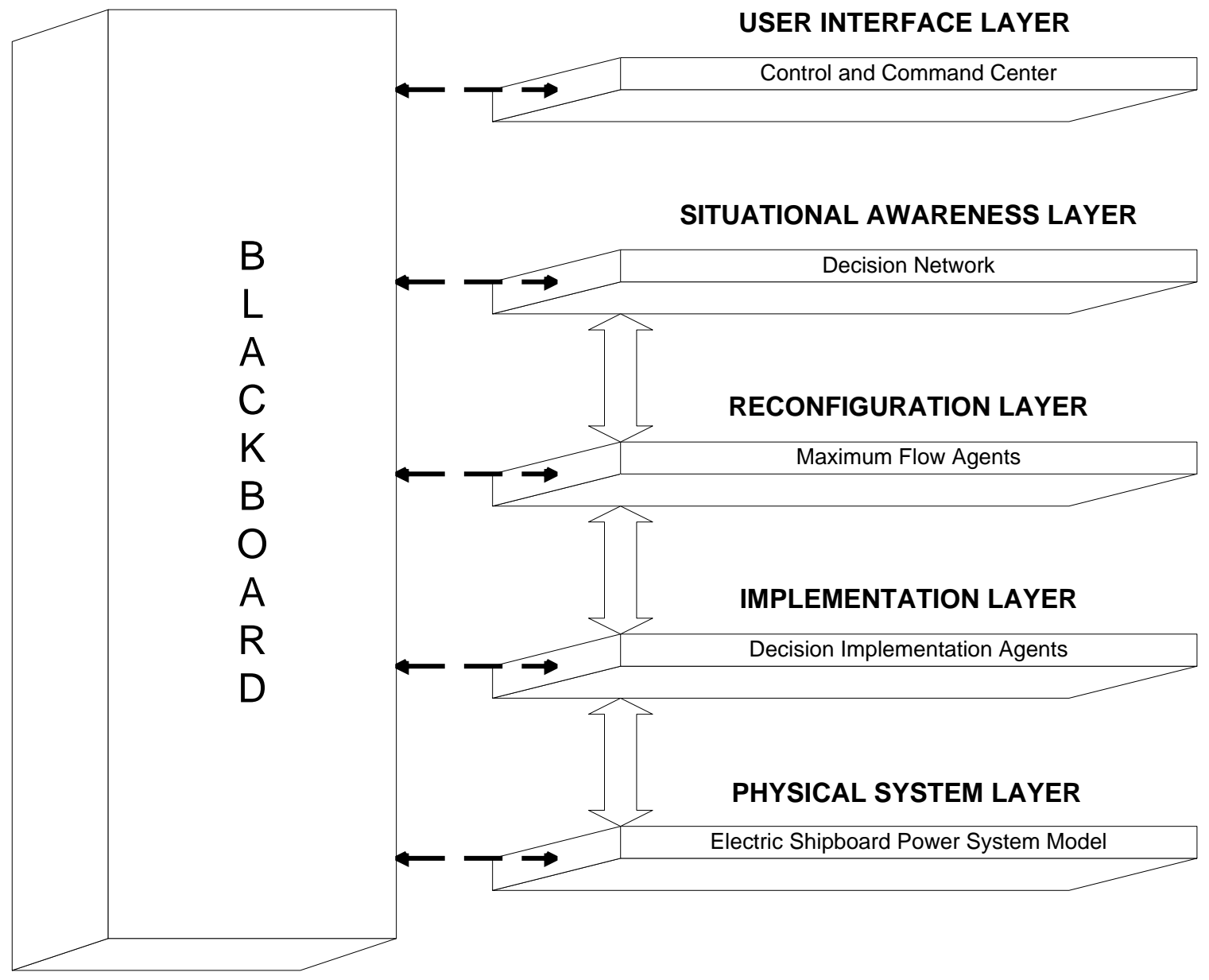

Figure 5.3: Layered architecture scheme for the ESPS energy management system

As [7] and this work are based on software simulations, a mathematical model of the ESPS represents the lowest physical system layer. Simulation of the various components of the ESPS and their interactions are performed in this layer.

The layer closest to the physical system layer is the implementation layer. The decision implementation agents are contained in this layer, which act as an interface between the individual devices. The agents in this layer continuously monitor the blackboard to implement the power flow solution agreed upon by the agents in the reconfiguration layer.

The reconfiguration layer is comprised of the decentralized power flow solution using the maximum flow algorithm [7]. This layer performs the negotiations for energy management. The agents execute their programs independently and communicate their 


\section{CHAPTER 5: ENERGY MANAGEMENT FOR ESPS}

status via the blackboard. Each agent follows a set of seven rules [7] based on the selfstabilizing maximum flow algorithm from graph theory.

The situational awareness layer is located above the reconfiguration and implementation layers. This layer updates the system operators on board with information regarding the operational status of the power system. The agents in this layer supervise the actions by the agents in the reconfiguration and implementation layer [7].

The human machine interface for the command and control center forms the topmost layer. It displays important system information, allowing the system operator to communicate with system components, e.g., request for increase/decrease in propulsion load, etc. This interface can also be used to simulate disturbances inflicted onto the power system such as loss of generation, etc.

\subsection{Expansion of Implementation Layer}

The implementation layer shown in Figure 5.3 is further decomposed into two layers Implementation Agent (IA) and PID controllers as shown in Figure 5.4. In [7], the physical system layer components have been represented by discrete transfer functions of first and second order to represent the input-output relationships concerning active power and voltage values. This work replaces the model in [7] by a detailed 3-phase model comprising of a gas turbine, generator and loads (propulsion, power supply and pulsed load) modeled by resistive and inductive components. 


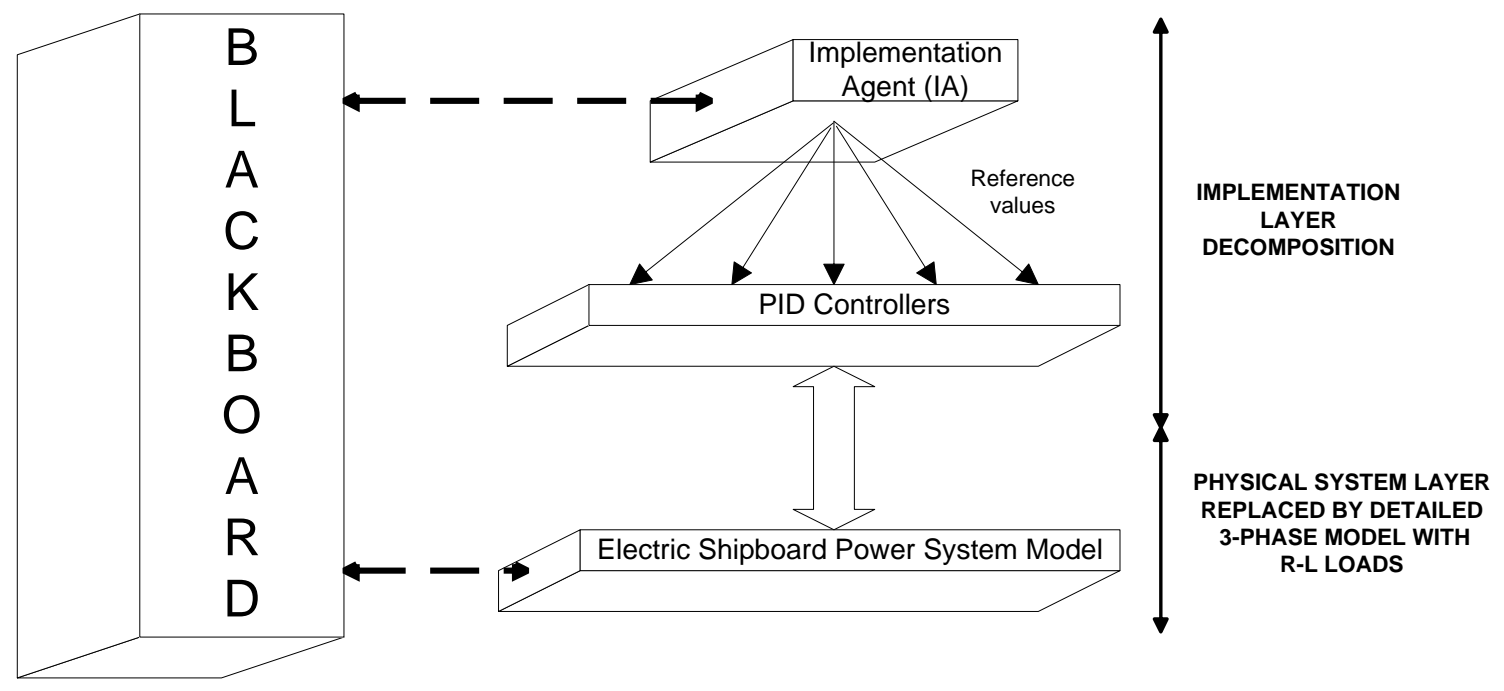

Figure 5.4: Decomposition of the Implementation Layer

The load allocation scheme algorithm presented in Section 5.4 is carried out by the implementation agent. This agent communicates via the blackboard with the agents in the reconfiguration layer developed in [7]. Based on this communication, the reconfiguration layer agents receive requests to reduce or turn off a lower priority load when sufficient power is unavailable, as per the algorithm. Based on the reconfiguration layer design, if the agents permit reduction or turn off of a load, this is then communicated to the implementation layer agent. This agent in turn modifies the PID controller reference values of the ESPS loads thereby increasing the remaining capacity and enabling the turn on of the higher priority load. If the reconfiguration layer does not permit the implementation layer agent to modify the corresponding load PID controller reference values, the operator at the command and control center is notified that the load cannot be turned on at this time. The load allocation scheme algorithm is explained in detail in the following section.

\subsection{Load Allocation Scheme}

This section introduces a load allocation scheme algorithm for the ESPS using stateflow diagrams [22]. The algorithm is developed for the implementation layer of the energy management architecture described in the previous section. A stateflow diagram is a graphical representation of an event driven system, where states and transitions form the 


\section{CHAPTER 5: ENERGY MANAGEMENT FOR ESPS}

basic building blocks of the system. Event driven systems transition from one operating mode to another in response to an event or condition, provided that the condition defining the change is true.

The following is an explanation of the stateflow terms used in this section.

State: A state describes the mode of an event driven system. The activity or inactivity of a state dynamically changes based on some events or conditions. It is represented by an oval shaped block in stateflow diagrams.

Transition: A transition links one state to another. One end of a transition is attached to a source state and the other end to a destination state. The source is where the transition begins and the destination is where the transition ends. A transition condition describes the circumstances under which the system moves from one state to another. It is always the occurrence of some event that causes a transition to take place. It is represented by an arrow from one state to another state.

Condition: A condition is a boolean expression that allows a transition to occur when the expression is true. Conditions appear as labels for the transition, enclosed in square brackets ([ ]).

Figure 5.5 shows the stateflow diagram for the load allocation scheme algorithm developed for the ESPS. 


\section{CHAPTER 5: ENERGY MANAGEMENT FOR ESPS}

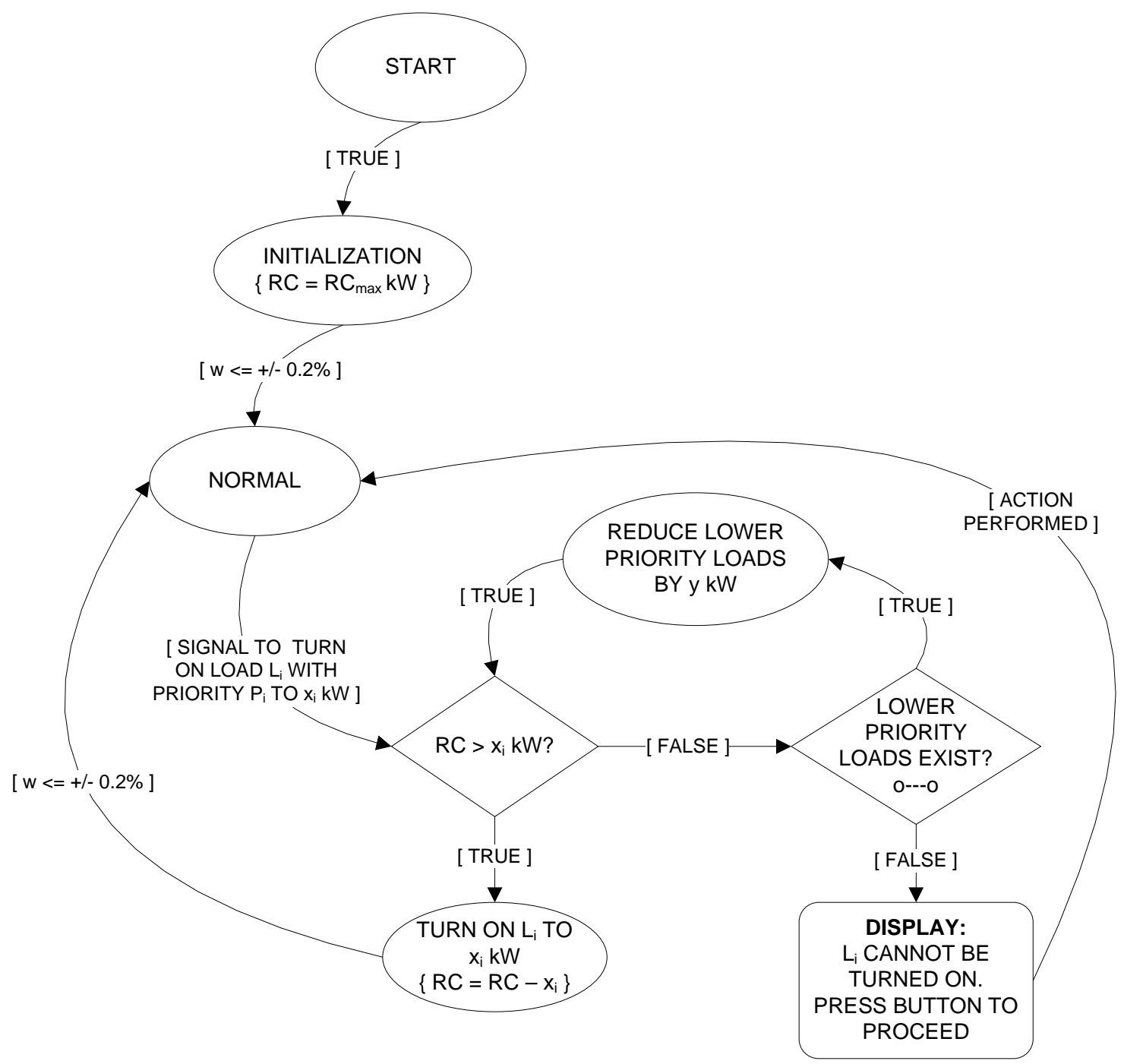

Figure 5.5: Stateflow diagram for ESPS load allocation scheme

For simplicity, let us assume that the system is initially at rest with all loads in the OFF state. The generation capacity of the gas turbine and generator is denoted by ' $\mathrm{RC}$ ' (Remaining Capacity). Initially, $\mathrm{RC}$ is set to $R C_{\max }$, which is the maximum power rating of the generator and gas turbine units.

1. On starting, the system goes through an initialization state and then enters the normal state. The initialization state comprises of the gas turbine and generator reaching no load steady state conditions after being turned $\mathrm{ON}$, i.e., generator losses are supplied and the gas turbine steady state speed error is less than or equal to $+/-0.2 \%$. 


\section{CHAPTER 5: ENERGY MANAGEMENT FOR ESPS}

2. Once in the normal state, it is triggered by a condition to turn ON load $L_{i}$ with priority $P_{i}$ to some $x_{i} \mathrm{~kW}(\mathrm{i}=1,2 \ldots \mathrm{n}$, where ' $\mathrm{n}$ ' is the total number of loads present). The remaining capacity has to be checked to ascertain that power is available to supply the $x_{i} \mathrm{~kW}$ demand.

3. If the remaining capacity is greater than $x_{i} \mathrm{~kW}$, then the condition is TRUE and the load is turned $\mathrm{ON}$. The remaining capacity is reduced by $x_{i} \mathrm{~kW}$ and on satisfying the steady state speed error condition the system returns back to the normal state (Step 2). The process in Step 2 is repeated until the remaining capacity is less than the power demanded by a successive load $\mathrm{L}_{i}$.

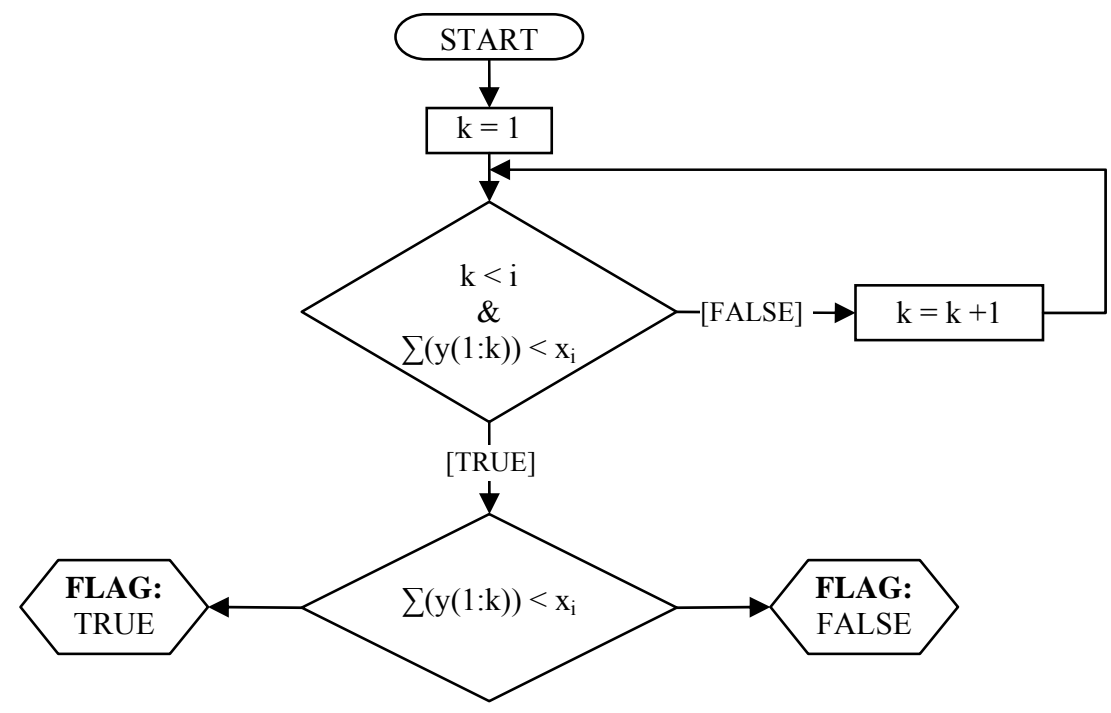

Figure 5.6: Hidden sub-state denoted by o- -0 in Figure 5.5

4. When remaining capacity is less than the power demanded by load $L_{i}$, then the condition is FALSE. A check is performed to see if lower priority loads have been turned ON previously which can be reduced or turned OFF so that the remaining capacity can be increased, thus allowing load $L_{i}$ to be turned ON. o-o denotes a hidden sub-state which is shown in Figure 5.6.

5. The hidden sub-state comprises of comparing the priority of the current load with the priorities of the loads turned on previously. An index $k$ is set to 1 and $\sum y(1: k)$ 


\section{CHAPTER 5: ENERGY MANAGEMENT FOR ESPS}

is the total $\mathrm{kW}$ of the lower priority loads that can be reduced or turned OFF. If the condition $k<i \& \& \sum(y(1: k))<x_{i}$ is FALSE, then the counter is incremented and the condition is checked again. When the condition is TRUE, the sum of the capacities of the lower priority loads is compared with $x_{i} \mathrm{~kW}$ which is the power demanded by load $L_{i}$, i.e., if $\sum(y(1: k))<x_{i}$, then the flag is FALSE, else the flag is TRUE.

6. If the flag returned by the hidden sub-state is FALSE, then the load $L_{i}$ cannot be turned on as it is the lowest priority load. The command and control center is notified by a display message and operator intervention is necessary to send the system back to the normal state for the next load to be triggered. On receiving operator attention, the process from Step 2 is then repeated.

7. If the flag returned by the hidden sub-state is TRUE, then the lower priority loads are reduced by $y \mathrm{~kW}$, thus increasing the remaining capacity by $y \mathrm{~kW}$. The process from Step 3 is then repeated.

To demonstrate the working of this load allocation scheme, two case studies are presented in the following section.

\subsection{Case Studies for Load Allocation Scheme}

Two case studies have been considered in this section to demonstrate the working of the algorithm developed in the previous section. Three loads have been considered - a propulsion load (pr) of $37 \mathrm{~kW}$, a power supply load (ps) of $15 \mathrm{~kW}$ and a pulsed load (pl) of $15.5 \mathrm{~kW}$, with priorities assigned to each load. The agent in the implementation layer executes the load allocation scheme algorithm while the reconfiguration layer agents perform the negotiations for effective energy management based on the load priorities. Information is exchanged among the layers via the blackboard system. 


\section{Case Study (a)}

In this case, the propulsion load is assigned the highest priority followed by the pulsed load and the power supply load is assigned the lowest priority. The load priority assignment for this case is shown in Table 5.1.

Table 5.1: Load priorities for case (a)

\begin{tabular}{|l|l|}
\hline Load & Priority \\
\hline pr & 1 \\
\hline pl & 2 \\
\hline ps & 3 \\
\hline
\end{tabular}

Figure 5.7 shows the individual demand of each load and the total load profile, along with the reconfiguration layer scheme for this case. Based on the algorithm, the propulsion load of priority 1 is ramped up to $37 \mathrm{~kW}$ from 5 to $7 \mathrm{~s}$. Once the system is back to the normal state, a signal to turn $\mathrm{ON}$ the $15 \mathrm{~kW}$ power supply load of priority 3 is received. As sufficient capacity is remaining, the load is turned ON. Again, when the system returns to the normal state, it receives a signal to turn ON the $15.5 \mathrm{~kW}$ pulsed load of priority 2. As sufficient power is not available to turn ON this load, a lower priority load, if turned on previously, needs to be turned OFF or reduced. So a check is performed to determine if a lower priority load has been turned ON (in this case the power supply load). The power supply load is then reduced by $10 \mathrm{~kW}$ so that the remaining capacity is now greater than the pulsed load demand. The enables the pulsed load to be applied on reduction of the power supply load without exceeding the generation capacity. 


\section{CHAPTER 5: ENERGY MANAGEMENT FOR ESPS}
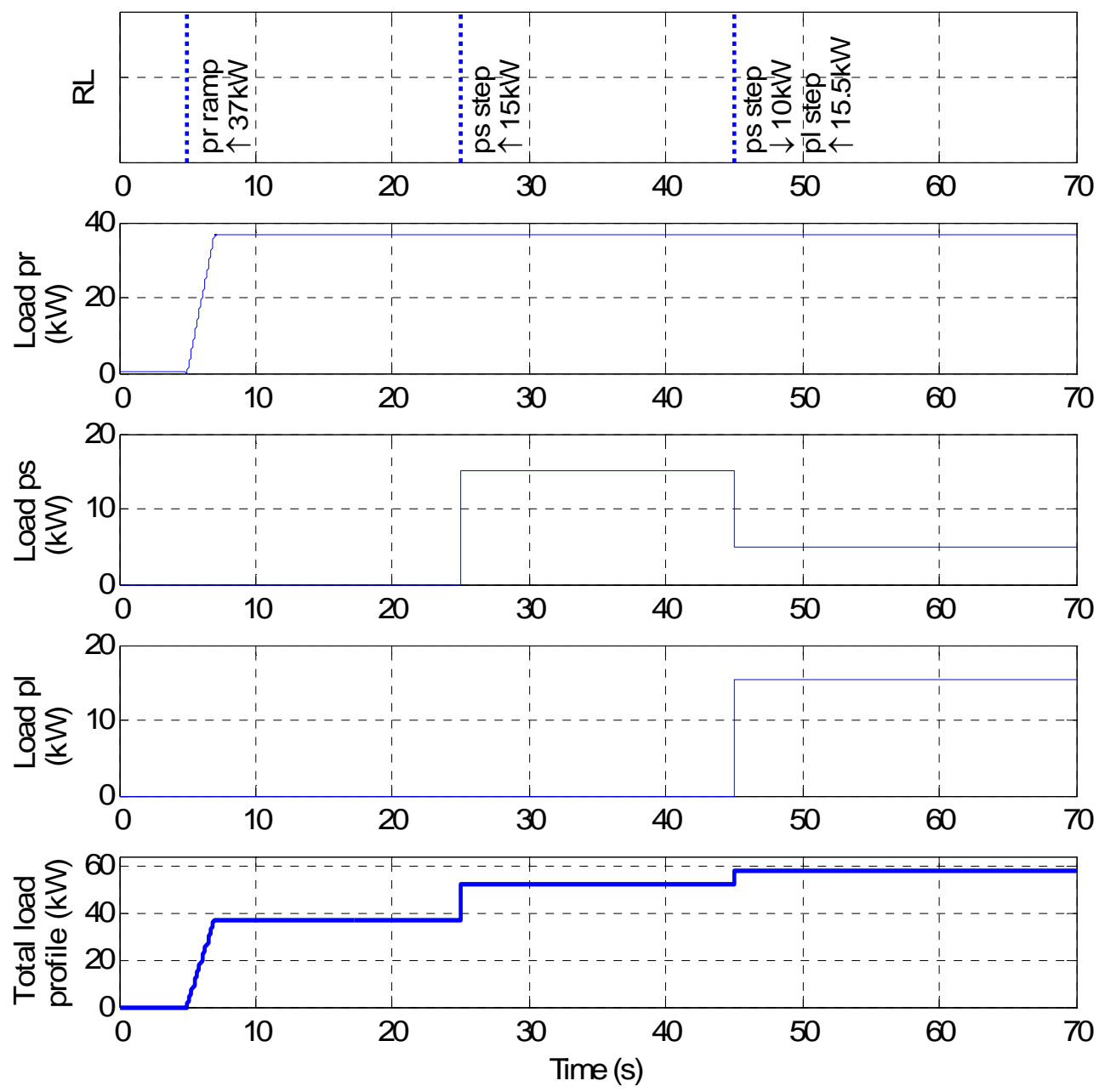

Figure 5.7: Reconfiguration Layer (RL), Individual and total load profiles for case (a)

This load shedding can also be seen in Figure 5.8, which represents the generator voltage and current along with the load currents. The generation voltage is represented by $\mathrm{V}_{\text {gen }}$ and the generation current by $\mathrm{I}_{\mathrm{gen}}$. The propulsion load current is represented by $\mathrm{I}_{\mathrm{pr}}$, the power supply load current by $\mathrm{I}_{\mathrm{ps}}$ and the pulsed load current by $\mathrm{I}_{\mathrm{pl}}$. 

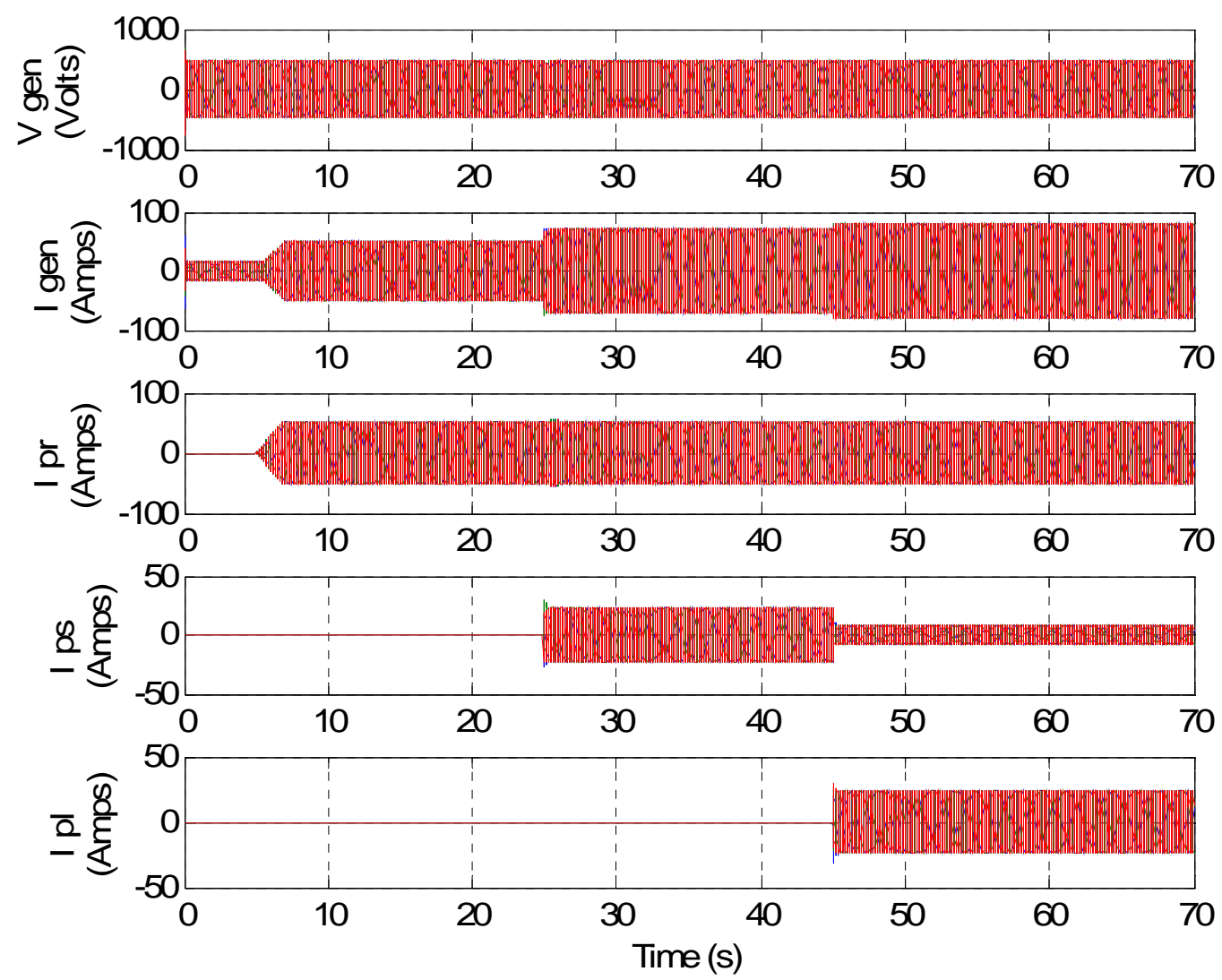

Figure 5.8: Generation voltage and current and load currents for case (a) 


\section{CHAPTER 5: ENERGY MANAGEMENT FOR ESPS}
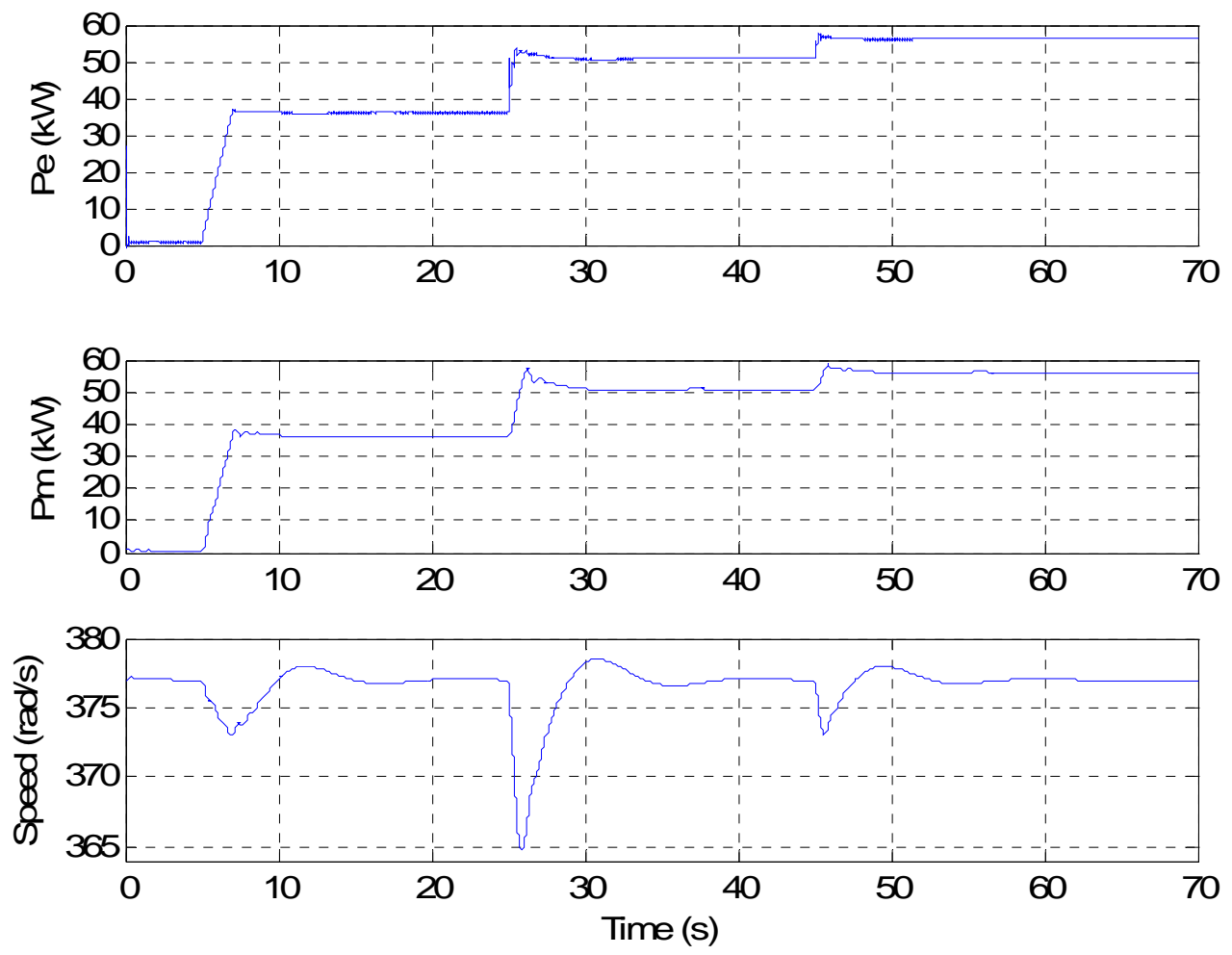

Figure 5.9: Dynamic responses of generator and gas turbine for case (a)

The generator electrical power $(\mathrm{Pe})$, gas turbine mechanical power $(\mathrm{Pm})$ and gas turbine speed are plotted in Figure 5.9.

Figure 5.10 shows the gas turbine controller signals. It can be seen that the generation capacity is not exceeded and hence there is no overloading. The speed control signal remains the minimum signal. 


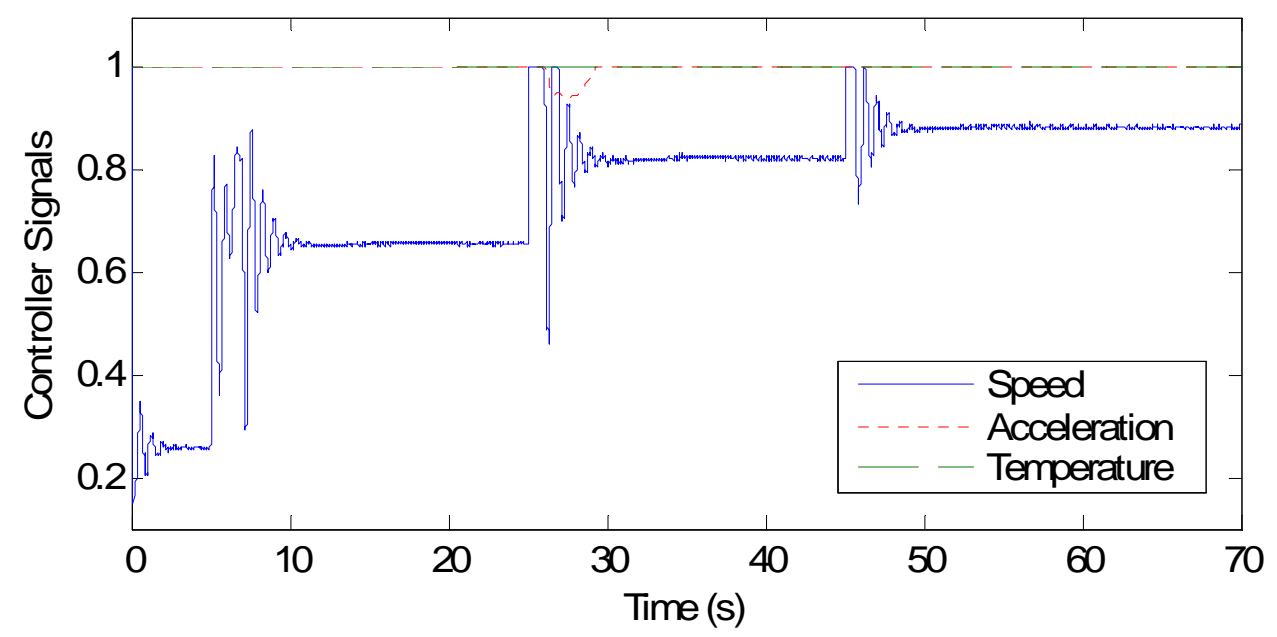

Figure 5.10: Gas turbine controller signals for case (a)

\section{Case Study (b)}

In this case, the power supply load is assigned the highest priority followed by the pulsed load and the propulsion load is assigned the lowest priority. The load priority assignment for this case is shown in Table 5.2.

Table 5.2: Load priorities for case (b)

\begin{tabular}{|l|l|}
\hline Load & Priority \\
\hline $\mathrm{ps}$ & 1 \\
\hline $\mathrm{pl}$ & 2 \\
\hline $\mathrm{pr}$ & 3 \\
\hline
\end{tabular}

Figure 5.11 shows the individual demand of each load and the total load profile, along with the reconfiguration layer scheme for this case. Based on the algorithm, the propulsion load of priority 3 is ramped up to $37 \mathrm{~kW}$ from 5 to $7 \mathrm{~s}$. Once the system is back to the normal state, a signal to turn ON the $15 \mathrm{~kW}$ power supply load of priority 1 is received. As sufficient capacity is remaining, the load is turned ON. Again, when the system returns to the normal state, it receives a signal to turn ON the $15.5 \mathrm{~kW}$ pulsed load which has a priority of 2 . As the remaining capacity is not sufficient to turn ON this load, a lower priority load, if turned ON previously, needs to be turned OFF or reduced. So a check is performed to determine if a lower priority load has been turned ON (in this case the propulsion load). This load is then reduced by $10 \mathrm{~kW}$ so that the remaining capacity is 


\section{CHAPTER 5: ENERGY MANAGEMENT FOR ESPS}

now greater than the pulsed load demand. This enables the pulsed load to be applied on reduction of the propulsion load.
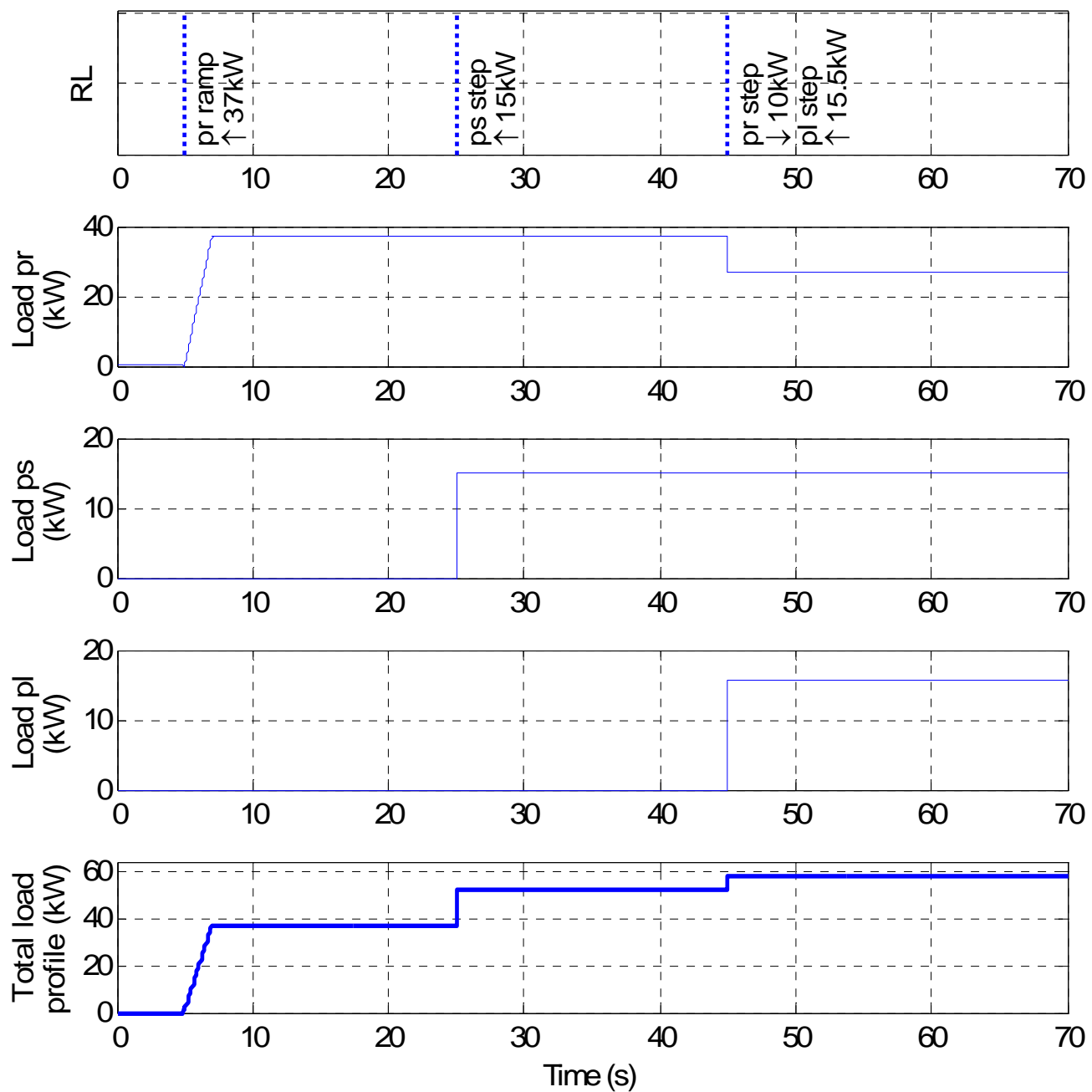

Figure 5.11: Reconfiguration Layer (RL), Individual and total load profiles for case (b)

This load shedding can also be seen in Figure 5.12, which represents the generator voltage and current along with the load currents. The generation voltage is represented by $V_{\text {gen }}$ and the generation current by $I_{\text {gen }}$. The propulsion load current is represented by $I_{p r}$, the power supply current by $I_{p s}$ and the pulsed load current by $I_{p l}$. 

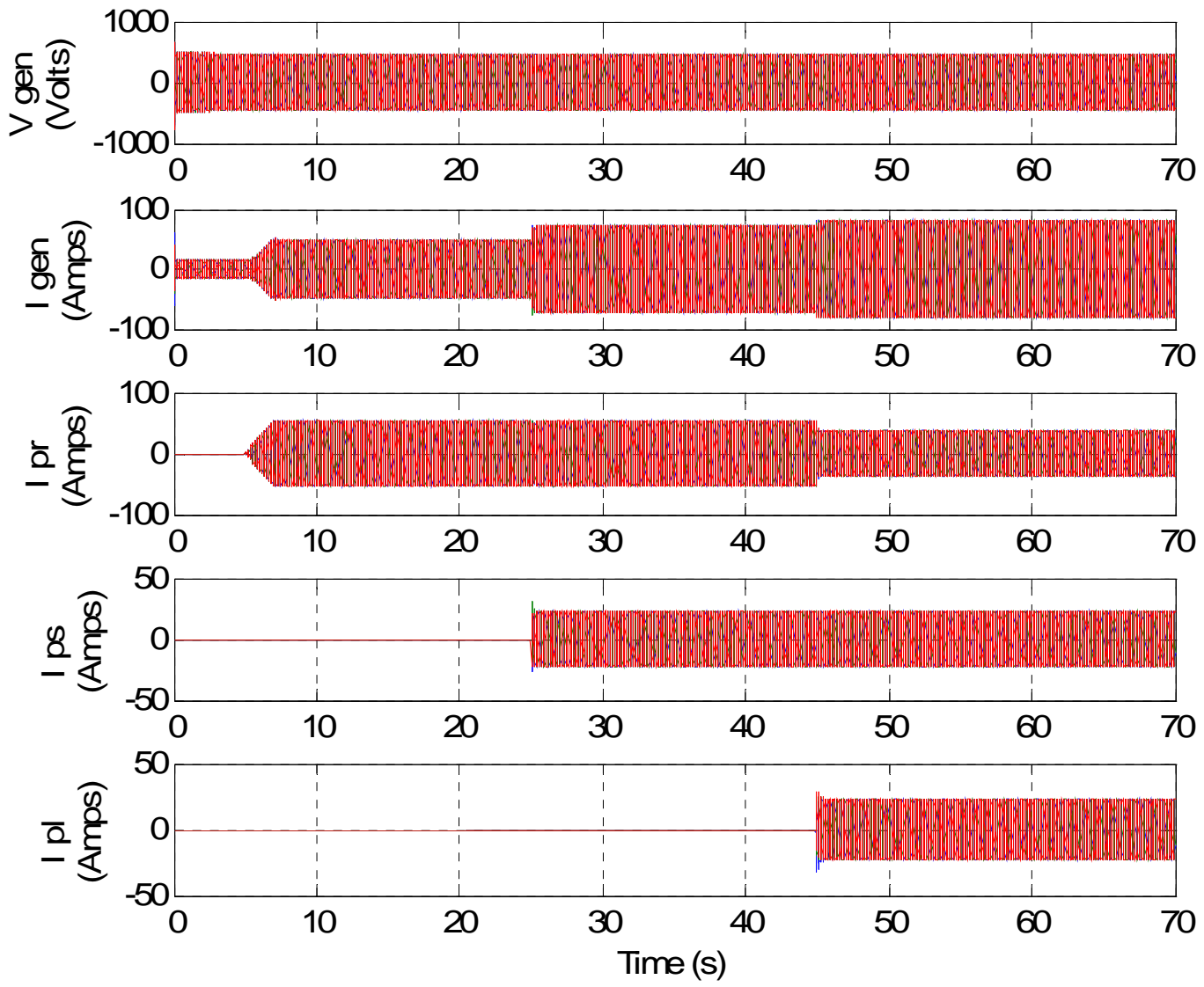

Figure 5.12: Generation voltage and current and load currents for case (b)

The generator electrical power $\left(\mathrm{P}_{\mathrm{e}}\right)$, gas turbine mechanical power $\left(\mathrm{P}_{\mathrm{m}}\right)$ and gas turbine speed are plotted in Figure 5.13. 

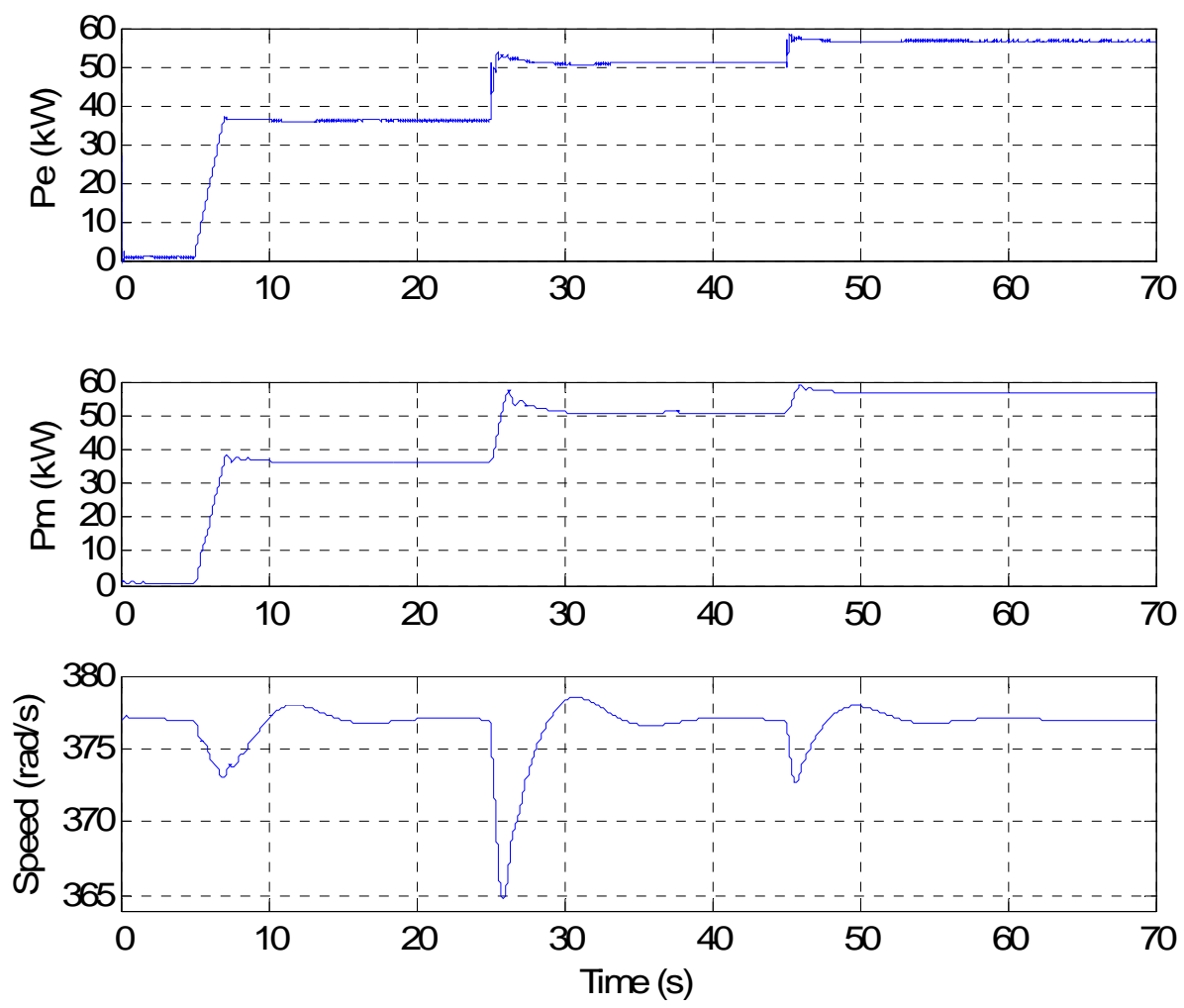

Figure 5.13: Dynamic responses of generator and gas turbine for case (b)

Figure 5.14 shows the gas turbine controller signals. With the reduction in the propulsion system load, it can be seen that the generation capacity is not exceeded and the speed control signal always remains the minimum signal.

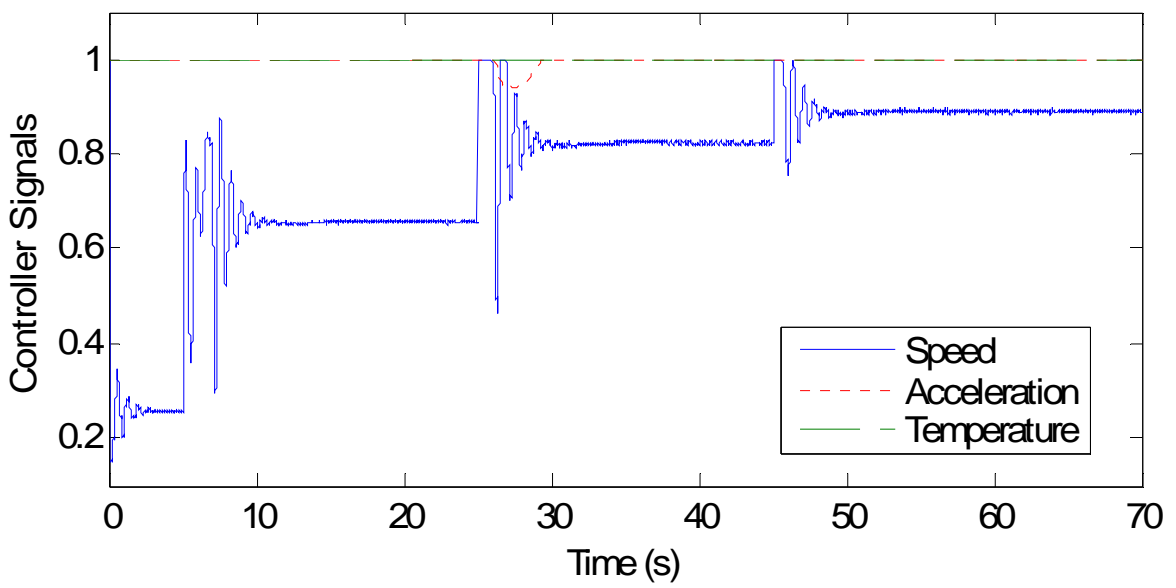

Figure 5.14: Gas turbine controller signals for case (b) 


\section{CHAPTER 5: ENERGY MANAGEMENT FOR ESPS}

\subsection{Conclusion}

To summarize, this chapter demonstrated the need for energy management for the ESPS. The research work in [7] implements a multiagent architecture scheme based on a layered approach to solve the energy management problem for the ESPS. Building upon this work, a generic load allocation scheme algorithm has been developed for the ESPS using stateflow diagrams. The potential of this algorithm has been demonstrated by two case studies considering three loads with different priorities assigned to them. Depending on the priority of a load, it can be reduced or turned OFF in order to avoid exceeding generation. The gas turbine and its controllers follow the load changes appropriately, proving that the tuned controller parameters are robust. From the case study results, effective energy management based on this algorithm has been demonstrated. This algorithm can be extended to consider all the loads of the ESPS. 


\section{CHAPTER 6: CONCLUSION}

\subsection{Summary}

In this research work, the speed controller for the gas turbine of the ESPS has been successfully designed and a load sharing strategy for its energy management has been developed. The Matlab/Simulink platform is used in this study as a simulation environment. The gas turbine model selected is a simple cycle, single shaft model based on the survey conducted in Chapter 2. The Particle Swarm Optimization (PSO) technique has been successfully implemented in tuning the speed controller PID parameters of this gas turbine. The performance index used in this optimization was based on a comparison of the four most common performance indices used in optimization problems. A pulsed power load has been modeled and successfully implemented for the ESPS, in addition to the other two loads already present. The pulsed load supplies high energy weapon systems on naval ships. It is modeled as a capacitor charging circuit, which is charged from the AC system bus of the ESPS.

Three cases of load pickup have been considered to show the speed response of the gas turbine incorporated as a prime mover. The following loading cases have been simulated:

1. The propulsion system loaded to $7 \mathrm{~kW}$

2. The power supply (loads such as pumps, lighting systems, etc.) loaded to $15 \mathrm{~kW}$

3. The pulsed load is applied and the capacitor is discharged in $0.15 \mathrm{~s}$ and then begins charging from the AC bus which is supplied by the gas turbine and generator

The simulation results showed stable operation of the ESPS with the gas turbine as prime mover. Furthermore, the three controllers speed, temperature and acceleration, of the gas turbine were tuned simultaneously using PSO and the simulation results documented. The effect of loading on fixed and varying controller gain values has also been compared. 


\section{CHAPTER 6: CONCLUSION}

Chapter 5 shows the need for energy management. Based on a layered architecture scheme, a load allocation algorithm has been developed for the implementation layer to resolve this issue. The algorithm is carried out by the decision implementation agent in this layer, in communication with the agents in the reconfiguration layer. Stateflow diagrams have been employed to depict this generic load allocation scheme based on prioritizing the loads. Two case studies have been performed to demonstrate the potential of this algorithm using the three loads of the ESPS. The gas turbine and its controllers follow each load change appropriately, showing that the tuned controller parameters are robust. These case studies demonstrate the feasibility and flexibility of this algorithm and the results are promising.

This work focuses on the detailed AC port side components of the ESPS as extremely slow simulation speed prevented the study of the entire ESPS testbed. The simulation time for the detailed components of the ESPS individually is very slow and when all the components are connected, the time taken for simulation increases drastically. Due to this, as well as the harmonics and high frequency switching transients produced by the components of the detailed model, the components could not be simulated together. The detailed model of the ESPS testbed requires the use of the ODE5 solver in Matlab with a step size of $1 \mu \mathrm{s}$, and the use of the accelerator mode in Simulink improves the simulation time to some extent. Table 6.1 shows the time taken for simulating the propulsion system, power supply and pulsed load of the ESPS as simulated in Section 4.4. The CPU time provided herein corresponds to a $1.6 \mathrm{GHz}$ Intel Pentium M processor with 1GB RAM.

Table 6.1 : Time taken for simulation

\begin{tabular}{|c|c|c|}
\hline Load & Simulation Time & CPU Time \\
\hline Propulsion System & $13 \mathrm{~s}$ & $2320 \mathrm{~s}$ \\
\hline Power Supply & $15 \mathrm{~s}$ & $6109 \mathrm{~s}$ \\
\hline Pulsed Load & $10 \mathrm{~s}$ & $3100 \mathrm{~s}$ \\
\hline
\end{tabular}




\subsection{Future Work}

The ESPS testbed used in this study requires the use of the ODE5 solver in Matlab with a step size of $1 \mu \mathrm{s}$, which greatly slows down the simulation when all the components are connected. This could be resolved by attempting to implement the ESPS testbed in another suitable simulation package.

The simulations performed in this research were limited to the AC port side of the ESPS. On improving the simulation speed, this can be further extended to simulate the entire shipboard system, comprising of the port and starboard AC subsystems and DC zones. Also, the gains of the speed, temperature and acceleration controllers can be tuned using PSO for every load change during simulation. This can be done by using a lookup table populated with the controller gains tuned offline for each loading condition. This would be beneficial especially when the load changes are large causing the system to shift to a different operating point. The energy management scheme can also be implemented using the detailed 3-phase loads for the ESPS and extended consider all the loads of the shipboard power system. 


\section{REFERENCES}

[1]. Al-Hinai, A., 'Multi-Agent Control and Operation of Electric Power Distribution Systems', PhD Dissertation, WVU, Morgantown, 2005

[2]. Anderson, P.M., Fouad, A.A., Power System Control and Stability, IEEE Press, 2002

[3]. Berube, G.R., Hajagos, L.M., "Testing and Modeling of Generator Controls", IEEE Power Engineering Society General Meeting, Vol. 3, July 13-17, 2003

[4]. CIGRE Task Force, "Modeling of Gas Turbines and Steam Turbines in Combined Cycle Power Plants", Task Force 25 of Advisory Group 02 of Study Committee C4, December 2003

[5]. Cohen, H., Rogers, G. F. C., Saravanamuttoo, H. I. H., Gas Turbine Theory, 3rd Edition, Longman, 1987

[6]. Gaing, Z., "A Particle Swarm Optimization Approach for Optimum Design of PID Controller in AVR System", IEEE Transactions on Energy Conversion, Vol.19, Issue 2, pp. 384-391, June 2004

[7]. Ganesh, S., 'Multiagent Autonomous Energy Management', Masters Thesis, WVU, Morgantown, 2005

[8]. Gorez, R., "A Survey of PID Auto-Tuning Methods", Journal A., Vol. 38, No. 1, pp. 3-10, 1997

[9]. Hajagos, L.M., Berube, G.R., "Utility experience with gas turbine testing and modeling", IEEE Power Engineering Society Winter Meeting, Vol. 2, pp. 671 - 677, January 28 - February 1, 2001

[10]. Haugen, F., PID Control, Tapir Academic Press, 2004

[11]. Heppner, F. and Grenander, U., "A Stochastic Nonlinear Model for Coordinated Bird Flocks", The Ubiquity of Chaos, AAAS Publications, Washington DC, 1990

[12]. http://www.mae.ufl.edu/samm/Courses/EML4314cPID_gw.ppt

[13]. Hung, W.W., "Dynamic Simulation of Gas-Turbine Generating Unit", IEE Proceedings $C$ - Generation, Transmission and Distribution, Vol. 138, Issue 4, pp. 342-350, July 1991

[14]. Kalita, D., Khargonekar, P.P., "SF2STeP: a CAD tool for formal verification of timed stateflow diagrams", IEEE International Symposium on Computer-Aided Control System Design, pp. 156 - 162, 25-27 September 2000

[15]. Karim, N., Lisner, R., Kazemi, H., Annaz, F., "Rule-based Power Management for the All-Electric Ship", http://www.itee.uq.edu.au/ aupec/aupec02/Final-Papers/NKarim1.pdf

[16]. Kennedy, J., Eberhart, R., "Particle Swarm Optimization", Proceeding of IEEE International Conference on Neural Networks (ICNN'95), Vol. IV , pp.1942-1948, Perth, Australia, 1995.

[17]. Killingworth, N.J., Krstic, M., "PID Tuning Using Extremum Seeking - Online, Model-Free Performance Optimization", IEEE Control Systems Magazine, pp. 7079, February 2006

[18]. Knopse, C., "PID Control", IEEE Control Systems Magazine, pp. 30-31, February 2006 


\section{REFERENCES}

[19]. Krause, P.C. and Associates, "Power System Control Development", Final Report, March 15, 2003

[20]. Krause, P.C., Wasynczuk, O., Suchoff, S.D., Analysis of Electric Machinery and Drive Systems, IEEE Press, 2002

[21]. Kuhn, B., Sudhoff, S., "Pulsed Power System with Railgun Model", http://nerc.aticorp.org/papers/railgun.pdf

[22]. Laplante, P. A., Real-Time Systems Design and Analysis, IEEE Press, 1997

[23]. Li, Y., Ang, K.H., Chong, G.C.Y., "PID Control System Analysis and Design Problems, Remedies and Future Directions", IEEE Control Systems Magazine, pp. 32-41, February 2006

[24]. Nagpal, M., Moshref, A., Morison, G.K., Kundur, P., "Experience with Testing and Modeling of Gas Turbines", IEEE Power Engineering Society Winter Meeting, Vol. 2, pp. 652-656, January 28 - February 1, 2001

[25]. ONR Control Challenge Problem, 19 January 2002, www.usna.edu/EPNES/ONR_Control_Challenge.pdf

[26]. Ordys, A.W., et.al., Modeling and Simulation of Power Generation Plants, Springer-Verlag, 1994

[27]. Pekarek, S., Tichenor, J., Sudhoff, S., Sauer, J.D., Delisle, D., and Zivi, E., "Overview of a Naval Combat Survivability Program", Proc. of Thirteenth International Ship Control Systems Symposium (SCSS), Orlando, Florida, April 7-9, 2003

[28]. Pomeroy, P., "An Introduction to Particle Swarm Optimization", www.adaptiveview.com, March 2003

[29]. Pourbeik, P., "Modeling of Combined-Cycle Power Plants for Power System Studies", IEEE Power Engineering Society General Meeting, Vol. 3, pp. 13081313, July 13-17, 2003

[30]. Rowen, W.I., "Simplified Mathematical Representations of Heavy-Duty Gas Turbines", Trans. of ASME, Vol. 105, No. 1, October 1983

[31]. Rowen, W.I., "Simplified Mathematical Representations of Single Shaft Gas Turbines in Mechanical Drive Service", Turbomachinery International, vol. 123, pp. 26-32, July/August 1992 and International Gas Turbine \& Aeroengine Congress and Exposition, Cologne, Germany, June 1-4, 1992

[32]. Sheldrake, A. L., Handbook of Electrical Engineering: For Practioneers in the Oil, Gas and Petrochemical Industry, John Wiley \& Sons, Ltd., 2003

[33]. Sudhoff, S.D., Kuhn, B.T., Zivi, E., Delisle, D.E., Clayton, D., "Impact of Pulsed Power Loads on Naval Power and Propulsion Systems", 13th International Ship Control Systems Symposium, Orlando, Florida, 2003.

[34]. Sun, L., Cartes, D. A., "Reconfiguration of Shipboard Radial Power System using Intelligent Agents", ANSE Electric Machine Technology Symposium, Philadelphia, PA, 2004

[35]. The Mathworks, Inc., http://www.mathworks.com, 2006

[36]. Tucker, A.J., "Opportunities and Challenges in Ship Systems and Control at ONR", IEEE Conference on Decision \& Control, December 4, 2001

[37]. Working Group on Prime Mover and Energy Supply Models for System Dynamic Performance Studies, "Dynamic Models for Combined Cycle Plants in Power 


\section{REFERENCES}

System Studies", IEEE Transactions on Power Systems, vol. 9, Issue 3, pp. 1698 1708 August 1994

[38]. www.cir.syr.edu/ mohan/pso/

[39]. Zhang, Q., So, P.L., "Dynamic Modeling of a Combined Cycle Plant for Power System Stability Studies", IEEE Power Engineering Society Winter Meeting, Vol. 2, pp. 1538-1543, January 23-27, 2000

[40]. Zhao, J., Li, T., Qian, J. "Application of Particle Swarm Optimization Algorithm on Robust PID Controller Tuning", Lecture Notes in Computer Science, Vol. 3612, pp. 948 - 957, July 2005, DOI 10.1007/11539902_118, URL http://dx.doi.org/10.1007/11539902_118

[41]. Ziegler, J. G., Nichols, N. B., "Optimum Settings for Automatic Controllers", Transactions ASME, Vol. 64, pp. 759-768, 1942

[42]. Zivi, E.L., "Integrated Shipboard Power and Automation Control Challenge Problem", IEEE Power Engineering Society Summer Meeting, Vol. 1, pp. 325 330,2002 


\section{APPENDIX}

Table A.1: ESPS synchronous generator parameters

\begin{tabular}{|l|l|l|}
\hline Parameter & Symbol & Value \\
\hline Rated power & $\mathrm{P}_{b}$ & $59 \mathrm{~kW}$ \\
\hline Base voltage & $\mathrm{V}_{b}$ & $570 \mathrm{~V}(1-1 \mathrm{rms})$ \\
\hline Base frequency & $\omega_{b}$ & $377 \mathrm{rad} / \mathrm{sec}$ \\
\hline Base impedance & $\mathrm{Z}_{b}$ & $9.5380 \Omega$ \\
\hline Number of poles & $\mathrm{P}$ & 4 \\
\hline Stator winding resistance & $\mathrm{r}_{s}$ & $0.003 \mathrm{pu}$ \\
\hline Stator winding leakage reactance & $\mathrm{X}_{l s}$ & $0.19 \mathrm{pu}$ \\
\hline D-axis reactance & $\mathrm{X}_{d}$ & $1.8 \mathrm{pu}$ \\
\hline Q-axis reactance & $\mathrm{X}_{q}$ & $1.8 \mathrm{pu}$ \\
\hline Rotor winding resistance & $\mathrm{r}_{f d}^{\prime}$ & $0.000929 \mathrm{pu}$ \\
\hline Rotor winding leakage reactance & $\mathrm{X}_{l f d}^{\prime}$ & $0.1414 \mathrm{pu}$ \\
\hline D-axis damper resistance & $\mathrm{r}_{k d}^{\prime}$ & $0.01334 \mathrm{pu}$ \\
\hline D-axis damper leakage reactance & $\mathrm{X}_{l k d}^{\prime}$ & $0.08125 \mathrm{pu}$ \\
\hline Q-axis damper resistance & $\mathrm{r}_{k q 1}^{\prime}$ & $0.00178 \mathrm{pu}$ \\
\hline Q-axis damper leakage reactance & $\mathrm{X}_{l k q 1}^{\prime}$ & $0.8125 \mathrm{pu}$ \\
\hline Q-axis damper resistance & $\mathrm{r}_{k q 2}^{\prime}$ & $0.00841 \mathrm{pu}$ \\
\hline Q-axis damper leakage reactance & $\mathrm{X}_{l k q 2}^{\prime}$ & $0.0939 \mathrm{pu}$ \\
\hline
\end{tabular}

Table A.2: ESPS power supply parameters

\begin{tabular}{|l|l|l|}
\hline Parameter & Symbol & Value \\
\hline Reference voltage & $\mathrm{V}_{\text {ref }}$ & $500 \mathrm{~V}$ \\
\hline Maximum command current & $\mathrm{i}_{\max }$ & $40 \mathrm{~A}$ \\
\hline PI controller proportional gain & $\mathrm{K}_{p}$ & 1 \\
\hline PI controller integral gain & $\mathrm{K}_{i}$ & 100 \\
\hline Current regulator integral gain & $\mathrm{K}_{s h}$ & 100 \\
\hline NSC exponent & $\mathrm{n}$ & 1 \\
\hline NSC time constant & $\mathrm{t}$ & $5 \mathrm{e}-3$ \\
\hline Hysteresis error bandwidth & $\mathrm{h}$ & $1 \mathrm{~A}$ \\
\hline
\end{tabular}

Table A.3: ESPS port AC bus parameters

\begin{tabular}{|l|l|l|}
\hline Parameter & Symbol & Value \\
\hline Shunt resistance & $\mathrm{r}$ & $500 \Omega$ \\
\hline Shunt capacitance & $\mathrm{C}$ & $40 \mu \mathrm{F}$ \\
\hline Filter resistance & $\mathrm{r}_{f}$ & $39 \mathrm{~m} \Omega$ \\
\hline Filter inductance & $\mathrm{L}_{f}$ & $5.61 \mathrm{mH}$ \\
\hline Filter capacitance & $\mathrm{C}_{f}$ & $49.75 \mu \mathrm{F}$ \\
\hline
\end{tabular}


Table A.4: ESPS propulsion system DC link parameters

\begin{tabular}{|l|l|l|}
\hline Parameter & Symbol & Value \\
\hline Inductance & $\mathrm{L}_{d c}$ & $11 \mathrm{mH}$ \\
\hline Resistance & $\mathrm{R}_{d c}$ & $0.056 \Omega$ \\
\hline Capacitance & $\mathrm{C}_{d c}$ & $1.988 \mathrm{e}-3 \mathrm{~F}$ \\
\hline
\end{tabular}

Table A.5: ESPS propulsion system induction machine parameters

\begin{tabular}{|l|l|l|}
\hline Parameter & Symbol & Value \\
\hline Poles & $\mathrm{P}$ & 4 \\
\hline Base frequency & $\omega_{b}$ & $377 \mathrm{rad} / \mathrm{sec}$ \\
\hline Stator resistance & $\mathrm{r}_{s}$ & $0.087 \Omega$ \\
\hline Stator leakage reactance & $\mathrm{X}_{l s}$ & $0.302 \Omega$ \\
\hline Magnetizing reactance & $\mathrm{X}_{m}$ & $13.08 \Omega$ \\
\hline Rotor resistance & $\mathrm{r}_{r}^{\prime}$ & $0.228 \Omega$ \\
\hline Rotor leakage reactance & $\mathrm{X}^{\prime}{ }_{l r}$ & $0.302 \Omega$ \\
\hline Inertia & $\mathrm{J}$ & $1.662 \mathrm{~kg}-\mathrm{m}^{2}$ \\
\hline Base torque & $\mathrm{T}_{b}$ & $198 \mathrm{Nm}$ \\
\hline
\end{tabular}

Table A.6: ESPS pulsed load parameters

\begin{tabular}{|l|l|l|}
\hline Parameter & Symbol & Value \\
\hline Filter capacitance & $\mathrm{C}_{\text {in }}$ & $5000 \mu \mathrm{F}$ \\
\hline Output inductor series resistance & $\mathrm{R}_{\text {out }}$ & $0.1 \Omega$ \\
\hline Output inductor inductance & $\mathrm{L}_{\text {out }}$ & $3 \mathrm{mH}$ \\
\hline Pulsed load resistance & $\mathrm{R}_{p}$ & $0.146 \Omega$ \\
\hline Energy storage capacitor & $\mathrm{C}_{e s}$ & $1.97 \mathrm{~F}$ \\
\hline Energy storage capacitor voltage reference & $\mathrm{V}_{\text {cref }}$ & $450 \mathrm{~V}$ \\
\hline Maximum power of energy storage capacitor & $\mathrm{P}_{\text {cmax }}$ & $15.5 \mathrm{~kW}$ \\
\hline Maximum current of energy storage capacitor & $\mathrm{I}_{\text {cmax }}$ & $40.5 \mathrm{~A}$ \\
\hline Input filter time constant & tau_if & $5 \mathrm{~ms}$ \\
\hline Output filter time constant & tau_of & $5 \mathrm{~ms}$ \\
\hline Proportional gain & $\mathrm{K}_{p c}$ & 13.35 \\
\hline Integral gain & $\mathrm{K}_{i}$ & 1000 \\
\hline Upper dynamic saturation limit & $\mathrm{u} \_$limit & $\mathrm{P}_{\text {cmax }} /\left(\max \left(\mathrm{V}_{\text {cf }}, \mathrm{P}_{\text {cmax }} / \mathrm{I}_{\text {cmax }}\right)\right)$ \\
\hline Lower dynamic saturation limit & $1 \_l i m i t$ & 0 \\
\hline Hysteresis level of hysteresis modulator & $\mathrm{h}$ & $2.62 \mathrm{~A}$ \\
\hline
\end{tabular}


Table A.7: ESPS gas turbine parameters

\begin{tabular}{|l|l|l|}
\hline Parameter & Symbol & Value \\
\hline Speed reference set point & $\mathrm{W}_{r e f}$ & 1 \\
\hline Acceleration control differentiator time constant & $\mathrm{T}_{a}$ & 0.1 \\
\hline Acceleration limit set point & $\mathrm{a}_{s e t}$ & 0.01 \\
\hline Speed governor proportional gain & $\mathrm{K}_{p g}$ & 21.9370 \\
\hline Speed governor integral gain & $\mathrm{K}_{i g}$ & 18.6264 \\
\hline Speed governor derivative gain & $\mathrm{K}_{d g}$ & 39.2917 \\
\hline Speed governor derivative time constant & $\mathrm{T}_{d g}$ & 0.01 \\
\hline Acceleration control proportional gain & $\mathrm{K}_{p a}$ & 0 \\
\hline Acceleration control integral gain & $\mathrm{K}_{i a}$ & 10 \\
\hline Temperature control proportional gain & $\mathrm{K}_{p t}$ & 1 \\
\hline Temperature control integral gain & $\mathrm{K}_{i t}$ & 0.2 \\
\hline Temperature limit & $\mathrm{T}_{l i m i t}$ & 0.9167 \\
\hline Maximum fuel flow command & $\max$ & 1 \\
\hline Minimum fuel flow command & $\min$ & 0.15 \\
\hline Thermocouple time constant & $\mathrm{T}_{t h c p}$ & 2.5 \\
\hline Heat transfer lag time constant & $\mathrm{T}_{d}$ & 5 \\
\hline Fuel system time constant & $\mathrm{T}_{v}$ & 0.5 \\
\hline Maximum valve opening & $\mathrm{V}_{\max }$ & 1 \\
\hline Minimum valve opening & $\mathrm{V}_{\min }$ & 0 \\
\hline Fuel flow multiplier & $\mathrm{F}_{m}$ & 1 \\
\hline Full speed no load fuel flow & $\mathrm{W}_{f o}$ & 0.25 \\
\hline Turbine gain & $\mathrm{K}_{t}$ & 1.5 \\
\hline Turbine transfer function time constant & $\mathrm{T}_{t d}$ & 0.5 \\
\hline Inertia (2*H) & $\mathrm{T}_{r}$ & 1.5 \\
\hline
\end{tabular}




\title{
CURRICULUM VITAE
}

\author{
Anisha M. C. Fernandes
}

Email: anisha.fernandes@yahoo.com

Birth Date: $8^{\text {th }}$ November, 1980

Place of Birth: Bangalore, Karnataka, India

Languages known: English, Konkani (mother tongue), Hindi, Kannada

Education:

Master of Science in Electrical Engineering

West Virginia University, Morgantown

Bachelor of Science in Electrical Engineering

Manipal Institute of Technology, Manipal, India

Bachelors Project: Fuzzy Logic Control of a DC Motor

Guide: Mr. V. Nagaraj

Experience:

Graduate Research Assistant

Lane Department of Computer Science and Electrical Engineering

West Virginia University, Morgantown, WV

Aug 2004 - Aug 2006

Electrical Engineer (Intern)

General Electric Power Controls, Bangalore, India

Jan 2002 - Feb 2002

Computer Skills:

Programming Languages: Matlab/Simulink, C, C++, PSpice, PSAT

Cost and Risk Analysis: Palisade Decision Tools Suite (@Risk 4.5 and Precision Tree 1.0 for Excel)

Desktop Applications: MS Office: Word / Excel / PowerPoint / Access / Visio /

FrontPage / Outlook, Adobe Acrobat

Activities:

Member of the Institute of Electrical and Electronics Engineers (IEEE)

Graduated with honors (Piano) from Trinity College of Music, London, UK 